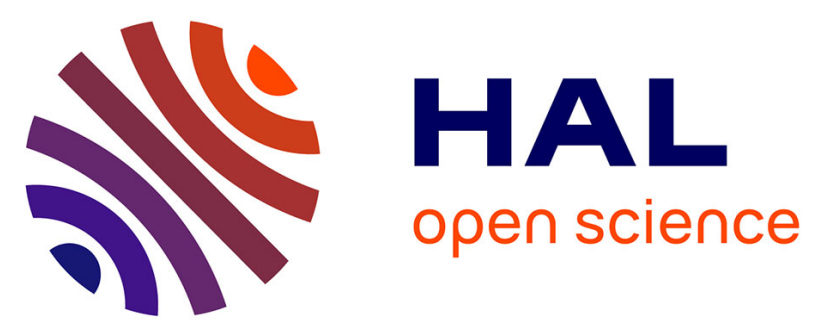

\title{
Bioprospecting of Nitrogenous Heterocyclic Scaffolds with Potential Action for Neglected Parasitosis: A Review
}

Sonaly Lima Albino, Jamire Muriel da Silva, Michelangela Suelleny de Caldas

Nobre, Yvnni Maria Sales de Medeiros E Silva, Mirelly Barbosa Santos, Rodrigo Santos Aquino de Araújo, Maria Do Carmo Alves de Lima, Martine Schmitt, Ricardo Olímpio de Moura

\section{- To cite this version:}

Sonaly Lima Albino, Jamire Muriel da Silva, Michelangela Suelleny de Caldas Nobre, Yvnni Maria Sales de Medeiros E Silva, Mirelly Barbosa Santos, et al.. Bioprospecting of Nitrogenous Heterocyclic Scaffolds with Potential Action for Neglected Parasitosis: A Review. Current Pharmaceutical Design, In press, 10.2174/1381612826666200701160904 . hal-02908646

\section{HAL Id: hal-02908646 https://hal.science/hal-02908646}

Submitted on 31 Jul 2020

HAL is a multi-disciplinary open access archive for the deposit and dissemination of scientific research documents, whether they are published or not. The documents may come from teaching and research institutions in France or abroad, or from public or private research centers.
L'archive ouverte pluridisciplinaire HAL, est destinée au dépôt et à la diffusion de documents scientifiques de niveau recherche, publiés ou non, émanant des établissements d'enseignement et de recherche français ou étrangers, des laboratoires publics ou privés. 


\section{Bioprospecting of Nitrogenous Heterocyclic Scaffolds with Potential Action for Neglected Parasitosis: A Review}

Sonaly Lima Albino1, Jamire Muriel da Silva², Michelangela Suelleny de Caldas Nobre $^{2}$, Yvnni Maria Sales de Medeiros e Silva ${ }^{1}$, Mirelly Barbosa Santos ${ }^{1}$, Rodrigo Santos Aquino de Araújo ${ }^{1}$, Maria do Carmo Alves de Lima², Martine Schmitt ${ }^{3}$, Ricardo Olímpio de Moura ${ }^{\mathbf{1} 2 *}$

'Universidade Estadual da Paraíba, R. Baraúnas, 351, Cidade Universitária, Campina Grande, Paraíba, 58429-500, Brasil. 'Universidade Federal de Pernambuco, Av. Prof. Moraes Rego 1235, Cidade Universitária, Recife, Pernambuco, 50670-901, Brasil. ${ }^{3}$ Université de Strasbourg, CNRS, LIT UMR 7200, Laboratoire d'innovation thérapeutique, Illkirch, France.

* Correspondence Author: Ricardo Olímpio de Moura Universidade Estadual da Paraíba, R. Baraúnas, 351, Cidade Universitária, Campina Grande, Paraíba, 58429-500, Brasil. E-mail: Ricardo.olimpiodemoura@gmail.com Tel/Fax: +558333153300 


\section{ABSTRACT}

Neglected parasitic diseases are a group of infections currently considered as a worldwide concern. This fact can be attributed to the migration of these diseases to developed and developing countries, associated with therapeutic insufficiency resulted from the low investment in the research and development of new drugs. In order to overcome this situation, bioprospecting supports medicinal chemistry in the identification of new scaffolds with therapeutically appropriate physicochemical and pharmacokinetic properties. Among them, we highlight the nitrogenous heterocyclic compounds, as they are secondary metabolites of many natural products with potential biological activity. The objective of this work was to review studies within a 10 year timeframe (2009-2019), focusing on the pharmacological application of nitrogen bioprospectives (pyrrole, pyridine, indole, quinoline, acridine, and their respective derivatives) against neglected parasitic infections (malaria, leishmania, trypanosomiases, and schistosomiasis), and their application as a template for semi-synthesis or total synthesis of potential antiparasitic agents. In our studies, it was observed that among the selected articles, there was a higher focus on the attempt to identify and obtain novel antimalarial compounds, in a way that an extensive amount of studies involving all heterocyclic nitrogen nuclei were found. On the other hand, the parasites with the lowest number of publications up until the present date have been trypanosomiasis, especially those caused by Trypanosoma cruzi, and schistosomiasis, where some heterocyclics have not even been cited in recent years. Thus, we conclude that despite the great biodiversity on the planet, little attention has been given to certain neglected tropical diseases, especially those that reach countries with a high poverty rate.

Keywords: Natural Products; Neglected Tropical Diseases; Molecular Design; Medicinal Chemistry; Semi-synthesis; Heterocyclic Compounds. 


\section{INTRODUCTION}

The term bioprospecting, pioneered by Thomas T Eisner as "chemical prospecting", refers to the investigation of the biodiversity for the obtainment of commercially valuable genetic and biochemical resources. The exploration of the biodiversity for new medicines, foods, crops, insecticides, pesticides, and additional commercially relevant genetic and biological products and processes is growing, acknowledgments to the prominent development of biotechnology, mainly genomics, proteomics, transcriptomics, enzymatic and transgenic technologies [1].

The application of ethnopharmacology has supported medicinal chemistry in the discovery of novel chemical entities, mainly by the bioprospection of secondary metabolites from several natural products. Despite the significant efforts on employing combinatorial chemistry to identify new drugs, mostly due to the incompatibility of natural products with traditional high-throughput screening paradigms, the natural product libraries result in a higher hit rate than combinatory libraries [2-4]. The literature reports many biologically active compounds identified based on ethnopharmacological work, many resulting in approved medicines, mainly as chemotherapeutic compounds with antitumor [5-7], antibiotic $[8,9]$ and antiparasitic properties [10, 11]. In that sense, as an interesting example, artemisinin was first isolated from Artemisia аппиа and is categorized as a lead compound approved to malaria treatment [11].

Therefore, bioprospecting has become a useful and current alternative in the search for new sources of drugs, mainly through the isolation of secondary metabolites. Those are intended for multiple therapeutic purposes, including the cure of neglected diseases, whose treatment options are limited and associated with alarming resistance mechanisms developed by these parasites to existing and used drugs.

Parasitic diseases are responsible for thousands of deaths yearly, affect about one billion individuals and constitute a major obstacle to socioeconomic advance in many developing countries [12]. These diseases are caused by parasites, which are considered as organisms capable of obtaining their food by ingesting other organisms or their products in nature. As previously noted, these parasites are responsible for causing a high morbidity and mortality rate around the world, being mainly represented by Malaria, Leishmaniasis, Trypanosomiasis (Chagas disease and African sleeping sickness) and Schistosomiasis [13]. Strategies for the development of antiparasitic chemotherapeutics require many strategies, such as the identification of active compounds from natural sources, exploration of drugs already licensed for distinct pathologies, or validation of specific targets identified within key metabolic pathways, among others [12].

Malaria is the most common of the parasitic diseases in tropical and subtropical regions. The World Health Organization (WHO) has reported the occurrence of 216 million clinical cases of malaria and 445 thousand deaths in 2016 [14-19]. Despite being preventable and treatable, nowadays, this disease is responsible for almost half a million deaths of children and pregnant women per year in Africa [14-16]. It stands out for its high morbidity and mortality percentages in poor or underdeveloped countries. However, reports of the emergence of malaria in developed countries have attracted the attention of the world scientific community [20]. Malaria is caused by several species of the genus Plasmodium, a protozoan parasite that is transmitted to humans by Anopheles mosquitoes' bite. Within the five species of malaria parasites (Plasmodium falciparum, P. vivax, P. ovale, P. malariae e P. knowlesi) known for 
affecting humans, the most virulent malaria parasite is Plasmodium falciparum. In the 1980s, this species was responsible for thousands of deaths in Africa, highter than any other parasitic disease [21]. Its treatment is usually conducted with the use of quinoline derivatives, designed from quinine structure, isolated from Cinchona bark, and, more recently, with artemisinin, which has been the drug of choice when standard treatments are insufficient. However, due to the widespread and ever-increasing resistance against antimalarial drugs, there is a growing need for novel therapeutic agents $[22,23]$.

Another neglected tropical disease is Leishmaniasis, which is included as one of the most relevant affections of the neglected tropical diseases, infecting millions of individuals worldwide. It is caused by different species of protozoa from the family Trypanosomatidae and the genus Leishmania [24]. In humans, the disease occurs in at least four major forms, depending on the parasite species and the cellular immune response of the patient, denominated as cutaneous leishmaniasis (CL), diffuse cutaneous leishmaniasis (DCL), mucocutaneous leishmaniasis (MCL) and visceral leishmaniasis (VL). VL caused by Leishmania donovani and L. infantum can be highlighted as the most severe form of leishmaniasis, while CL caused by L. major, L. amazonensis, L. mexicana, L. braziliensis, and L. panamensis, is significantly associated with morbidity $[25,26]$.

Nowadays, the drugs used for the treatment of leishmaniasis include pentavalent antimonials (sodium stibogluconate and meglumine antimoniate), amphotericin B, miltefosine, pentamidine and paromomycin. Many of these drugs exhibit high toxicity, the occurrence of side effects, and limitations due to the development of resistant strains. Besides, there are no effective vaccines; consequently, there is an urgent need to accelerate the development process of a new generation of more effective and safer antileishmanial compounds [26].

The third disease addressed in this review proposal is Chagas disease or American trypanosomiasis. This illness, caused by the flagellated protozoan Trypanosoma cruzi, represents a significant health problem in America and, due to human migration, is now a global public health issue. This disease is considered a neglected tropical disease, which means that it is associated with poverty and neglected by the socio-economic system and by policymakers [27, 28].

Chagas disease is characterized by an initial acute phase, which is fatal for $5 \%$ of the infected infants, followed by a long-term chronic phase, which can eventually be fatal due to associated cardiac problems [29]. Currently, only nifurtimox and benzimidazole, developed over four decades ago, are used as treatment for American trypanosomiasis. Both drugs cause multiple side effects and have efficacy, mainly, on patients in the chronical form of the disease. Thus, the development of drugs more efficient against $T$. cruzi is of high priority [29, 30].

Besides Trypanosoma cruzi, another type of trypanosomiasis has stood out. Human African Trypanosomiasis (HAT), also designated sleeping sickness, is caused by the parasite Trypanosoma brucei and affects people mainly in central Africa. This parasitic disease occurs subsequently the bite of a tsetse fly and develops in two clinical stages, a peripheral haemolymphatic stage (phase 1) followed by a meningoencephalitic stage (phase 2), in which the parasite crosses the blood-brain barrier and invades the central nervous system, leading to death $[30,31]$. The HAT is caused by two subspecies of the parasite Trypanosoma brucei (T. b.), known as T. b. rhodesiense and T. b. gambiense. Currently, five drugs are used to treat HAT, depending on the stage. These include: Pentamidine, suramin, melarsoprol, 
eflornithine and NECT (nifurtimox-eflornithine combination treatment). However, the current treatment is unsatisfactory due to pharmacokinetic limitations and considerable toxicity [31].

Last, but not least, we emphasize schistosomiasis. In an extensive review article published by Silva et al. (2017), schistosomiasis is defined as a group of diseases caused by helminths from the genus Schistosoma, and the most prevalent etiologic agents are the species Schistosoma mansoni, S. intercalatum, S. haematobium, S. japonicum, and S. mekongi. This disease is the most common within pathologies caused by worms in the world, being endemic in 78 countries, and affecting millions of people in Africa, Middle East, Southeast Asia, and South America as a result. Also, it is estimated that over 700 million people are living in areas that present a risk of contamination. Regions like America, Suriname, Venezuela, Caribbean Islands, and Brazil are considered endemic zones, and over 240 million people lack treatment for schistosomiasis. Currently, praziquantel is the first-line treatment against schistosomiasis and many other cestode infestations, while oxamniquine is used in case of treatment failure with praziquantel [32-34]. Table 1 summarizes the main compounds used to treat the parasitic agents cited in this review and, in some cases, their natural source compounds.

\section{INSERT HERE THE TABLE 1.}

Table 1. Main compounds used to treat the parasitic agents.

Despite the availability of some drugs for the treatment of neglected tropical diseases, there are strong reports of toxicity associated with these drugs, besides the emergence of resistance mechanisms, which includes, among others, drug efflux by ATP-binding cassette (ABC) transporters, target multation, decrease in drug uptake, transport defects and changes of membrane composition, that has made their use unfeasible, which is leading to treatment abandonment. For example, miltefosine is an antileishmanial drug that acts by achieving intracellular drug accumulation, however, a decrease in drug accumulation results in miltefosine resistance through two autonomous mechanisms: increased drug efflux by the overexpression of P-glycoprotein and decreased drug uptake by the inactivation of protein transporter LdMT $[35,36]$. Thus, there is an urgent need for the discovery of new chemicals that can overcome these drawbacks, and bioprospection from natural compounds is an extremely valid alternative.

In the evaluation and search of molecules with biological potentials, heterocyclic compounds occupy a prominent place in the attention of several research groups worldwide. A variety of heteroatoms may be part of the constitution of these heterocycles, providing them unique properties, as interference in its chemical reactivities and physicochemical properties and the creation of new interactional places between these compounds and biological targets [37]. Over $90 \%$ of the drugs used in the overall therapy possess heterocyclic rings in their structure, in which $95 \%$ of these have at least one nitrogen atom incorporated [38, 39]. Among these, we highlight the pyrrole, pyridine, indole, quinolone, acridine, and their analogs as relevant nuclei for antiparasitic chemotherapeutic action [40]. These differ in terms of the number of members in the ring, which can provide a spectrum of structural characteristics that can make the compound more potent or more selective for a given pathogen.

In the compounds of natural origin, these heterocycles are classified into alkaloids group, responsible for a wide rate of biological activities [41-43]. In this topic of this review, we will focus our discussion in natural nitrogen heterocycles, whether from the direct isolation of the active substance, or 
from semi-synthetic mechanisms, in the insertion and/or reproduction of nitrogen heterocyclic rings, or total synthesis of natural compounds and/or based on these.

For the design and development of synthetic routes for bioactive compounds based on natural products, several strategies are applied. Among which, stands out the molecular hybridization, based on the combination of chemical structures of known biological activity to generate a possibly more active hybrid compound [44]; and the bioisosterism, which aims the preservation or augmentation of the positive effects produced by a portion of the active molecule after their replacement by an isosteric group. In this last molecular modification strategy, nitrogen rings are usually well known to be bioisosteres of peptide bonds constituents, aromatic rings or double bonds [45-47]. This insertion of azole, pyridine, indoles, quinolones and acridine moieties in classes of natural products is, therefore, a good strategy for the obtainment of new biologically promising compounds [48, 49].

Among the potentialities of nitrogen heterocycles, their antiparasitic properties have some prominence [50,51], of which some are the aim of our review. Therefore, this review included articles published within the last ten years $(2009$ - 2019) focused on the use of aforementioned nuclei derivatives, with potential antileishmanial, antiplasmodial, antitrypanosomal (Trypanosoma cruzi and Trypanosoma brucei) and antischistosomal activities. These key-words were included into the "ScienceDirect", "Pubmed" and "Periódicos Capes" platforms, focusing the attention and giving preference to the articles that included studies of natural products or based on these.

\section{PYRROLE, IMIDAZOLE, TRIAZOLE AND TETRAZOLE DERIVATIVES}

\subsection{Antiparasitic mechanism of action}

Heterocycle compounds such as pyrrole, imidazole, triazoles and tetrazole are reported in the literature with antiparasitic actions for different species of parasites, however, few are the studies that deeply address the antiparasitic mechanism of action of pyrrole, imidazole, triazole and tetrazole derivatives. But some studies provide evidence of possible molecular targets that show the route of action of these derivatives in their antiplasmodial, antileishmanial, antitrypanosomal and antischistosomal activities.

For antiplasmodial activity, some evaluation indicated that these compounds can act similarly to pyrrole atorvastatin, by inhibition of lactate dehydrogenase enzyme, an essential protein in the erythrocytic cycle period of Plasmodium falciparum [52]. For the compounds used to antileishmanial and antitrypanosomal activities (Kinetoplastida parasites), the literature indicates that some antifungal azoles can act similarly in their antiparasitic action mechanisms. Azole derivatives as imidazole and triazole act directly in the lipid biosynthesis, including membrane lipids, by cytochrome P450-dependent C14 $\alpha$ sterol demethylase inhibition, leading non-formation of ergosterol, an important membrane steroid [53, 54]. For antitrypanosomal activity, the interference in the redox metabolism and formation of reactive oxygen species (ROS) on parasite be a mechanism of action known for the nitroimidazole drug Benznidazole, showing that this derivative class can have multiple biochemical targets in the growth inhibition of Trypanosoma sp. [55]. Finally, for the antischistosomal activity, azole derivatives represents, in the study of Botros et al. [56], a promising alternative for having, as therapeutic target, the cyclic nucleotide 
phosphodiester of Schistosoma sp., allowing to kill the adult forms of the parasite, as well as to reduce the number os eggs.

\subsection{Antiplasmodial activity}

In recent years, the search by potent anti-Plasmodium falciparum agents has been directed at the insertion of azole rings in non-alkaloid natural compounds, the example of quinone derivatives, that is very used in obtaining a variety of bioactivity structures [57]. One naphtoquinone well known for their applications is Lapachol, that occurring in Bignoniaceae family [58], and was used by Brandão et al. (2018) [59] in the synthesis of molecules containing 1,2,3-triazole and evaluation of its potentialities against chloroquine-resistant strains of Plasmodium falciparum. The five-membered heterocyclic ring triazole is selected for the anti-negelcted diseases because of its ability to act as both hydrogen bond acceptor (HBA) and donor (HBD), structure rigidity and stability under oxidative and reductive conditions [60]. Click chemistry methodology was used in the junction of lapachol pharmacofore with other biological important structures, linked by a triazole ring. Of this series, the compound 1 (Figure 1) exhibited better antimalarial activities and selectivity index (SI) against HepG2 (hepatocellular carcinoma) cell line $\left(\mathrm{IC}_{50}=5.2 \mu \mathrm{M}, \mathrm{SI}=197.7\right)$ when compared to start lapachol $\left(\mathrm{IC}_{50}=123.5 \mu \mathrm{M}, \mathrm{SI} \geq\right.$ 33.4; Figure 1). The additional molecular docking studies with Plasmodium falciparum dihydroorotate dehydrogenase (PfDHODH) performed by these authors, demonstrated that the 1,2,3-triazole moiety have a central role in the PfDHODH inhibition, for accomplish hydrophobic interactions with the enzyme amino acids, leading to conclusion that the insertion of the 1,2,3-triazol, was essential for increased potentiality.

\section{INSERT FIGURE 1 HERE}

Figure 1. Chemical structure of compound 1.

Artemisinin, a lactone sesquiterpene extracted from Artemisia annua, has antimalarial properties well established, however, it has been associated with resistance events by its target parasites [61, 62], which led to development of potent derivatives against Artemisinin-resistant strains, as trioxolanes and tetraoxanes, studied by Lobo et al. (2018) [63], that drawn and synthesized a library of new endoperoxide-derived compounds where the peroxide pharmacophore is part of a trioxolane (ozonide) or a tetraoxane moiety, flanked by adamantane and a substituted cyclohexyl ring including tetrazole rings in some of these. The library was evaluated for their anti- $P$. falciparum activity against chloroquinesusceptible (3D7) and multidrug-resistant (Dd2) strains. Among the eight more active compounds (submicromolar antimalarial activity with $\mathrm{IC}_{50}=0.3-71.1 \mathrm{nM}$, no cross-resistance with artemisinin or quinolone derivatives and negligible cytotoxicity in hepatocellular carcinoma and hamster lung), four possessed a tetrazole ring (compounds 2-5, Figure 2). In addition, these four tetrazole derivatives demonstrated excellent in vivo results against Plasmodium berghei, with total parasite growth inhibition for the compounds 3 and 4, 94.46\% for the compound 2 and 96.46\% for the compound 5, after 10 days. Finally, 3 and 4 emerged as potential anti-malarial candidates; they show negligible toxicity towards mammalian cells, ability to kill intra-erythrocytic asexual stages of artemisinin-resistant P. falciparum and capacity to totally suppress $P$. berghei parasitaemia in mice. Hence, authors have attributed the potentiality of the derivatives to the presence of the tetrazole ring. 


\section{INSERT FIGURE 2 HERE}

Figure 2. Compounds 2-5 of [63].

Prodigiosin (Figure 3), a known tripyrrole of bacterial pigment of Serratia spp., have its antiPlasmodium spp. activity related [64], and for this reason was isolated, from S. nematodiphila, and evaluated by Rahul et al. (2015) [65] in their combinations with the gold and silver metals against chloroquine-resistant strains of $P$. falciparum, where the administration together with these nanoparticles reduced the $\mathrm{IC}_{50}$ values of isolated natural compound from $1.1 \pm 0.1 \mu \mathrm{g} \mathrm{mL} \mathrm{m}^{-1}$ to $0.36 \pm 0.014 \mathrm{e} 0.4 \pm 0.028 \mu \mathrm{g}$ $\mathrm{mL}^{-1}$ for the combinations with the silver and gold nanoparticles, respectively, showing a synergistic action.

Kancharla et al. (2015) [66] evaluated the antimalarial activity of analogs of the natural product undecylprodiginine (Figure 3) [67], getting a series of azole derivatives, of which the compounds 6 and 7 (Figure 3) were more active than undecylprodigine against all $P$. falciparum strain lines tested, with $\mathrm{IC}_{50}$ values of 6.1, 4.8 and $5.5 \mathrm{nM}$ for the compound 6 and 6.5, 7.0 and $5.9 \mathrm{nM}$ for the compound 7, against the D6, Dd2 and 7G8 lines, respectively. For evaluate de importance of the three pyrrole rings, this study performed a accurate chemical structure - biological activity relationships of these compounds, where conclude that the ring $\mathrm{C}$ is not essential and can be replaced by an alkylamine group retained/enhanced anti-P. falciparum potency, as example of KAR425 (Figure 3), a bipyrrole tambjamine derivative, with greater efficacy than prodiginine derivatives, providing $100 \%$ of protection to malaria-infected mice until day 28 at doses of 25 and $50 \mathrm{mg} / \mathrm{kg} /$ day, being also curative in this model in a single oral dose of $80 \mathrm{mg}$ $\mathrm{kg}^{-1}$.

\section{INSERT FIGURE 3 HERE}

Figure 3. Chemical structures of Prodigiosin, Undecylprodigiosin, Compounds 6, 7 and KAR425 of [66].

\subsection{Antileishmanial activity}

In the recent search for new antileishmanial agents, non-alkaloid natural molecules have been used in semi-synthesis strategies through the insertion of azole rings in their structures. Thus, eugenol (Figure 4), a natural product present in several aromatic plants, with Eugenia caryophyllata as their main source, and of high biological potentiality, was the object of study of Teixeira et al. (2018) [68], in an attempt to improve its already described leishmanicidal activity [69], by the insertion of triazole moieties via a click reaction strategy. The more active eugenol-triazole derivatives are also presented in Figure 4, with $\mathrm{IC}_{50}$ values against Leishmania amazonensis promastigotes of 30.2 (9), 59.4 (10), 49.2 (11), 37.9 (12), 32.2 (13) and $7.4 \mu \mathrm{mol} \mathrm{L} \mathrm{L}^{-1}$ (14), making them more active than eugenol alone (with the already related $\mathrm{IC}_{50}$ of $487 \mu \mathrm{mol} \mathrm{L}{ }^{-1}$ ). From these data, the more active compound 14 also demonstrated great results against amastigote intracellular forms, with $\mathrm{IC}_{50}$ values of $1.6 \mu \mathrm{mol} \mathrm{L}^{-1}$, more active than the standard-drugs pentamidine and glucantime (table 1), besides showing lower toxicity than these, showing the increase of the anti-leishmanial potentiality obtained with the triazole moiety insertion.

\section{INSERT FIGURE 4 HERE}

Figure 4. Chemical structures of triazole-eugenol derivatives. 
Flavonoids is another natural class well known for its leishmanicidal effects, with quercetin as one of their main representants, thus Dwivedi et al. (2015) [70] evaluated antileishmanial activity of triazole-linked $O$-benzylquercetin glycoconjugates, obtained via click chemistry reaction, against Leishmania donovani promastigote and amastigote forms. Between these, the compounds 15, 16 and 17 (Figure 5) were the most active for both promastigote and amastigote forms, with $\mathrm{IC}_{50} \pm$ standard deviation values of $9.92 \pm 2.16$ (15), $8.12 \pm 2.44$ (16) and 7.76 \pm 2.44 (17) $\mu \mathrm{g} \mathrm{mL}^{-1}$, for promastigote forms, and $7.65 \pm 0.93(15), 9.08 \pm 0.03$ (16) and $6.08 \pm 0.03$ (17) $\mu \mathrm{g} \mathrm{mL} \mathrm{m}^{-1}$, for amastigote forms. The more active 15 and 16 were evaluated according to their cytotoxicity effects and both demonstrated no toxicity in their $\mathrm{IC}_{50}$ active concentrations against macrophage lines, highlighting the important role of triazole moiety in the increased activity against L. donovani.

\section{INSERT FIGURE 5 HERE}

Figure 5. Chemical structure of triazole-quercetin derivatives.

Known antileishmanial tetrahydrofuran neolignans (Figure 6) were used by Cassamale et al. (2016) [71] as a bioisosteric strategic base in the replacement of its tetrahydrofuran portions by a 1,2,3triazole core. Among the 16 derivatives obtained, 3 were more active against Leishmania amazonensis and Leishmania infantum promastigote forms. Compounds 18, 19 and 20 (Figure 6) presented with $\mathrm{IC}_{50}$ values of $1.1,3.71$ and $7.23 \mu \mathrm{M}$, for L. amazonensis, and 19.5, 15.4 and 5.2 $\mu \mathrm{M}$, for L. infantum, respectively; being this results most promising that known tetrahydrofuran neolignans Veraguensin, Grandisin and Machilin G (Figure 6), that have antileishmanial activities related in the literature. In all these cases, the results of $\mathrm{IC}_{50}$ against $L$. amazonensis were more active than the standarddrug pentamidine $(8.9 \mu \mathrm{M})$, besides being less cytotoxic than both standard-drug pentamidine and amphotericin B (Table 1). These results, when compared with the potentialities of tetrahydrofuran neolignans, lead to the conclusion that the replacement of a tetrahydrofuran ring by a 1,2,3-triazole moiety is responsible for increased antileishmanial activity of the analyzed products.

\section{INSERT FIGURE 6 HERE}

Figure 6. Chemical structure of compounds 17-19 of [71].

This study of Cassamale et al. [71] allowed conclude important scaffolds in molecular modification studies due to their antileishmanial activities on promastigote forms. So, this library of triazole derivatives was also evaluated by Costa et al. (2016) [72], for antileishmanial activity against $L$. (L.) amazonensis amastigote strains. The ability to inhibit the growth of parasites apparently depends on the index of molecular hydrophobicity $(\mathrm{Clog} \mathrm{P})$ of the compounds. A ClogP ranged from 2.8 to 3.4 reflect a lipophilicity/hydrossolubility rate suitable for transport across membranes. In particular, compounds 21 (Figure 7) and 20 (Figure 6) containing a trimethoxy group on ring B, were the most active ( $\mathrm{IC}_{50}$ values of 5.6 and $4.4 \mu \mathrm{M}$, respectively), with low cytotoxicity on mammalian cell (SI = 14.1 and 10.6). These compounds induced nitric oxide production by the host macrophage cells, which could be suggested as the mechanism involved in the intracellular killing of parasite. It is important to highlight that the compound 20 also showed the best activity in promastigote forms of the Cassamale et al. (2016) study [71], confirming their potentiality in both parasite forms.

\section{INSERT FIGURE 7 HERE}

Figure 7. Compound 30 structure. 
Hederagenin (Figure 8), a natural pentacyclic triterpene from Sapindus saponaria, presents significant activity against Leishmania infantum and Leishmania tropica [39]. So, Rodríguez-Hernández et al. (2016) [73] synthesized and evaluated the antileishmanial activity against L. infantum amastigote forms of esters and amides of hederagenin derivatives, with inclusion of triazole moieties as important pharmacophore. This study highlighted two amide derivatives (compounds 22 and 23 - Figure 8) with promising $\mathrm{IC}_{50}$ values of $2.0 \pm 0.16$ and $6.0 \pm 0.06 \mu \mathrm{M}$, respectively. These were more active than hederagenin alone $\left(\mathrm{IC}_{50}=61.6 \pm 0.25 \mu \mathrm{M}\right)$. Even though the two derivatives obtained have shown higher toxicity for macrophage lines, compound 22 showed, however, just a little less toxicity than hederagenin for epithelial spleen-like.

The group also identified (2017) [74] two active ester derivatives bearing two triazole moieties 24 and 25 (Figure 8) with $\mathrm{IC}_{50}$ values of $5.6 \pm 0.14$ and $7.4 \pm 0.12 \mu \mathrm{M}$, respectively. Both were noncytotoxic to monkey African Green kidney and human hepatocytes.

\section{INSERT FIGURE 8 HERE}

Figure 8. Triazole-hederagenin derivatives.

A series of semi synthetic lupine triterpenoids of betulin and betulinic acid (Figure 9), known in some literature for its anti-Leishmania potentialities, have been used by Sousa et al. (2014) [75] for evaluation of their antileishmanial activity against $L$. infantum. Of the whole series of derivatives utilized, an imidazole carboxylic ester of betulin derivative (compound 26 - Figure 9) and a $N$-acylimidazole of betulinic acid derivative (compound 27 - Figure 9) were found to be the most active with $\mathrm{IC}_{50}$ values of $50.8 \mu \mathrm{M}$ and $25.8 \mu \mathrm{M}$ respectively. The superior anti-Leishmania activity of the compound 27 could be associated with the higher capacity as a Michael acceptor of this derivative. Drug interactions between these two active compounds and one currently antileishmanial drug miltefosine (Table 1), were also tested and the combination of 26/miltefosine and 27/miltefosine were more effective at reducing the viability of promastigotes relative to the derivatives alone. As an illustration, the combination of the 27 with miltefosine at $4 \mu \mathrm{M}$ induced decrease of the $\mathrm{IC}_{50}$ value from $25.8 \mu \mathrm{M}$ to $6.0 \mu \mathrm{M}$. Finally, neither of these two derivatives (26 and 27) induced significant apoptosis/necrosis or induced death in macrophage cell lines. In addition they do not present any potential risk of toxicity for the host cells and so they can be considered as promising molecules in the development of new alternative therapies for leishmaniasis, including those involving combined-therapy with miltefosine.

\section{INSERT FIGURE 9 HERE}

Figure 9. Betulin and Betulinic Acid and their Derivatives evaluated by [75].

\subsection{Antitrypanosomal activity: Trypanosoma cruzi}

Zimmermann et al. (2018) [76], have drawn and synthesized analogs of natural lignans aiming to identify new trypanocidal compounds. In particular, they synthesized a series of bis-heterocyclic derivatives containing the isoxazole moiety and a triazole ring as a spacer group between the aromatic units (Figure 10). A qualitative structure activity relationship study using three dimensional descriptors was carried out and showed a correlation between growth inhibitory potency and the presence of i) a 3,4di-OMe substitution on ring $\mathrm{A}$ and ii) a hydrophobic and highly flexible group located at ring D of the compounds. Compound 3-(3,4-dimethoxyphenyl)-5-((4-(4-pentylphenyl)-1H-1,2,3-triazol-1- 
yl)methyl)isoxazole (28) was the most active in the series ( $\mathrm{GI}_{50} 12.2 \mu \mathrm{M}$ ), showing, in vitro, low toxicity and potency similar to benznidazole $\left(\mathrm{GI}_{50} 10.2 \mu \mathrm{M}\right)$ and a selectivity index to the parasite in a value greater than 49.1 .

\section{INSERT FIGURE 10 HERE}

Figure 10. 1,2,3-Triazole-containing lignan derivative.

Cassamale et al. (2016) studies [71], above mentioned, also evaluated the anti-T. cruzi activity of their serie of triazole derivatives from the tetrahydrofurane neolignans, by bioisosteric modifications. Antitrypanosomal evaluations showed that some derivatives were only moderately active against parasite trypomastigote forms. Compounds 20 (Figure 6), 29 (Figure 11) and 30 (Figure 11) are the most active compounds with $\mathrm{IC}_{50}$ values of 56.1, 28.6 and $53.9 \mu \mathrm{M}$, respectively. Even though they have shown to be less active than the standard-drug benznidazole $\left(\mathrm{IC}_{50}\right.$ of $\left.7.3 \mu \mathrm{M}\right)$ (Table 1), these results can provide important information in the search of great characteristics for the development of new antitrypanosomal drugs.

\section{INSERT FIGURE 11 HERE}

Figure 11. Compounds 29 and 30 of [71].

Gould et al. (2017) [77] have reported bis-tetrahydropyran 1,4-triazole analogs drawn as mimics of the annonaceous acetogenin natural product chamuvarinin (Figure 12), which maintained trypanocidal activity. This acetogenin compounds are polyketides found in Annonaceae spp [78]. In another manuscript, these researchers group evaluated trypanocidal activity of acetogenin derivatives with results that inspired the anti-leishmanial activities of analogs of this class, by retaining important structural and stereochemical features. Thus, this authors contructed triazole derivatives acetogenin-based from bioisosterism in the replacement of a tetrahydrofuran ring by a 1,2,3-triazole moiety, among others structural modifications. Among these, compound 31 (Figure 12) was the most promising in anti-T. cruzi essays, exhibiting an $\mathrm{EC}_{50}$ value of $3.1 \pm 0.2 \mu \mathrm{M}$. Moreover, compound 32 (Figure 12) showed the most prominent potential of the tested series against Leishmania major, with an $\mathrm{EC}_{50}$ of $7.8 \pm 0.3 \mu \mathrm{M}$, also still proving to be non-toxic for the HeLa and Vero cell lines. So, these modifications maintain the antineglected disease potentialities, beside provide a low cytotoxicity profile.

\section{INSERT FIGURE 12 HERE}

Figure 12. Chamuvarin and the promising triazole derivatives analyzed.

\subsection{Antitrypanosomal activity: Trypanosoma brucei}

The same work of Gould et al. (2017) [77], evaluated anti-Trypanosoma brucei activity of the chamuvarinin (Figure 12) analogs, where, of the whole series of triazole compounds obtained, only compound 31 (Figure 12) demonstrated an increase in the anti-T. brucei activity, when compared to chamuvirinin, with $\mathrm{IC}_{50}$ of $0.037 \pm 0.003 \mu \mathrm{M}$, not being cytotoxic in HeLa cells, but with an $\mathrm{EC}_{50}$ value of $4.5 \pm 0.3 \mu \mathrm{M}$ in Vero cells, representing possible essential changes in the combat to T. brucei infection.

Similar studies were performed by Tulloch et al. (2017) [79], in which exclusively the compound 33 (Figure 13) showed potentiality comparable to chamuvarinin, with an $\mathrm{EC}_{50}$ value of $1.8 \pm 0.1$ $\mu \mathrm{M}$ against blood forms of $T$. brucei, accompanying $\mathrm{EC}_{50}$ values of $7.0 \pm 1.0 \mu \mathrm{M}$ for both HeLa and Vero cell lines. 


\section{INSERT FIGURE 13 HERE}

Figure 13. Chamuvarin and triazole-chamuvarinin derivative.

Scott et al. (2016) [80] reported the azole action as a binder to DNA minor grooves, which inhibits the protein-DNA interaction, being of useful application in parasite infections treatment, among others diseases [81], by inducing apoptosis of invasive cells. Distamycin, a polyamide natural product which act as binder to DNA minor groves, was used as base for prepare a series of analogs, where five derivatives (Figure 14) demonstrated anti-Trypanosoma brucei activity in the nanomolar range $\left(\mathrm{IC}_{50}>40\right.$ $\mathrm{nM}$ ). These compounds showed high levels of selectivity to the parasite when compared to their activities in human embryonic kidney (HEK 293) cell line. Once the activity of distamycin was $48 \mu \mathrm{M}$, these results allowed important conclusions for the optimization of molecules even more active in anti-parasitic modulation, with the parasite DNA as a possible target in the development of new minor groove binders.

\section{INSERT FIGURE 14 HERE}

Figure 14. Chemical structure of compounds $34,35,36,37$ and 38 of [80].

Prodigiosin (Figure 3) was also used by Rahul et al. (2015) [65] in gold and silver nanoparticles and evaluated for its anti-Trypanosoma brucei gambiense activity. The administration of prodigiosin in these nanoparticles improved its anti-T. $b$. gambiense potentiality in $4 \mathrm{x}$ approximately, reducing the $\mathrm{IC}_{50}$ value of the tripyrrole compound alone from $0.158 \pm 0.019 \mu \mathrm{g} \mathrm{mL}^{-1}$ to $0.044 \pm 0.014 \mu \mathrm{g} \mathrm{mL}^{-1}$, for their combination with silver nanoparticles, and $0.046 \pm 0.006 \mu \mathrm{g} \mathrm{mL} \mathrm{m}^{-1}$, for their combination with gold nanoparticles; besides maintaining their cytotoxic activity values without significant differences between them against PBMCs, HeLa and MCF7 cells.

\subsection{Antischistosomal activity}

Among the natural compounds evaluated for antischistosomal activity, some imidazole alkaloids that receive great notability can be obtained from plant species as Pilocarpus microphyllus [82-85]. Encouraged by this fact, Rocha et al. (2018) [86] performed molecular docking studies of known imidazole alkaloids (compounds Epiisopiloturine (39), Epiisopilosine (40), Isopilosine (41), Pilosine (42) and Macaubine (43), Figure 15) with some structurally known enzymes of Schistosoma mansoni, for identification of the imidazole ligand-protein target interaction mechanisms, that can clarify the anti-S. mansoni activities already reported in the literature for some of these molecules. Among the molecular targets studied, putative uridine phosphorylase (UP), involved in nucleotide metabolism, and thioredoxin glutathione reductase (TGR) enzymes, which possess an important role of parasite detoxification, demonstrated highest molecular affinities with Epiisopilosine (40). Additionally, TGR also showed good values of molecular affinity with Epiisopiloturine (39), Isopilosine (41), and Pilosine (42). Epiisopiloturine and Epiisopilosine were the most promising binders of purine nucleoside phosphorylase (PNP), acting in the purine and nucleotide bases recovery pathway, while the same Epiisopilosine, together with Isopilosine, were the most promising to interact with methylthioadenosine. Therefore, these could also be considered as potential antischistosomal targets. 
Figure 15. Chemical structures of Epiisopiloturine (39), Epiisopilosine (40), Isopilosine (41), Pilosine (42) and Macaubine (43).

Portes et al.(2016) [87] synthesized metal compounds from the natural compound Epiisopiloturine (Figure 15) with $\mathrm{Cu}$ and $\mathrm{Zn}$ metals, demonstrating that the $\mathrm{Cu}$ coordinating compounds, in a concentration of $250 \mu \mathrm{M}$, were as active against $S$. mansoni as Epiisopiloturine in 1000 $\mu \mathrm{M}$. However, those increased the worm mortality percentage from $20 \%$, in Epiisopiloturine, to $60 \%$ in $250 \mu \mathrm{M}$ of the tested metal compound. Besides that, both caused extensive changes in the parasite tegument. The parasite oviposition inhibition was also evaluated, keeping the $\mathrm{Cu}$ complexes as the most promising, inhibiting eggs laid for less than $25 \%$ at $62.5 \mu \mathrm{M}$, and totally at high concentrations, compared to suppression caused by Epiisopiloturine in $100 \mu \mathrm{g} \mathrm{mL}^{-1}$ obtained by Veras et al. (2012) [88].

Epiisopiloturine (Figure 15) was also the subject of study of Guimarães et al. (2015) [83], whose observed reducing the amount of juvenile worms in mice, after 21 days of infection, treated with doses of 40 and $300 \mathrm{mg} \mathrm{kg}^{-1}$ (reduction of $50.2 \%$ and $46.3 \%$, respectively) of the compound under analysis. These promising results could also be seen in the anti-S. mansoniaction of the lowest tested dose of Epiisopiloturine against their adult forms in mice after 45 days of infection, in doses of 40, 100 and $300 \mathrm{mg} \mathrm{kg}^{-1}$, resulting in a reduction of $70 \%, 39.0 \%$, and $46.7 \%$, respectively. These authors also found the ability of oviposition inhibition and a dose-response inverse relationship in the in vivo studies at 40, 100 and $300 \mathrm{mg} \mathrm{kg}^{-1}$ concentrations, accompanied by the observation of decreased liver and spleen weight in mice after treatment with $40 \mathrm{mg} \mathrm{kg}^{-1}$ of Epiisopiloturine, which is the most advantageous concentration for the treatment, and of damage to the worms tegument after the administration of this natural product. This promising compound presented some acute toxicity only in concentrations equal to or greater than $530 \mathrm{mg} \mathrm{kg}^{-1}$.

Guimarães et al. (2018) [89], in another manuscript, also evaluated the in vivo antischistosomal potential of Epiisopilosine (Figure 15). S. mansoni adult infected mice had a significant reduction of the number of worms in $400 \mathrm{mg} \mathrm{kg}^{-1}$ and $100 \mathrm{mg} \mathrm{kg}^{-1}$ of Epiisopilosine, with a reduction of $57.78 \%$ and $60.61 \%$, respectively, thus, showing no significant difference, even with the decrease in the dose utilized. As seen in studies with Epiisopiloturine, alkaloid Epiisopilosine, at $100 \mathrm{mg} \mathrm{kg}^{-1}$, demonstrated a reduction of the number of eggs collected in the feces of the infected mice (in this case, a reduction of 58\%), decreasing of liver and spleen weight, when compared to control group, and changes in the morphology of $S$. mansoni adults tegument, mainly in male worms. S. mansoni juvenile forms also had their amounts in the infected mice reduced, in this case, a decrease of $58.06 \%$. Epiisopilosine did not show significant cytotoxicity against the mammalian cells tested, in concentrations up to $512 \mu \mathrm{g} \mathrm{mL}^{-1}$, nor in vivo toxicity.

By analyzing these studies, we can observe the importance of different isomers in the biological response and how it can affect the interaction with different targets, thus justifying their possible pharmacological responses. However, there is an evident shortage of compounds evaluated for this parasitosis associated with this core.

\section{PYRIDINES, DIAZINES AND TRIAZINES DERIVATIVES}

\subsection{Antiparasitic mechanism of action}


Based on the studies related to pyridine, diazine and triazine nucleus from the literature, these present a antiparasitc potential and the main mechanism of action for antiplasmodial and antileishmanial activity occurs by inhibiting the enzyme dihydrofolate reductase (DHFR) that affect the biosynthesis of purines and pyrimidines, DNA synthesis, cellular multiplication and nuclear division of the parasite [9094]. Additionally, in some cases, the overexpression of pteridine reductase 1 (PTR1) can overcome the DHFR inhibition, thus becoming also a target of interest and its inhibition can corroborate for antileishmanial activity [95]. Another mechanism exhibited is the inhibition of hypoxantine with consequent growth interruption of the parasite as antiplasmodial activity [96]. Moreover, nitroreductases (NTRs) enzymes trigger the generation of toxic free radicals by bioactivating the nucleus of pyridine and its derivatives that is suggested as antileishmanial [30]. Regarding to antitrypanosomal activity the inhibition of CYP 51 is reported as lead mechanism of action, which is important to lanosterol's production by Trypanosoma cruzi $[29,97]$. However, it is not described on the literature antischistosomal mechanisms related to the nucleus analyzed, thus might become a relevant subject to invest new researches.

\subsection{Antiplasmodial activity}

Heterocyclics are extensively present on the chemical structures of natural products, making them excellent starting points to the development of new drugs due to the diverse biological properties of these compounds. Secondary metabolites, especially alkaloids, terpenoids, flavonoids, and saponins with antimalarial activity already described can be highlighted $[96,97]$.

Azaguanine (44) (Figure 16), also known as pathocidin, was first isolated from fermentation broth of Streptomyces albus var. pathocidicus in 1961, bearing pyrimidine nucleus. This natural compound displays antimicrobial and cytotoxic properties against a wide range of bacteria, viruses, fungi and human cancer cell lines. Antimalarial activity occurs by the inhibition of hypoxanthine capitation $\left(\mathrm{IC}_{50}=6.6 \mu \mathrm{M}\right)$ and consequently, inhibition of parasite growth $\left(\mathrm{IC}_{50}=18 \mu \mathrm{M}\right)$, presenting itself a potential compound for the development of new antimalarial drugs [96].

\section{INSERT FIGURE 16 HERE}

Figure 16. Chemical structure of 8-Azaguanine (44)

Cassiarin A (45) (Figure 17) is a natural alkaloid isolated from Cassia simea [85], which bears pyridine ring in its skeleton and showed important antimalarial activity $\left(\mathrm{IC}_{50}\right.$ of $0.005 \mu \mathrm{g} \mathrm{mL} \mathrm{m}^{-1}$ ). Other members of this family, such as cassiarin C (46) (Figure 18), also have demonstrated vasorelaxant, anticancer and antimalarial activities [98].

\section{INSERT FIGURE 17 HERE}

Figure 17. Chemical structure of cassiarin A (45) e cassiarin C (46)

Rcognizing the pyridine nucleus and its derivatives obtained from natural products as potential antimalarials, studies were performed to synthesize new pyridine derivatives with promising antimalarial activity. In this context, Thipathi et al. (2019) synthesized, by hybridization, eighteen 4'-fluoroamodiaquine-pyrimidine (FAQ-pyrimidines) (47) (Figure 18). Strains of $P$. falciparum NF54 were 
sensitive to the reference drug, chloroquine (CQ), and strains of $P$. falciparum Dd2 were resistant to CQ. All FAQ-pyrimidines synthesized exhibited greater antiplasmodial potency against the resistant strain (Dd2) than the reference drug, except for intermediate $6 \mathrm{~b}$ (48). Compound 8b (49) was the most active with an $\mathrm{IC}_{50}$ of $7.5 \mathrm{nM}$, demonstrating the importance of cyclic amines of FAQ-pyridines against these strains [16].

\section{INSERT FIGURE 18 HERE}

Figure 18. Chemical structure of FAQ-pyrimidine hybrid (47), (48) and (49)

Maurya et al. (2017) synthesized twenty-four 4-aminoquinoline-pyrimidine hybrids (Figure 19) and evaluated their antimalarial activity in vitro against chloroquine-sensitive and resistant strains of Plasmodium falciparum (D6 clone and W2 clone, respectively). Results demonstrated that most of the hybrids displayed great antimalarial activity against both strains of $P$. falciparum. The best activity, although, was performed in W2 strains, in which all hybrids, except 51 and $53\left(\mathrm{IC}_{50}=0.454\right.$ and 0.506 $\mu \mathrm{M}$, respectively), presented higher activity than the standard drug chloroquine $\left(\mathrm{IC}_{50}=0.31 \mu \mathrm{M}\right)$, with $\mathrm{IC}_{50}$ values ranging from 0.039 to $0.257 \mu \mathrm{M}$ [17].

\section{INSERT FIGURE 19 HERE}

Figure 19. Chemical structure of compounds 50, 51, 52, 53, 54, 55 .

Le Manach et al. (2014) synthesized new imidazopyridazines identified from high throughput screening of SoftFocus kinase library, with antiplasmodial activity against K1 (multiple drug-resistant $P$. falciparum strain) and NF54 (sensitive P. falciparum strain). Structure-activity relationship (SAR) studies identified highly potent compounds against both cell lines, highlighting compound 56 (Figure 20) as lead compound with $\mathrm{IC}_{50}$ of $6.3 \mathrm{nM}$ and $7.3 \mathrm{nM}$, against $\mathrm{K} 1$ and NF54, respectively, being comparable to the reference drug, artesunate (table 01). This compound also exhibited $98 \%$ in vivo activity against $P$. berghei mouse model, analyzed in mice, at $50 \mathrm{mg} \mathrm{kg}^{-1}$ dose by oral administration [99, 100].

\section{INSERT FIGURE 20 HERE}

Figure 20. Chemical structure of compound 56

Continuing his work, Le Manach et al. (2016) synthesized a new series of 2-aminopyrazine derivatives compounds, obtained through the introduction of water-solubilizing groups on the 5-phenyl ring of a 2-aminopyrazine series, and evaluated their biological activity against strains of K1 (multidrugresistant $P$. falciparum) and NF54 (multidrug-sensitive $P$. falciparum). The authors observed that all compounds were equipotent against both strains, indicating no existing cross-resistance with the reference drug. Moreover, compound 57 (Figure 21) proved to be the most promising against P. falciparum, with $\mathrm{IC}_{50}=5.2 \mathrm{nM}$ and $5.4 \mathrm{nM}$, on K1 and NF54 strains, respectively [101].

\section{INSERT FIGURE 21 HERE}

\section{Figure 21. Chemical structure of compound 57}

Xue et al. (2019) synthesized 3,3'-Disubstituted 5,5'-Bi(1,2,4-triazine) derivatives and initially evaluated antiplasmodial activity of these compounds against erythrocytic stage of Plasmodium Falciparum 3D7 line, highlighting 58 (figure 22) as the most potent dimer with $\mathrm{IC}_{50}=0.008 \mu \mathrm{M}$, and reference drug chloroquine with $\mathrm{IC}_{50}=0.004 \mu \mathrm{M}$. This compound was evaluated also against strains of chloroquine-resistant $\left(\mathrm{W} 2, \mathrm{IC}_{50} \mathrm{CQ}=0.150 \pm 0,03 \mu \mathrm{M}\right)$ and artemisinin-resistant $\left(\mathrm{MRA} 1240, \mathrm{IC}_{50} \mathrm{CQ}=\right.$ 
$0.097 \pm 0,021 \mu \mathrm{M}) P$. falciparum, obtaining promising values of $\mathrm{IC}_{50}=0.0047 \pm 0.0011 \mu \mathrm{M}$ and $\mathrm{IC}_{50}=$ $0.0086 \pm 0.0010$. Researchers analyzed antimalarial potency of compound 58 on $P$. falciparum and $P$. vivax isolated from the blood of outpatients with uncomplicated malaria and observed that compound 58 had excellent potency with $\mathrm{IC}_{50}$ values of $0,022-0,034 \mu \mathrm{M}$ and $0,0093-0,031 \mu \mathrm{M}$, respectively [90].

\section{INSERT FIGURE 22 HERE}

Figure 23. Chemical structure of compound 58

Pathak et al. (2017) synthesized twenty-six 2,4,6 s-triazine derivatives compounds. Analysis in silico based on ADME properties and docking studies selected compounds 59, 60 and 61 (Figure 23) to evaluate antimalarial activity against 3D7 strain line of $P$. falciparum (cycloguanil sensitive strain) and the possible inhibition of dihydrofolate reductase (DHFR). All three compounds (59, 60 and 61) presented potency 30 times better than the reference drug, cycloguanil, based on minimum inhibitory concentrations (MIC), in which, compounds 59, 60, 61, and cycloguanil presented values of $4.47 \mathrm{nM}$, $7.94 \mathrm{nM}, 2.75 \mathrm{nM}$, and $255 \mathrm{nM}$, respectively. Compound 61 was the most active, while 60 the less active. The authors stated that the presence of electron-donating groups, the number of hydrogen bond formation, lipophilicity of ligands and charge of nitrogen in the triazine ring enhances the DHFR inhibition significantly [91].

\section{INSERT FIGURE 23 HERE}

Figure 24. Chemical structure of compounds 59, 60 and 61

\subsection{Antileishmanial activity}

The enzyme dihydrofolate reductase (DHFR) is an important target for antileishmanial compounds, acts by catalyzing the reduction of dihydrofolate to tetrahydrofolate. Tetrahydrofolate, when methylated is a vital cofactor to convert deoxyuridine monophosphate into thymidine monophosphate, and DHFR inhibition prevents biosynthesis of thymidine, leading to cell death, because these microorganisms do not have a mechanism of transport of this cofactor from the host. Most known DHFR inhibitors contain a heterocyclic aromatic ring, such as pyridine, that was substituted with alkyloxy groups of different chain lengths. These were synthesized and evaluated by Linãres et al. (2012), and three compounds (62, 63 and 64, Figure 24) presented potent results against Leishmania mexicana promastigotes with $\mathrm{IC}_{50}$ of 16,12 and $20 \mu \mathrm{g} \mathrm{mL} \mathrm{m}^{-1}$, respectively, better than the reference inhibitor geneticin $\left(\mathrm{IC}_{50}=50 \mu \mathrm{g} \mathrm{mL}^{-1}\right)$. The acetylated compound 63, presenting 14 carbon atoms in the side chain, was the most potent, indicating that the presence of the acetyl group increased the inhibitory activity exhibited by compound 62 [92].

\section{INSERT FIGURE 24 HERE}

Figure 24. Chemical structure of compouds 62,63 and 64

Annomontine (65) (Figure 25) is a pyrimidine-betacarboline alkaloid isolated from Annona foetida that presents an $\mathrm{IC}_{50}$ value of $34.8 \mu \mathrm{M}$ against promastigote forms of L. braziliensis. Based on that activity, as stated by Acevedo et al. (2019), nine pyrimidine-pentamidine hybrids were synthesized and presented $\mathrm{IC}_{50}$ values, of in vitro tests against $L$. donovani amastigotes, ranging from 0.30 to $1.72 \mu \mathrm{M}$, demonstrating the importance of pyrimidine nucleus [102]. 


\section{INSERT FIGURE 25 HERE}

Figure 25. Chemical structure of compound 65

As stated by Suryawanshi et al. (2013), pyrimidine derivatives are known DHFR inhibitors, so a novel series of 4-S and 4-N-substituted pyrimidine derivatives were synthesized, 66 and 67 as lead compounds (Figure 26). According to their in vitro activity against Leishmania donovani amastigotes, compound 66 showed $\mathrm{IC}_{50}=2.0 \pm 0.1 \mu \mathrm{M}$ and selectivity index $(\mathrm{SI})=188$, while compound 67 obtained $\mathrm{IC}_{50}=0.5 \pm 0.1 \mu \mathrm{M}$ and $\mathrm{SI}=116$, demonstrating superior results when compared to the reference drugs, pentamidine and sodium stibogluconate (table 01). Moreover, the in vivo activity of compounds 66 and 67 was similar to standard drugs [93].

\section{INSERT FIGURE 26 HERE}

Figure 26. Chemical structure of compounds 66 and 67

Small peptides (3-9 amino acid residues) find applications in diverse therapeutic areas, amino acid and dipeptide esters that contain at least one hydrophobic amino acid show leishmanicidal activities, moreover, triazines act as dihydrofolate reductase (DHFR) inhibitors. Therefore, Khattab et al. (2018) synthesized 1,3,5-triazino-peptide derivatives that against Leishmania aethiopica promastigotes, which had greater or comparable activity to miltefosine $\left(\mathrm{IC}_{50}=7.8 \pm 0.34 \mu \mathrm{M}\right)$. Among them, compound 68 (Figure 27), demonstrated the best activity $\left(\mathrm{IC}_{50}=1.4 \pm 0.04 \mu \mathrm{M}\right)$, also overcame miltefosine $\left(\mathrm{IC}_{50}=\right.$ $0.74 \pm 0.04 \mu \mathrm{M}$ ) against $L$. aethiopica amastigote with $\mathrm{IC}_{50}=0.22 \pm 0.02 \mu \mathrm{M}$ and exhibited activity very close to amphotericin $\mathrm{B}\left(\mathrm{IC}_{50}=0.15 \pm 0.02 \mu \mathrm{M}\right)$. Besides, it had the highest selective index (SI=2457.88), and in vivo acute toxicity studies indicated their safety when administered orally and parenterally up to 250 and $100 \mathrm{mg} \mathrm{kg}^{-1}$ of body weight [94].

\section{INSERT FIGURE 27 HERE}

Figure 27. Chemical structure of compound 68

However, Leishmania is known to proficiently overcome DHFR inhibition by overexpressing pteridine reductase 1 (PTR1) and it is associated with the pterin and folate metabolism that is essential for the growth. Also, PTR1 is an excellent drug target due to the unusual salvage of pterin from the host while the host synthesizes pterin derivatives de novo from GTP and lack PTR1 activity. Using PTR1 as a target, Chauhan et al. (2013) synthesized triazine dimers and most of the compounds exhibited better potency than the reference drug pentamidine $\left(\mathrm{IC}_{50}=13.68 \pm 1.57 \mu \mathrm{M}\right)$ against Leishmania donovani intracellular amastigotes, also presenting low cytotoxicity. Compound 69 (Figure 28) showed very consistent and promising leishmanicidal activity with $\mathrm{IC}_{50}=1.99 \pm 0.31 \mu \mathrm{M}$ and also displayed in vivo potential on $L$. donovani with good percentage inhibition $(74.41 \pm 10.26 \%)$. As well, docking studies showed that compound 69 stood out due to its favorable hydrophobic and hydrogen bond interactions with binding domain of PTR1, presenting binding energy of $-8.54 \mathrm{kcal}_{\mathrm{mol}}{ }^{-1}$, in contrast to $6.95 \mathrm{kcal} . \mathrm{mol}^{-1}$ of reference drug pentamidine (table 01) [95].

\section{INSERT FIGURE 28 HERE}

Figure 28. Chemical structure of compound 69 
The sequencing of the parasite genome provided new targets that can be potential to antileishmanial drugs, among them, Leishmania kinases. According to Castera-ducros et al. (2013), the inhibition of the parasite casein-kinase 1 by imidazo[1,2-a]pyridines demonstrated antileishmanial activity. Studies of several derivative's structure-activity relationships led to the characterization of 6halo-3-nitro-2-phenylsulfonyl-methylimidazo[1,2-a]pyridine as pharmacophore, through substitutions emerged the lead compound 70 (Figure 29). When compared to the reference drugs, compound 70 presented a very good activity on $L$. donovani and $L$. infantum promastigotes with $\mathrm{IC}_{50}=1.8 \pm 0.8 \mu \mathrm{M}$ and $3.3 \pm 0.7 \mu \mathrm{M}$, respectively, being more active than standard compounds, pentamidine $\left(\mathrm{IC}_{50}=6.0 \pm\right.$ $0.8 \mu \mathrm{M}$ and $8.2 \pm 0.1 \mu \mathrm{M}$ ) and miltefosine ( $\mathrm{IC}_{50}=3.1 \pm 0.06 \mu \mathrm{M}$ and $11.6 \pm 0.4 \mu \mathrm{M}$ ). Promising results were reported also on $L$. donovani amastigotes with $\mathrm{IC}_{50}=5.5 \pm 0.2 \mu \mathrm{M}$, compared to pentamidine $\left(\mathrm{IC}_{50}>\right.$ $20 \mu \mathrm{M})$ and miltefosine $\left(\mathrm{IC}_{50}=6.8 \pm 0.3 \mu \mathrm{M}\right)$. Additionally, the selectivity index for L. donovani was higher than 17.2, which is more promising than pentamidine $(\mathrm{SI}=0.4)$ and miltefosine $(\mathrm{SI}=16.2)$ [103].

\section{INSERT FIGURE 29 HERE}

Figure 29. Chemical structure of compound 70

According to Marhadour et al. (2012), 2,3-diarylimidazo[1,2-a]pyridine based compounds were synthesized and evaluated on the promastigote stage of Leishmania major. Eight compounds displayed $\mathrm{IC}_{50}$ values below $10 \mu \mathrm{M}$, among the most active compounds on L. major promastigotes, the selectivity index of compounds 71, 72 and 73 (Figure 30) overcame the reference drug, pentamidine (SI = 3.13), with SI $=5.43,5.51$ and 3.85, respectively. The highest SI of the second series were exhibited by compounds 74 and 75 (Figure 30) with SI = 8.65 and 18.46, respectively. Moreover, compound 76 (Figure 30) remained active at concentration $1 \mu \mathrm{M}$, with low cytotoxicity on HeLa cells $\left(\mathrm{IC}_{50}=67.0 \pm\right.$ $2.0 \mu \mathrm{M})$. Furthermore, derivatives 71,74 and 75 also presented activity comparable to pentamidine (99\% inhibition with $10 \mu \mathrm{M}$ concentration) against L. major amastigotes [25].

\section{INSERT FIGURE 30 HERE}

Figure 30. Chemical structure of compounds $71,72,73,74,75$ and 76.

Secondary metabolites from marine microorganisms are important sources for the discovery of novel bioactive natural products. Indolepyrazines A (77) and B (78) (Figure 31) were isolated from a coastal mud sample of gram-negative bacterial strain Acinetobacter sp. ZZ1725. Both compounds showed inhibitory activities against the growth of MRSA, Escherichia coli, and Candida albicans, demonstrating the importance of pyrazine nucleus that was also included in the following synthesis [104].

\section{INSERT FIGURE 31 HERE}

Figure 31. Chemical structure compound 77 and 78

As a continuation to enhance previous results, Marchand et al. (2015) synthesized 2-phenyl-3(pyridin-4-yl)imidazo[1,2-a]pyrazine (compound 79) that was starting point to two others sub-series with compounds 80 and 81 . Both fluorine analogs have a polar substituent on C-8 position and are lead compounds (Figure 32). Tests in vitro on L. major promastigotes highlighted the stronger activity of compound 78, with $\mathrm{IC}_{50}=2.8 \pm 0.4 \mu \mathrm{M}$ in comparison to pentamidine $\left(\mathrm{IC}_{50}=4.6 \pm 1.1 \mu \mathrm{M}\right), 77\left(\mathrm{IC}_{50}=\right.$ $20.1 \pm 12.2 \mu \mathrm{M})$ and $79\left(\mathrm{IC}_{50}=6.4 \pm 0.2 \mu \mathrm{M}\right)$. Also, cytotoxicity and selectivity index were comparable to the reference drug. The molecule 78 presented even better activity on $L$. major amastigotes, with $\mathrm{IC}_{50}=$ 
$0.2 \pm 0.1 \mu \mathrm{M}$ and $\mathrm{SI}=466$, followed by $79\left(\mathrm{IC}_{50}=0.8 \mu \mathrm{M}, \mathrm{SI}=52.5\right)$. Through these results, as stated by the authors, the introduction of fluorine atom and a polar substituent increased the activity [26].

\section{INSERT FIGURE 32 HERE}

Figure 31. Chemical structure of compounds 79, 80 and 81

The pyrazolopyridine derivatives revealed potential new drugs against Leishmania and $1 H$ Pyrazolo[3,4-b]pyridine is an example of a fused system, which is known to possess remarkable and significant biological and medicinal importance. Moreover, the introduction of a phosphoramidate group changes the physical and chemical properties, because it accentuates the polarization and intermolecular bonding characteristics, since the $\mathrm{P}=\mathrm{O}$ group presents a significant role as a strong hydrogen bond acceptor, which is essential for the non-covalent bonding of proteins or other specific ligands to their substrates [105].

Based on that, Medeiros et al. (2018) synthesized a series of 1H-Pyrazolo[3,4-b]pyridinephosphoramidates, in order to evaluate antileishmanial activity, tests on Leishmania amazonensis promastigotes highlighted cyano substituted molecules $82\left(\mathrm{IC}_{50}=9.81 \pm 3.10 \mu \mathrm{M}\right)$ and 83 $\left(\mathrm{IC}_{50}=6.44 \pm 1.49 \mu \mathrm{M}\right)$ as lead compounds (Figure 33$)$ that obtained better results than pentamidine $\left(\mathrm{IC}_{50}\right.$ $=13.00 \mu \mathrm{M}$ ), demonstrating the importance of phenyl substituent at position $\mathrm{R} 1$ of the pyrazole ring on compound 83. Furthermore, cytotoxicity responses on macrophages and selectivity index values were similar to the reference drug pentamidine [105].

\section{INSERT FIGURE 33 HERE}

Figure 32. Chemical structure of compounds 82 and 83

\subsection{Antitrypanosomal activity: Trypanosoma cruzi}

Pyridine derivatives, such as 1,2,4-triazine, obtained from synthetic and natural sources, possess different biological activities, being part of chemical structure of some natural antibiotics, such as fervenulin (planomycin), reumycin and toxoflavin (panthothricin), demonstrating the importance of this nucleus as starting point for discovery of new drugs with diverse biological activities [106]. Therefore, antitrypanosomal tests were performed with the alkaloid pyrimidine- $\beta$-carboline (annomontine compound 65) (Figure 25), isolated from dichloromethane extract of Annona foetida (Annonaceae), that revealed strong activity against $T$. cruzi with $\mathrm{IC}_{50}$ of $4.2 \pm 1,9 \mu \mathrm{g} \cdot \mathrm{mL}^{-1}$ [107].

In this context, Lapier et al. (2019) synthesized twenty-four triazolopyridine derivatives and evaluated their trypanocidal activity, in which compound 84 (Figure 34) exhibited better trypanocidal activity than the reference drug nifurtimox (table 01), showing $\mathrm{IC}_{50}$ values of $6.8 \pm 1.8 \mu \mathrm{M}$ and 17.4 \pm 1.3 $\mu \mathrm{M}$, respectively, against Trypanosoma cruzi epimastigotes (DM28c strain) [27].

\section{INSERT FIGURE 34 HERE}

Figure 34. Chemical structure of compound 84

Braga et al. (2017) performed a molecular simplification of 8-chloro- $N$-(3-morpholinopropyl)5H-pyrimido[5,4-b]indol-4-amine. Hence, five series were obtained: indole, pyrimidine, quinoline, aniline and pyrrole derivatives. Remarkably, compound 85 (Figure 35), a pyrimidine derivative, was 
highly active against $T$. cruzi, presenting $\mathrm{IC}_{50}=3.1 \pm 0 \mu \mathrm{M}$ and selectivity index (SI) of 128 , comparable to the reference drug benznidazole, $\mathrm{IC}_{50}=3.8 \pm 0.8 \mu \mathrm{M}$ and $\mathrm{SI}=626$, demonstrating to be a promising trypanocidal agent [108].

\section{INSERT FIGURE 35 HERE}

Figure 35. Chemical structure of compound 85

\subsection{Antitrypanosomal activity: Trypanosoma brucei}

On the search for new efficient agents for the treatment of this disease, Fersing et al. (2018) synthesized twenty-one 6,8-dibromo-3-nitroimidazo[1,2-a]pyridine derivatives. Compounds 86 and 87 (Figure 36) demonstrated potent antiparasitic activity against $T$. brucei, presenting $\mathrm{IC}_{50}$ of $0.16 \mu \mathrm{M}$ and $0.04 \mu \mathrm{M}$, respectively, in comparison to the reference drug suramin $\left(\mathrm{IC}_{50}=0.03 \mu \mathrm{M}\right)$ and eflornithine $\left(\mathrm{IC}_{50}=13.3 \mu \mathrm{M}\right)$, indicating a remarkable trypanocidal potential of this compounds [38].

\section{INSERT FIGURE 36 HERE}

Figure 36. Chemical structure of compounds 86 and 87

\subsection{Antischistosomal activity}

Natural products (NPs) are structurally diverse and a valuable source for new molecular scaffolds on the development of drugs. About $65 \%$ of all drugs are approved and classified as NPs or are inspired by NP nucleus, which was the case of ivermectin that is used for tropical neglected diseases with antihelmintic action, being a semi-synthetic drug obtained from monocyclic lactones produced by Streptomyces avermitilis [109]. In this context, given the lack of therapeutic arsenal for this pathology (schistosomiasis), the research of new drugs with antischistosomal activity is relevant, starting from the pyridine nucleus and its derivatives, due to diverse biological activity already demonstrated by this nucleus, including antiparasitic and antimicrobial. However, until the end of this work, the literature did not report any bioprospective derivatives of pyridine with this activity investigated.

\section{INDOLE DERIVATIVES}

\subsection{Antiparasitic mechanism of action}

A large number of compounds with the indole nucleus are described in the literature with significant activities against parasitic diseases, such as malaria, leishmaniosis, Chagas disease, sleeping sickness and schistosomiasis [20]. However, in most studies, the mechanisms of action of the indole compounds that have relevant activities are not reported. Even the drugs that are currently used as a standard (despite not containing the indole nucleus) do not have well-defined mechanisms [110]. However, the derivatives containing the indole nucleus that will be cited here may be related to the mechanisms of action involving DNA interactions and fragmentations [110, 111], topoisomerase II inhibition [112], inhibition of cysteine protease, and enzymatic inhibition [113-115]. 


\subsection{Antiplasmodial activity}

One of the first reports about antiplasmodial natural compounds is the alkaloid cryptolepine (88) (Figure 37), a hybrid of indole and quinoline that stood out as the main part of bloody Cryptolepis roots, a plant from Africa occidental used for malaria treatment [110]. In vitro studies of this isolated compound demonstrated activity against chloroquine-resistant $P$. falciparum strains with $\mathrm{IC}_{50}=0.033 \mu \mathrm{gL} \mathrm{m}^{-1}$ [20]. In vivo study of cryptolepine demonstrated notable results to parasitemia reduction when administrated orally in a dose of $50 \mathrm{mg} \mathrm{kg}^{-1}$ during 4 days [116]. Moreover, cryptolepine and other 12 alkaloids containing a fusion between indole and quinoline rings were reported for antimalarial activity and other diseases [117]. Manzamine A (89) (Figure 37), another promising alkaloid containing an indole ring, is naturally found in sea sponges and was first isolated from Okinawa Haliclona sp. This compound has presented antimalarial activity with $\mathrm{IC}_{50}$ values of $13.5 \mathrm{ng} \mathrm{mL}^{-1}$ and $25 \mathrm{ng} \mathrm{mL}^{-1}$ against W2 and D6 $P$. falciparum strains, respectively [100].

\section{INSERT FIGURE 37 HERE}

Figure 37. Cryptolepine (88) and manzamine A (89) structures

New obtainment methods with semisynthetic and synthetic routes are described in the literature on the search for more efficient antimalarial compounds, with the indole nucleus from natural product as starting point. Pursuing this approach, Yadav et al. (2015) synthesized a series of $N$-aryl and heteroaryl sulfonamide derivatives of meridianins, which is an indolic alkaloid of marine origin, and evaluated their antimalarial activity against two Plasmodium falciparum strains (D6 and W2). Compound 90 (Figure 38) showed significant antiplasmodial activity against both strains with $\mathrm{IC}_{50}$ of 2.56 and $3.41 \mu \mathrm{M}$. These meridianin sulfonamide derivatives were also found to have no cytotoxicity against mammalian cell lines up to $25 \mu \mathrm{g} \mathrm{mL}^{-1}$. The results sustain meridianin sulfonamide derivatives as potential candidates in the discovery of new antimalarial agents [118].

\section{INSERT FIGURE 38 HERE}

Figure 38. Compound 90 structure

Another natural product that has been frequently reported with antiplasmodial activity is tryptanthrin, compound 91 (Figure 39), despite its low solubility in water. In an attempt to solve this issue, Onambelle et al. (2015) synthesized tryptanthrin analogs and evaluated their antiplasmodial activity against Plasmodium falciparum in the asexual and sexual phase. The compound 92 (Figure 39) presented the best antiplasmodial activity ( $\mathrm{IC}_{50} 30 \mathrm{nM}$; SI: 155.9) in both strains. In in vivo tests, compound was able to interfere with gametogenesis, decreasing microgamet exflagulation by $20 \%$ at $\mathrm{IC}_{90}$. The results suggest tryptanthrin derivatives are able to eliminate the intraerythrocytic asexual stages and intervene in the parasite development in the sexual stage [119].

\section{INSERT FIGURE 39 HERE}

Figure 39. Compound 91 and 92 structures

A new class of glycine-extracted compounds with potential antimalarial activity was suggested by Svogie et al. (2016). A series of indolyl-3-ethanone- $\alpha$-thioethers derivatives were synthesized and evaluated in vitro. Results emphasized compounds 93 and 94 (Figure 40) significant activities, both exhibited potent and selective antiplasmodial activity against chloroquine-sensitive strains of Plasmodium 
falciparum (3D7), presenting $\mathrm{IC}_{50}$ of 0.24 and $0.09 \mu \mathrm{M}$, and SI of 2083 and $5556 \mu \mathrm{M}$, respectively. The SAR study further demonstrated that the para-substituted thiophenyl group is an indispensable pharmacophore for antiplasmodial activity, even though its mechanism of action is yet unknown [115].

\section{INSERT FIGURE 40 HERE}

Figure 40. Compound 93 and 94 structures

Another naturally occurring product containing the indole nucleus, found sponges and corals, is aplysinopsin, first isolated by Fusetani [120]. Based on its structure (95), Yadav et al. (2016) initially synthesized and evaluated several new indole derivatives against Plasmodium falciparum. SAR studies demonstrated that the activity increased when there were alkyl and carboxylate substitutions at the positions N1 and C2, and aryl substitution at the indole C3. Compound 96 (Figure 41) showed significant potency with MIC values below $0.70 \mu \mathrm{g} \mathrm{mL}^{-1}$, which were better than standard drugs quinine (MIC 0.27 $\mu \mathrm{g} \mathrm{mL}^{-1}$ ) and chloroquine (MIC $0.02 \mu \mathrm{g} \mathrm{mL}^{-1}$ ) [121].

\section{INSERT FIGURE 41 HERE}

Figure 41. Aplysinopsin structure (95) and indolic derivatives N1, C2 and C3 substituted (96)

A new class of C2-arylalkanimino tryptamine 97 (Figure 42) derivatives has been developed by Luthra et al. (2019), adopting as inspiration the structure of melatonin, a hormone naturally secreted by mammalian glands. Following a preliminary antimalarial in silico, a series of derivatives showed activity to inhibit the parasite intra-erythrocytic cycle progression, mainly interrupting the melatonin hormone-induced synchronization that induces parasite growth. Among the derivatives, compound 98 (Figure 42) stood out with the highest potential with $\mathrm{IC}_{50}$ of $0.74 \mu \mathrm{M}$. The evaluation on MT1 melatonin receptor revealed that compound 98 binds to the enzyme, impacting on the improvement and elevation of the concentration of the molecules [122].

\section{INSERT FIGURE 42 HERE}

Figure 42. Tryptamine and compound 98 structures

Adamantane was isolated from petroleum by two Czech Chemists in 1932 [123] and has already been reported to treat several diseases [124, 125]. Based on its possible chemotherapeutic action, Devender et al. (2017) synthesized a series of fifty-three new adamantyl/cycloheptyl-indoleamide derivatives and evaluated their antiplasmodial activity in vitro against $P$. falciparum chloroquine-sensitive and resistant strains. The results highlighted compounds 99, 100, 101 and 102 (Figure 43) as promising, given their relevant antiplasmodial activity, with $\mathrm{IC}_{50}$ values of $1.87,1.93,2.0,2.17 \mu \mathrm{M}$, respectively, against the chloroquine-sensitive strain (Pf3D7). Similar results were found against the chloroquineresistant strain (Pfk1), with $\mathrm{IC}_{50}$ values of 1.69, 2.12, 1.60 and $2.19 \mu \mathrm{M}$, respectively. The SAR study also pointed out that the incorporation of large groups into sulfonamide derivatives favored antiplasmodial activity [126].

\section{INSERT FIGURE 43 HERE}

Figure 43. Indoleamide derivatives structures

Yeung et al. (2017) synthesized a series of cipargamine spiroindolones, based on GNF 493, a naturally occurring compound first identified as a potent $P$. falciparum growth inhibitor, and evaluated their antimalarial activity. Compound 103 (Figure 44) had a favorable oral pharmacokinetic (PK) profile 
when evaluated in mice, showing $\mathrm{Cmax}=3.6 \mathrm{mM}$ and bioavailability of $59 \%$. The same compound also exhibited notable activity against Plasmodium falciparum chloroquine-resistant strains NF54 and K1 ( $\mathrm{IC}_{50}$ of 27 and $21 \mathrm{nM}$, respectively) [127].

\section{INSERT THE FIGURE 44 HERE}

Figure 44. Spiroindolone derivative 103

The cryptolepine extracted from the native African Cryptolepis sanguinolenta plant and was first isolated in 1951 by Gellert et al. [128]. Through that, halogenated isocryptolepine derivatives were based on alkaloid isocryptolepine 104 (Figure 45) were synthesized and evaluated by Aroonkit et al. (2015) for in vitro antiplasmodial activity against Plasmodium falciparum strains K1, 3D7, SKF58 and SRIV35. Compound 105 showed the best results against the four strains with $\mathrm{IC}_{50}$ values $61.8,37.9$, 92.4 and $83.0 \mathrm{nM}$, respectively. Moreover, in vitro antiproliferative properties of isocryptolepine derivatives were evaluated against HepG2, HuCCA-1, MOLT-3, and A549 cancer cell lines, portraying derivatives 106 and 107 as potent and selective compounds against cancer cell lines [129].

\section{INSERT THE FIGURE 45 HERE}

Figure 45. Isocryptolepine derivatives

Chakka et al. (2015) evaluated a group of derivatives with the pyrrolidine fraction at T2 position showed potent inhibition of 2-falcipain. Compound 108 (Figure 46) displayed notable anti-parasitic activity $\left(\mathrm{IC}_{50}=0.9 \pm 0.1 \mu \mathrm{M}\right)$, matching with its inhibitory activity against falcipain-2, with a Ki of $1.1 \pm$ $0.1 \mu \mathrm{M}$. Furthermore, the same compound exhibited a potency against Dd2 and Mcamp isolates about 7 to 12 times greater than the laboratory strain (3D7), while compound 109 inhibited the growth of the drug resistant parasite $\mathrm{Dd} 2$ with more efficacy $\left(\mathrm{EC}_{50}=1.7 \mu \mathrm{M}\right)[130]$.

\section{INSERT FIGURE 46 HERE}

Figure 46. Compound 108 and 109 structures

Ugwu et al. (2017) performed in silico and in vitro studies to subsequently synthesize a series of twenty-four new carboxamide derivatives. Selected compounds with antimalarial potential were evaluated in silico, through molecular docking, against plasmepsin II enzyme and displayed good interaction with the target, indicating the possible mechanism of action. Among the derivatives, compound 110 (Figure 47), demonstrated better results with MIC value of $0.03 \mu \mathrm{M}$ compared to chloroquine $(0,06 \mu \mathrm{M})$. In addition, showed antioxidant action with $\mathrm{IC}_{50}$ of $0.045 \mathrm{mM}$ comparable with $0.34 \mathrm{mM}$ for ascorbic acid. The compound series synthesized presents a promising performance for reducing the oxidative stress caused by the malaria parasite [131].

\section{INSERT FIGURE 47 HERE}

Figure 47. Carboxamide derivative (110)

\subsection{Antileishmanial activity}

Antileishmanial molecules originated from isolated natural products are also reported in the literature. For example, staurosporine (111) (Figure 48), isolated from sponges of the Mediterranean Sea, showed activity against Leishmania major promastigotes with $\mathrm{EC}_{50}$ of $5.30 \mu \mathrm{M}$. Another alkaloid 
resulting from bioprospection is the indole tryptophol, isolated from sponges Spongia sp. of Aegean Sea, displayed activity in vitro against $L$. donovani with $\mathrm{EC}_{50}$ of $5.30 \mu \mathrm{g} \mathrm{mL}^{-1}$ [132].

\section{INSERT FIGURE 48 HERE}

Figure 48. Staurosporine structure (111)

In this perspective, Ashok et al. (2016a) synthesized a series of 1-(thiophen-2-yl)-9H-pyrido[3,4b]indole derivatives and evaluated their biological activity against promastigote and amastigote forms of L. donovani and also L. amazonensis. Two of the above compounds, 112 and 113 (Figure 49), expressed excelled in vitro activity against amastigotes forms of $L$. donovani, with $\mathrm{IC}_{50}$ values of 8.80 and $7.50 \mu \mathrm{M}$, respectively, therefore showing better results than the standard drugs, miltefosine and pentamidine $\left(\mathrm{IC}_{50}\right.$ 15.70 and $32.70 \mu \mathrm{M}$ respectively), in addition demonstrated an excellent selectivity [133].

\section{INSERT FIGURE 49 HERE}

Figure 49. Compound 112 and 113 structures

Ashok et al. (2016b) in another study, synthesized and evaluated a series of sixteen new tetrahydro- $\beta$-carboline derivatives against promastigote and amastigote forms of Leishmania infantum. Among the derivatives, compound 114 (Figure 50) displayed better effects, with high selectivity and potency for the amastigote form with $\mathrm{IC}_{50}$ value of $0.67 \pm 0.05 \mu \mathrm{M}$ and SI selectivity index higher than 298.5, values comparable to standard drug amphotericin B [134].

\section{INSERT FIGURE 50 HERE}

Figure 50. Tetrahydro- $\beta$-carboline derivative structure

Ashok et al. (2018), designed using the molecular hybridization strategy, synthesized (1-phenyl9H-pyrido [3,4-b]indol-3-yl) (4-phenylpiperazin-1-yl)methanone derivatives and evaluated for cytotoxicity and inhibition activity against L. infantum and L. donovani. Compound 115 (Figure 51), in particular, is highlighted due to its $\mathrm{EC}_{50}$ values of $2.8 \mu \mathrm{M}$ for axenic amastigote, and $4.0 \mu \mathrm{M}$ for intracellular. These values are comparable to the standard drugs miltefosine (EC $\mathrm{E}_{50} 1.6$ and $\left.23.7 \mu \mathrm{M}\right)$ and pentamidine $\left(\mathrm{EC}_{50} 2.8\right.$ and $\left.6.4 \mu \mathrm{M}\right)$ (Table 1) [135].

\section{INSERT FIGURE 51 HERE}

Figure 51. Chemical structure of 115

In the sequence of the study described earlier, Ashok et al. (2019) synthesized and evaluated the anti-Leishmania activity of piperazinyl- $\beta$-carboline-3-carboxamide derivatives against $L$. infantum and $L$. donovani. Selected derivatives have shown significant inhibition against both promastigote and amastigote forms, exhibiting $\mathrm{EC}_{50}$ values of less than $3.73 \mu \mathrm{M}$ for promastigote forms and less than 2.6 $\mu \mathrm{M}$ against amastigote forms of $L$. infantum, which outperforms standard drugs miltefosine and pentamidine. Compound 116 (Figure 52) showed the best inhibition of L. donovani promastigotes, axenic amastigotes and intracellular amastigotes with $\mathrm{EC}_{50}$ values of 0.91, 0.90, $1.30 \mu \mathrm{M}$, respectively [136].

\section{INSERT FIGURE 52 HERE}

Figure 52. Compound 116 structure

Sangshetti et al. (2016) synthesized twelve new 3-(3-(1H-indol-3-yl)-3-phenylpropanoyl)-4hydroxy-2H-chromen-2-one derivatives, from the fusion of two natural groups: indolic and coumarin 
nucleus, natural product found in plants, bacteria and fungi [137]. All the synthesized compounds showed better activity than standard sodium stibogluconate $\left(\mathrm{IC}_{50}=490 \mu \mathrm{g} \mathrm{mL}^{-1}\right.$ ) (Table 1). Among the derivatives, compound 117 (Figure 53) showed the most potent antileishmanial activity, with $\mathrm{IC}_{50}$ of 95.5 $\mu \mathrm{g} \mathrm{mL} \mathrm{mL}^{-1}$, in addition presented excellent antioxidant activity $\left(\mathrm{IC}_{50}=12.40 \mu \mathrm{g} \mathrm{mL}^{-1}\right.$ ) compared to hydroxytoluene $\left(\mathrm{IC}_{50}=16.5 \mu \mathrm{g} \mathrm{mL}{ }^{-1}\right)$ and ascorbic acid $\left(\mathrm{IC}_{50}=12.8 \mu \mathrm{g} \mathrm{mL}^{-1}\right)$ as the standard. In silico studies of compound 117 exhibited a potential to inhibit pteridine reductase 1 enzyme, in addition to good pharmacokinetic parameters [114].

\section{INSERT FIGURE 53 HERE}

Figure 53. Compound 117 structure

Félix et al. (2016) also performed the fusion of groups from natural products, indole and aminothiophene nucleus, the last one found in oil and its derivatives in plants of the Family Asteraceae [138], thus synthesized thirty-two compounds containing cycloalka[b]thiophene and indole moieties that had their cytotoxic and antileishmanial activity evaluated against L. amazonensis promastigotes. Compound 118 (Figure 54) showed the most potent activity, with $\mathrm{IC}_{50}$ of $2.1 \mu \mathrm{g} \mathrm{mL}^{-1}$. The compound also showed efficiency against trivalent antimony resistant parasitic strains. DNA fragmentation of $L$. amazonensis promastigotes justifies the activity of compound 118. Additionally, none of the thiopheneindole derivatives evaluated revealed cytotoxicity to human erythrocytes in the highest concentration tested $\left(400 \mu \mathrm{g} \mathrm{mL}^{-1}\right)[111]$.

\section{INSERT FIGURE 54 HERE}

Figure 54. Compound 118 structure

Preclinical studies of thiophenic-indolics derivative were performed by Rodrigues et al. (2018) and evaluated on its acute toxicity, genotoxicity, in vivo oral efficacy in a murine model, and in vitro antileishmanial activity against an L. amazonensis SbIII-resistant strain. Compound 119 \{2-[(5-bromo1H-indol-3-ylmethylene)-amino]-4,5,6,7-tetrahydro-4H-benzo[b]thiophene-3-carbonitrile) (Figure 55) demonstrated, at acute preclinical toxicity, $\mathrm{LD}_{50}$ of $2500 \mathrm{mg} \mathrm{kg}^{-1}$ orally. Also, it did not show genotoxicity in vivo at $2000 \mathrm{mg} \mathrm{kg}^{-1}$. The results showed that after seven weeks of oral treatment, there was a reduction of over $50 \%$ in the paw lesion size and decreased the parasite load of the popliteal lymph node $(42.57 \pm 3.14 \%)$ and spleen $(100 \%)$ at the highest dose tested $\left(200 \mathrm{mg} \mathrm{kg}^{-1}\right)$. These results place the compound as a potential drug candidate [139].

\section{INSERT FIGURE 55 HERE}

Figure 55. Compound 119 structure

\subsection{Antitrypanosomal activity: Trypanosoma cruzi}

Researches have shown cryptolepine (88) and neocryptolepine (120) derivatives (Figure 56) to possess activity against $T$. cruzi and $T$. brucei, exhibiting $\mathrm{IC}_{50}$ of 2.01 and $2.23 \mu \mathrm{M}$, respectively. However, these values have not been superior the reference drugs, melarsoprol $\left(\mathrm{IC}_{50}=0.004 \mu \mathrm{M}\right)$ and benznidazole $\left(\mathrm{IC}_{50}=1.50 \mu \mathrm{M}\right)[100]$. Studies since then were performed and the search for more effective molecules against neglected diseases are reported in the literature [140, 141]. 
Figure 56. Cryptolepine and neocryptolepine structures

A series of fourteen $N$-arylsulfonyl benzimidazole derivatives (NBSBZD) synthesized by Miana et al. (2019) and evaluated against epimastigote and amastigote forms of Trypanosoma cruzi. The compounds 121, 122 and 123 (Figure 57) showed the highest inhibitory potencies against epimastigote and amastigote forms of $T$. cruzi, with an increase in their bioactivities when compared to the reference compound BZN. There was also a significant increase in SI calculated for all reported compounds [142].

\section{INSERT FIGURE 57 HERE}

Figure 57. $\mathrm{N}$-arylsulfonyl benzimidazole derivatives structures

Only the study described above was found using the indole nucleus in possible compounds with anti-T. cruzi activity.

\subsection{Antitrypanosomal activity: Trypanosoma brucei}

Besides the isolated alkaloid cryptolepine, another alkaloid, polysin (124) (Figure 58) was isolated from Polyalthia suaveolens (Annonaceae). Polysin demonstrated significant activity against $T$. brucei, by acting as a competitive reversible inhibitor $(\mathrm{Ki}=10 \mu \mathrm{M})$ of phosphofructokinase $(\mathrm{PFK})$, while its derivative 3-O-acetyl greenwayodendrin presented selective inhibition of $T$. brucei aldolase with $\mathrm{IC}_{50}$ of approximately $0.5 \mu \mathrm{M}[119]$.

\section{INSERT FIGURE 58 HERE}

Figure 58. Chemical structure of alkaloid polysin (124)

Karaman et al. (2018) describes Sirtuins as nicotinamide adenine dinucleotide (NAD+)dependent class III histone deacetylases. Two inhibitors of sirtuin 1, 2 and 3 (sirt1-3), the bichalcones, known as rhuschalcone IV (125) and an analogue of rhuschalcone I (126), previously isolated from the medicinal plant Rhuspyroides, were shown to be active in the in vitro assay. The rhuschalcone I analogue showed the best activity against sirt1, with an $\mathrm{IC}_{50}$ value of $40.8 \mu \mathrm{M}$ [143]. Similarly, Farahat et al. (2018) reported the synthesis of a new class of indole and benzimidazole bichalcophene diamidine hybrids, and biological evaluation against T. brucei parasites. Benzimidazole diamidines displayed antitrypanosomal activity against Trypanosoma brucei rhodesiense with $\mathrm{IC}_{50}$ values from 25 to $102 \mathrm{nM}$, being less effective than indole analogs, which were highly active against trypanosomes with $\mathrm{IC}_{50}$ values in the range of 2-15 nM. The indole analogs synthesized by the authors displayed SI ranging from 1046 to 5800 against $T$. brucei rhodesiense. Due to the excellent activity and in vitro selectivity of bichalcophenes indole diamidines, they were tested in the rigorous T. brucei rhodesiense STIB900 mouse model for the acute hemolymphatic stage of African trypanosomiasis at a daily intraperitoneal dose of $5 \mathrm{mg} \mathrm{kg}^{-1}$ four times daily. Compound 127 (Figure 59) was highly efficacious in vivo curing all T. brucei rhodesiense infected mice at a low dose of $4 \times 5 \mathrm{mg} \mathrm{kg}^{-1}$ i.p., proving to be more active in vivo than the standard drug pentamidine [144].

\section{INSERT FIGURE 59 HERE}

Figure 59. Compound 125, 126 and 127 structures 
Ferrigno et al. (2018) conducted an in vitro and SAR study on the selected set of compounds from previous work in the field of histone deacetylase inhibitors (HDAC). From the seven compounds substituted with indole nucleus, compound 128 (Figure 60), obtained using the bioisosterism strategy, was the most active in the initial study, showing low nanomolar $\left(\mathrm{EC}_{50}=10 \mathrm{nM}\right)$ activity in the T. brucei growth inhibition assay, and a large window between growth inhibition and cytotoxicity in HeLa cells ( 3 orders of magnitude). There was no activity in the biochemical assay against a panel of human HDACs (hHDAC1-9) up to a concentration of $5 \mu \mathrm{M}[145]$.

\section{INSERT THE PICTURE 60 HERE}

Figure 60. Compound 128 structure

Hymenialdysine (129) is an alkaloid that was isolated in 1982 from a variety of marine sponges including Hymeniacidon species. Its synthetic structural, analog kenpaulone (130), has also been used as a prototype in the design of new protein kinase inhibitors [146]. Orban et al. (2016), aiming at the development of new drugs against $T$. brucei and starting from the observation that $N$-(5)-substituted paullone FS-554 (131) is a trypanothione synthase (TryS) inhibitor of parasites L. infantum, designed and synthesized, aryl-substituted alkyl 3-chlorokenpaullone derivatives as potentially improved trypanosomal inhibitors. Of the compounds obtained, compound 131 (Figure 61) showed $\mathrm{EC}_{50}=40 \mathrm{nM}$ and SI> 1000, exhibiting potent and selective antitrypanosomal activity, along with the absence of inhibitory activity against host kinases. Structure 131 can be considered promising against sleeping sickness and can be used as a prototype for the development of derivatives with better pharmacological properties [147].

\section{INSERT THE FIGURE 61 HERE}

Figure 61. Compound 129, 130, and 131 structure

\subsection{Antischistosomal activity}

Neocryptolepine derivatives (Figure 56), as stated previously as promising antiparasitic agents, showed relevant schistosomicidal activity in in vitro tests. In a review article, Bracca et al. (2014) presented a hybrid quinoline-indolic compound, designated 132 (Figure 62). This derivative stood out due to its $\mathrm{IC}_{50}$ of 1.26 and $4.05 \mu \mathrm{M}$ against $S$. mansoni strains from Egypt and Puerto Rico, respectively [110]. These results will be better discussed in the quinolone derivatives section.

\section{INSERT FIGURE 62 HERE}

Figure 62. Compound 132 structure

Another natural compound widely used as starting point in synthesis is Isatisin A (133) (Figure 63), found in leaves of the Isatis plant found in China, and isolated in 2007 [148]. Based on this nucleus, Jiang et al. (2017), with an innovative methodology that had not yet been reported in the literature, synthesized a series of 2-(1H-indol-3-yl)-3-oxoindoline-2-carbonitrile derivatives via catalyzed oxidative homo-dimerization and evaluated their antischistosomicidal activity against $S$. japonicum adult worms. The compound 134 (Figure 63) displayed 100\% inhibition within 24 hours at $10 \mu \mathrm{M}$ [149].

\section{INSERT FIGURE 63 HERE}

Figure 63. Isatisin A and compound 134 structures 
Almeida Junior et al. (2019) synthesized and evaluated in vitro schistosomicidal activity of indol-3-yl-thiosemicarbazones and 4-thiazolidinones derivatives against juvenile and adult worms of $S$. mansoni, in addition to in silico prediction of pharmacokinetic parameters and oral bioavailability. Compound 135 (Figure 64) caused 100\% mortality at 24 and 48 hours in adult and juvenile worms. Moreover, this compound caused a reduction of viability of the adult parasites by $85 \%$ and $83 \%$ at concentrations of 200 and $100 \mu \mathrm{M}$. Similar results were obtained in juvenile worms, with a reduction in the viability of $85 \%, 81 \%$ and $64 \%$ at concentrations of 200,100 and $50 \mu \mathrm{M}$, respectively. Furthermore, this compound presented good pharmacokinetic properties and satisfactory oral availability [112].

\section{INSERT FIGURE 64 HERE}

Figure 64. Compound 135 structure

\section{QUINOLINE DERIVATIVES}

\subsection{Antiparasitic mechanism of action}

Quinolinic compounds possess antiparasitic potential, being observed primarily as antimalarial compounds. In this sense, the general mechanism of action developed by quinoline compounds is properly elucidated in terms of antimalarial activity, taking into consideration reference quinoline drugs used in the treatment of malaria, which include, among others: chloroquine, quinine, and mefloquine [150]. Their mechanism of action involves the formation of quinoline heme complexes, responsible for inhibiting heme crystallization into hemozoin, leading to high levels of free heme and inducing prooxidant effects that culminate in parasite death [151].

Unlike antimalarial activity, there are no exact definitions of the mechanism of action generated by compounds containing quinoline nucleus in the other parasites aforementioned. The action of the studied derivatives has been attributed to a mechanism similar to that performed in Plasmodium spp. [151-153], as well as topoisomerase IB inhibition (LTopIB and hTopIB) [154] and increase in ROS levels and NO generation, which induces bioenergetic collapse and apoptosis of the parasite by decreasing ATP production and mitochondrial membrane potential [155].

\subsection{Antiplasmodial activity}

Chemotherapy for malaria based on natural products began with the isolation of quinine (Table 1), a quinoline derivative. In the mid-17th century, Europe used Cinchona bark from species of Chincona trees for the treatment of malaria. The alkaloid quinine, isolated in 1822, was the most effective against Plasmodium [23]. The quinine structure served as an excellent template for the development of structural analogs such as chloroquine, primaquine, mepacrine, and mefloquine (Table 1) that showed as effective antimalarial activity [20].

Nevertheless, in spite of widespread resistance to 4-aminoquinolines, quinoline scaffold is still considered very promising for the development of novel antimalarial agents. Therefore, many compounds containing the quinoline nucleus have been isolated and/or synthesized with this purpose [156].

Aiming naturally occurring compounds isolated from the roots of the West African plants Cryptolepis sanguinolenta, the alkaloid neocryptolepine was selected by El Sayed et al. (2009) as a lead 
compound for the development of new antimalarial agents [157]. This alkaloid was previously described on its antiplasmodial activity by Cimanga et al. (1997), exhibiting $\mathrm{IC}_{50}$ of $35 \mathrm{ng} \mathrm{mL}^{-1}, 51 \mathrm{ng} \mathrm{mL}$, and 65 ng mL ${ }^{-1}$, against $P$. falciparum D6, K1, and W2 strains, respectively [116]. Therefore, a series of chloroand aminoalkylamino-substituted neocryptolepine was synthesized and evaluated for in vitro antiplasmodial activity against a chloroquine-sensitive $P$. falciparum strain and for cytotoxicity on a human cell (MRC5) line. Compound 136 displayed $\mathrm{IC}_{50}=0.01 \mu \mathrm{M}$, value comparable to chloroquine, and SI $=1800$ (Figure 65). It was also found that these compounds were able to inhibit $\beta$-hematin formation and to interact with DNA. Two selected derivatives were evaluated in vivo against $P$. berghei in Swiss mice, but they were not sufficiently potent or toxic to the animals [156].

Further exploration of the antimalarial potential of the neocryptolepine core through molecular modifications was also the objective of Mei et al. (2013). Several analogs were synthesized and evaluated in vitro against two Plasmodium falciparum strains (CQS, NF54; CQR, K1). A significant antimalarial activity was obtained by the urea derivatives, 2-Cl substituted 137 displayed excellent inhibition, with an $\mathrm{IC}_{50}$ value of $2.2 \mathrm{nM}$ for CQS (NF54) and the highest SI value, among all the synthesized compounds, of 1400 (Figure 65). Against CQR (K1), almost all compounds were significantly more active than chloroquine, especially 138, which had an $\mathrm{IC}_{50}$ value of $2.2 \mathrm{nM}$ for K1, SI of 1243 and resistance index value of 0.5 by K1/NF54. Three selected compounds were tested in vivo drug screening model against Plasmodium berghei in Swiss mice, however, they were not sufficiently potent or toxic to the mice. These results show the viability of the use of natural compounds as leads, even though further substitutions may be necessary to obtain active compounds in vivo [158].

Likewise, Wang et al. (2013) reported the synthesis of C2 or C8 and C11-disubstituted 6-methyl$5 H$-indolo[2,3-b]quinoline (neocryptolepine congener) derivatives. The best results of antiplasmodial activity against $P$. falciparum NF54 were achieved by compounds 139 and 140 , which displayed IC $_{50}$ values of $86 \mathrm{nM}$ and $317 \mathrm{nM}$, and SI values of 20 and 370, respectively (Figure 65). Moreover, further experiments showed a linear correlation between $\beta$-hematin inhibition and cell growth inhibition in NF54 strain, as well as the influence of physicochemical factors related to solvation and polarity in the antiplasmodial activity [159].

\section{INSERT FIGURE 65 HERE}

Figure 65. Isolated compound, neocryptolepine, and its promising synthetic derivatives

Structurally related alkaloids ellipticine (141), cryptolepine triflate (142), cryptolepine synthetic derivative (143) and olivacine (144) were investigated for their antiplasmodial activity by Silva et al. (2012). Cryptolepine analog displayed $\mathrm{IC}_{50}$ values against $P$. falciparum $\mathrm{K} 1$ and 3D7 strains of 0.10 and $0.087 \mu \mathrm{M}$, respectively. However, in vivo studies against $P$. berghei-infected mice showed ellipticine as the most active compound, suppressing parasitemia by $100 \%$ and providing mean survival time of $>40$ days at an oral dose of $50 \mathrm{mg} / \mathrm{kg} / \mathrm{day}$. Besides in vivo tests, ellipticine and olivacine also proved to be less toxic than cryptolepine compounds $(142,143)$. These data reveal the potential of ellipticine and olivacine as antimalarial leads (Figure 66) [160].

\section{INSERT FIGURE 66 HERE}

Figure 66. Quinoline alkaloids isolated and synthetic analog 
Followed by a screen of compounds containing structural features of natural products that are pharmacologically relevant, Roberts et al. (2017) selected 4-nitro styrylquinoline (145) as an antiplasmodial pharmacophore. It presented excellent antiplasmodial potency, with $\mathrm{EC}_{50}$ values of $67 \mathrm{nM}$ against Dd2, $119 \mathrm{nM}$ against 3D7 and $12.92 \mu \mathrm{M}$ against HepG2 host cells, therefore displaying a selectivity index of 192. Furthermore, extensive experiments concluded that 145 does not interfere in $\beta$ hematin formation; blocks quickly at multiple stages of intraerythrocytic development of P. falciparum; displays novel mechanism of action by inhibiting merozoite invasion, and exhibits curative property in the rodent malaria model when administered orally. Accordingly, these results provide a strong indication that the styrylquinoline chemotype potentially is a new therapeutic alternative for malaria directed against unique cellular targets (Figure 67) [156].

\section{INSERT FIGURE 67 HERE}

Figure 67. Antiplasmodial scaffold 141

In order to solve chloroquine resistance issues, Çapc1 et al. (2019) reported the synthesis of 17 novel artemisinin-isoquinoline and artemisinin-quinoline hybrids, and evaluation of antimalarial activity on the $P$. falciparum drug-sensitive strain (3D7) and in two multidrug-resistant strains (Dd2 and K1) (Figure 68). Within designed compounds, 146 gave $\mathrm{EC}_{50}$ values of $2.7 \mathrm{nM}, 1.0 \mathrm{nM}$, and $780 \mathrm{pM}$ against 3D7, Dd2, and K1 strains, respectively. In vivo evaluations against Plasmodium berghei in Swiss mice were conducted, demonstrating outstanding efficacy of hybrid 147, superior to artesunate. Applying a chemical proteomics approach, it was concluded that these hybrids affect important targets for the development and survival of blood-stage P. falciparum, such as the PfATP6 enzyme (responsible for artemisinin action) and the $40 \mathrm{~S}$ ribosomal protein machinery (classically recognized for quinoline action) [161].

\section{INSERT FIGURE 68 HERE}

Figure 68. Most promising artemisinin-quinoline hybrid evaluated for antiplasmodial activity by Capci et al. (2019)

Okanya et al. (2011) isolated six marinoquinoline alkaloids from gliding bacterium Ohtaekwangia kribbensis. These compounds were evaluated for their antiprotozoal activity against several parasites in vitro and performed promising activity against $P$. falciparum K1. For example, compound 148 (marinoquinoline $\mathrm{B}$ ) presented good antimalarial activity $\left(\mathrm{IC}_{50}=1.8 \mu \mathrm{M}\right)$ associated with low cytotoxicity against L6 cells $\left(\mathrm{IC}_{50}=58.7 \mu \mathrm{M}\right)$ (Figure 69) [162].

Isolated from marine sponge Zyzza sp., pyrroloiminoquinones alkaloids displayed potent antiplasmodial activity in Davis et al. (2012) report. Tested against P. falciparum 3D7 and Dd2 strains, new bispyrroloiminoquinone alkaloid, compound 149 (tsitsikammamine C), presented itself as the most efficient compound, due to its $\mathrm{IC}_{50}$ of $13 \mathrm{nM}$ (3D7) and $18 \mathrm{nM}(\mathrm{Dd} 2)$, and SI > 200 against HEK293 host cells. Moreover, in in vitro stage specific assays, tsitsikammamine $\mathrm{C}$ inhibited both ring and trophozoite stages of the malaria parasite life cycle. Sufficient quantities of alkaloids makaluvamines $\mathrm{J}$ and makaluvamines $\mathrm{G}$ were available for additional biological studies to be performed. Therefore, in vivo tolerability and efficacy studies were undertaken, and results showed that makaluvamine G was not toxic to mice and suppressed parasite growth in $P$. berghei infected mice following subcutaneous 
administration at $8 \mathrm{mg} \mathrm{kg}^{-1} \mathrm{day}^{-1}$, indicating that this structure class has promising antimalarial activity (Figure 69) [163].

\section{INSERT FIGURE 69 HERE}

Figure 69. Isolated pyrroloquinolines, marinoquinoline B and tsitsikammamine C, evaluated against $P$. falciparum.

Ferroquine (SSR97193) (Figure 70), a ferrocenic derivative of chloroquine, is an antimalarial drug candidate, currently in phase IIb combination clinical trials with artefenomel, an antiparasitic trioxolane, formulated for children as a single dose [164]. It was first designed in 1994 by Biot and coworkers at the University of Lille, and has previously shown potent activity against chloroquine-sensitive and resistant $P$. falciparum strains, efficient curative effect in mice infected with $P$. vinckei, absence of significant cross sensitivity with other antimalarials currently used, action in hematin and inhibition of hemozoin formation, and presence of highly active metabolite ( $N$-monodemethylated) [165, 166]. Mombo-Ngoma et al. (2011) report two clinical phase I trials in asymptomatic young males with $P$. falciparum infection, which aimed to assess the clinical, and laboratory safety and tolerability profile of ferroquine. Results showed a favorable tolerability and safety profile up to 1,600 mg when administered as a single dose. Moreover, adverse events were mainly gastrointestinal and nervous system disorders. Consequently, further clinical development of ferroquine is highly warranted and currently underway [165].

Stringer et al. (2019) aimed at the synthesis of two ferroquine-derived polyamines (compounds 150 and 151) that target a resistant strain of P. falciparum (Figure 70). Both compounds displayed similar antimalarial activity against chloroquine-sensitive (NF54) and resistant (K1) strains. Compound 150 revealed a two-fold more prominent activity than compound 151 in both sensitive and resistant strains, presenting $\mathrm{IC}_{50}$ values of 0.305 and $0.328 \mu \mathrm{M}$, respectively. Their mechanism of action appears not to be involved with inhibition of haemozoin formation, but with the capacity to generate reactive oxygen species [164].

\section{INSERT FIGURE 70 HERE}

Figure 70. Antimalarial drug candidate ferroquine and analogs

Chalcones are naturally occurring key structural motifs among biologically active compounds, characterized as key intermediates for combinatorial assembly of heterocyclic scaffolds. Therefore, based on the remarkable progress of ferroquine as an antimalarial agent and chalcones' promising broad biological activity spectrum, which includes oxygenated chalcone Licochalcone A as a potential antimalarial agent, Raj et al. (2015) proposed the synthesis, using molecular hybridization and expansion strategies, and biological evaluation of amide tethered 7-chloroquinoline chalcones and 7chloroquinoline-ferrocenyl chalcones. The most potent of the synthesized compounds, the chalcone derivative $\mathrm{N}$-[6-(7-chloro-quinolin-4-ylamino)-hexyl]-2-\{4-[3-(4-methoxy-phenyl)-acryloyl]-phenoxy\}acetamide (152), exhibited activity comparable to that of chloroquine, with an $\mathrm{IC}_{50}$ value of $17.8 \mathrm{nM}$ against $P$. falciparum W2 strain (Figure 71) [167].

\section{INSERT FIGURE 71 HERE}

Figure 71. Amide tethered 7-chloroquinoline chalcone 
Several additional studies involve the evaluation of the antiplasmodial action of quinoline compounds. This fact reflects the relevance of this nucleus in the treatment of this neglected disease, thus rendering it indispensable for such purpose.

\subsection{Antileishmanial activity}

Given the extensive biological activity of chalcones, along with quinoline nucleus potential, as presented previously in this article by Raj et al. (2015) [167] in the investigation of their antimalarial activity, Coa et al. (2017) reported the synthesis and biological activities (cytotoxicity, leishmanicidal and trypanocidal) of six quinoline-chalcone and five quinoline-chromone hybrids. Compound 153 was the most active against $L$. (V) panamensis, with $\mathrm{EC}_{50}=6.11 \pm 0.26 \mu \mathrm{g} \mathrm{mL}^{-1} / 16.91 \mu \mathrm{M}$ (Figure 72). These derivatives, however, proved to be toxic against human macrophages (U937 cells). Nonetheless, they may still have potential to be considered as candidates to antileishmanial drug development [168].

\section{INSERT FIGURE 72 HERE}

Figure 72. Quinoline-chromone hybrid

Based on the fact that steroid transporters have been reported as able to accept and carry a variety of drugs and its derivatives are known to exhibit antimicrobial activities, Antinarelli et al. (2012) proposed increasing leishmanicidal activity of aminoquinoline compounds through conjugation with cholic acid. Three aminoquinoline/steroid conjugates (154, 155, and 156), along with their respective alkyne intermediates, were tested against promastigote forms of L. major and M. tuberculosis. Focusing on the antileishmanial assay, all conjugates displayed better results than their intermediates, particularly compound $154\left(\mathrm{IC}_{50}=10.6 \mu \mathrm{M}\right)$. Intracellular antiamastigote tests also evidenced that the addition of a steroid group to aminoquinoline molecules once more enhanced the biological activity of the compounds. Results showed that compounds 155 and 156 exhibited higher inhibition of parasite burden, of $64 \%$ and $80 \%$, respectively. Hence, these results highlight the importance of steroids as carriers (Figure 73) [169].

\section{INSERT FIGURE 73 HERE}

Figure 73. Aminoquinoline/steroid (bile acid) conjugate products 154, 155, and 156.

Oxoaporphine alkaloids are widely found in nature and known for their pharmacological activities as antiparasitic agents. Given their potential, Sobarzo-Sánchez et al. (2013) aimed to investigate, for the first time, in vitro and in vivo leishmanicidal activity of several novel synthetic oxoisoaporphine compounds. In vitro assays of axenic amastigotes from L. amazonensis evidenced compounds $157\left(\mathrm{IC}_{90}<0.05 \mu \mathrm{g} \mathrm{mL}^{-1}, \mathrm{IC}_{50}<0.05 \mu \mathrm{g} \mathrm{mL}^{-1}\right)$ and $158\left(\mathrm{IC}_{90}<0.025 \mu \mathrm{g} \mathrm{mL}^{-1}, \mathrm{IC}_{50}<0.025\right.$ $\mu \mathrm{g} \mathrm{mL}^{-1}$ ) as the fittest for further evaluations to determine the in vitro effectiveness against promastigotes of four species of Leishmania representative of the main clinical forms of the disease (L. infantum, L. amazonensis, L. braziliensis, and L. guyanensis) (Figure 74). Both compounds were active against

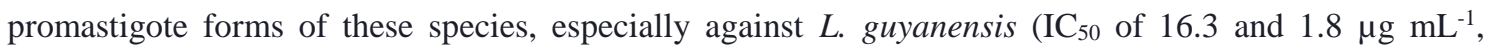
respectively). These were also tested against intracellular amastigotes using $L$. infantum and $L$. amazonensis. In both assays, 158 was more active but more cytotoxic against J774.2 cell line. Finally, 
both in vitro active compounds were tested in vivo in BALB/c mice infected with L. infantum. Compound 157 caused, in a dose of $10 \mathrm{mg} \mathrm{kg}^{-1}, 99.62 \%$ and $78 \pm 33 \%$ of reduction of the parasite in livers and spleens, respectively [170].

\section{INSERT FIGURE 74 HERE}

Figure 74. Novel oxoisoaporphine derivatives

Quinazolinone is a building block of naturally occurring alkaloids and is utilized as a druglike scaffold in several natural products. In that sense, Sharma et al. (2013) synthesized four series of quinazolinone hybrids via the introduction of heterocyclic systems previously reported as potent antileishmanial agents (pyrimidine, triazine, tetrazole, and peptide). Fifty-three compounds were synthesized and evaluated against L. donovani intracellular amastigotes. Most of these molecules displayed potent antileishmanial activity $\left(\mathrm{IC}_{50}\right.$ from $0.65 \pm 0.2$ to $7.76 \pm 2.1 \mu \mathrm{M}$ ), in which compounds 159, 160, and 161 showed very consistent and promising leishmanicidal activity against intracellular amastigotes and in vivo efficacy in the golden hamster model (Figure 75). In conclusion, these analogs are good candidates for a lead optimization for identifying new analogs as possible antileishmanial agents [171].

\section{INSERT FIGURE 75 HERE}

Figure 75. Quinazolinone-triazine $(159,160)$ and quinazolinone-peptide (161) derivatives

Subsequently, Sharma et al. (2014) designed and synthesized a series of triazino indolequinoline hybrids as potential antileishmanial chemotherapeutics. Evaluated against L. donovani amastigotes and promastigotes, compound 162, particularly, exhibited good antipromastigote activity $\left(\mathrm{IC}_{50}=6.27 \pm 0.65 \mu \mathrm{M}\right)$, high antiamastigote action $\left(\mathrm{IC}_{50}=0.36 \pm 0.10 \mu \mathrm{M}\right)$, and low cytotoxicity $\left(\mathrm{CC}_{50}\right.$ $>400 \mu \mathrm{M})$ (Figure 76) [172].

\section{INSERT FIGURE 76 HERE}

Figure 76. Structure of triazino indole-quinoline derivative

A series of novel triazolyl 2-methyl-4-phenylquinoline-3-carboxylate analogs were designed and synthesized via molecular hybridization approach by Upadhyay et al. (2018). Compound 163 presented high activity against promastigote forms of $L$. donovani, obtaining an $\mathrm{IC}_{50}$ value of $3 \mu \mathrm{M}$, but proved to be inactive against intracellular amastigote. Among synthesized compounds, 164 and 165 displayed significant antiamastigote activity, both presenting an $\mathrm{IC}_{50}$ of $7 \mu \mathrm{M}$, and lower cytotoxicity against J77A.1 cell line in comparison to standard drugs (miltefosine and sodium stibogluconate). Compound 165 also demonstrated promising in vivo leishmanicidal activity (Figure 77). Thereupon, these results revealed the therapeutic potential of the novel synthesized compounds as potential antileishmanial agents [173].

\section{INSERT FIGURE 77 HERE}

\section{Figure 77. Structure of triazolylquinoline 165}

Consecutively, Upadhyay et al. (2019) designed and synthesized a series of quinolinemetronidazole hybrid compounds. Antileishmania in vitro evaluation against L. donovani highlighted compound 166 due to its $\mathrm{IC}_{50}$ values against promastigote $\left(\mathrm{IC}_{50}=5.42 \mu \mathrm{M}\right)$ and amastigote $\left(\mathrm{IC}_{50}=3.75\right.$ $\mu \mathrm{M}$ ) stages of the parasite (Figure 78). Further experiments revealed that compound 166 effectively inhibited the parasite burden in the liver and spleen $(>80 \%)$ of infected BALB/c model of visceral 
leishmaniasis, and triggers oxidative stress by enhancing ROS and NO generation. These results suggest the potential of quinoline-metronidazole derivatives for the future development of specific clinical agents for counteracting leishmaniasis and other neglected parasitic diseases [155].

\section{INSERT FIGURE 78 HERE}

Figure 78. Chemical structure of the most promising quinoline-metronidazole conjugate as an antileishmanial agent

Almandil et al. (2019) reported the synthesis of quinoline-based thiadiazole hybrid analogs and their excellent in vitro leishmanicidal activity against L. major promastigotes (JISH118). Fourteen compounds exhibited higher inhibition than standard compound, pentamidine $\left(\mathrm{IC}_{50}=7.02 \mu \mathrm{M}\right)$. Structure-activity relationship study indicated that dihydroxylated compounds displayed better activity, especially compound 167, a 2,3-dihydroxy analogue ( $\left.\mathrm{IC}_{50}=0.04 \mu \mathrm{M}\right)$ (Figure 79) [174].

\section{INSERT FIGURE 79 HERE}

Figure 79. Quinoline based thiadiazole derivative

Valdivieso et al. (2018) evaluated previously synthesized drugs 168 and 169 for their antileishmanial activity against $L$. donovani strain (Figure 80). Antipromastigote assay demonstrated that both compounds were able to inhibit the parasite proliferation, displaying IC $_{50}$ values of $13.03 \pm 3.4$ (168) and $7.90 \pm 0.6 \mu \mathrm{M}(169)$. These were also active against intracellular amastigotes, as 168 showed an $\mathrm{IC}_{50}$ value of $0.66 \pm 0.2 \mu \mathrm{M}$, while for derivative 169 resulted in an $\mathrm{IC}_{50}$ of $1.02 \pm 0.17 \mu \mathrm{M}$. The derivatives were evaluated in combined therapy with miltefosine and amphotericin B, and presented a synergistic effect for both combinations, with a Fractional Inhibitory Concentration (FIC) Index lower than 1 for promastigotes and less than 0.3 for intracellular amastigotes. Therefore, beyond presenting two molecules as potential leishmanicidal compounds, this research validates the combination of drugs as an effective alternative to potentiate the action of antileishmania agents [175].

\section{INSERT FIGURE 80 HERE}

Figure 80. Structures of tested 4-aryloxy-7-chloroquinoline compounds 168 and 169

Novel hybrid tetrahydroquinoline and quinoline derivatives with phosphorus substituents have been synthesized by Tejería et al. (2019) (Figure 81). The tetrahydroquinolylphosphine sulfide 170 presented a good antipromastigote activity $\left(\mathrm{IC}_{50}=10.66 \mu \mathrm{M}\right)$, the lowest $\mathrm{EC}_{50}$ value against amastigotes forms, of $0.61 \mu \mathrm{M}$, and the highest selectivity index (56.87). The compounds were also evaluated on inhibition of recombinant LTopIB and hTopIB activities in vitro, being 171 the most active compound with $\mathrm{IC}_{50}=23.64 \mu \mathrm{M}$, whereas compounds 170 presented an $\mathrm{IC}_{50}=93.73 \mu \mathrm{M}$. This result suggests that the antileishmanial activity of some of these compounds could be explained partially by the inhibition of TopIB [154].

\section{INSERT FIGURE 81 HERE}

Figure 81. Structure of 1,2,3,4-tetrahydroquinolinyl-phosphine sulfide derivatives

\subsection{Antitrypanosomal activity: Trypanosoma cruzi}


Waltheria indica L. (Malvaceae) is a short-lived shrub commonly used in traditional medicine. Throughout the analysis of dichloromethane extracts of the aerial parts and roots of W. indica, Cretton et al. (2014) isolated 10 quinoline alkaloids from the roots. The isolated molecules presented excellent activity when evaluated against protozoan causer of Chagas disease, $T$. cruzi, with $\mathrm{IC}_{50}$ values ranging from 0.02 to $3.1 \mu \mathrm{M}$. Compound 172 (waltherione $\mathrm{G}$ ) was found to be the most promising alkaloid, due to its exceptional antitrypanosomal activity $\left(\mathrm{IC}_{50}=0.02 \mu \mathrm{M}\right)$ associated with the highest selectivity index displayed by these molecules (33.8), when tested for cytotoxicity against mouse skeletal L-6 cells (Figure 82) [176].

\section{INSERT FIGURE 82 HERE}

Figure 82. Isolated alkaloid waltherione $\mathrm{G}$

Ensuing, Cretton et al. (2015) isolated two novel quinoline alkaloids, Waltherione A (173) and Waltherione C (174), from the dichloromethane extract from the roots of $W$. indica. Waltherione C showed a potent antitrypanosomal activity towards $T$. cruzi with an $\mathrm{IC}_{50}$ value of $1.93 \mu \mathrm{M}$, correlated with low cytotoxicity towards L6 cell line $\left(\mathrm{IC}_{50}=101.23 \mu \mathrm{M}\right)$ (Figure 83). This resulted in a selectivity index superior to 50, meaning this alkaloid falls into the criteria required by the WHO/TDR for $T$. cruzi to be considered as a hit. As a result of promising outcomes, in vivo studies with waltherione C (174) are in progress and further investigations are required to determine cellular target(s) [177].

\section{INSERT FIGURE 83 HERE}

Figure 83. Structure of the alkaloid waltherione C

Ramírez-Prada et al. (2017) synthesized a novel series of quinoline-based 4,5-dihydro-1Hpyrazoles from quinoline-chalcones and determined its biological activity as potential anticancer, antifungal, antibacterial and antiprotozoal agents (Figure 84). Most compounds displayed satisfying in vitro antitrypanosomal activity against $T$. cruzi, with $\mathrm{EC}_{50}$ ranging from 0.70 to $22.58 \mu \mathrm{g} \mathrm{mL}^{-1}$, for active compounds. Compound 175 was highly active, displaying with $\mathrm{EC}_{50}=0.70 \mu \mathrm{g} \mathrm{mL}^{-1}$, superior to standard drug benznidazole $\left(\mathrm{EC}_{50}=10.7 \mu \mathrm{g} \mathrm{mL}^{-1}\right)$ [178].

\section{INSERT FIGURE 84 HERE}

Figure 84. $N$-substituted 2-pyrazoline derivative 175

Studies performed by Coa et al. (2015) presented quinoline-hydrazone hybrids as potential trypanocidal agents [116]. Compounds 176 and 177 presented activity against $T$. cruzi with EC Ev values of $1.4 \pm 0.3 \mu \mathrm{g} \mathrm{mL}^{-1} / 4.8 \mu \mathrm{M}$ and $6.6 \pm 0.3 \mu \mathrm{g} \mathrm{mL} \mathrm{m}^{-1} / 4.6 \mu \mathrm{M}$, respectively. Besides, these compounds presented better activity against $T$. cruzi than antitrypanosomal drug, benznidazole $\left(\mathrm{EC}_{50}=10.5 \pm 1.8 \mu \mathrm{g}\right.$ $\left.\mathrm{mL}^{-1} / 40.3 \mu \mathrm{M}\right)$. As previously mentioned, Coa et al. (2017) also evaluated the antitrypanosomal activity of quinoline-chalcone and quinoline-chromone hybrids. Compound 178 presented itself as the best hybrid derivative against $T$. cruzi, exhibiting $\mathrm{EC}_{50}$ value $>2 \mu \mathrm{g} \mathrm{mL}^{-1} />4.63 \mu \mathrm{M}$ (Figure 85) [179].

\section{INSERT FIGURE 85 HERE}

Figure 85. Antitrypanosomal compounds synthesized by Coa et al. (2015) and Coa et al. (2017) 
Synthetic 2-alkylaminomethylquinoline derivatives were obtained and tested for their trypanocidal activity by Muscia et al. (2011). A series of ten analogous derivatives were tested towards epimastigotes, trypomastigotes, and amastigotes stages of T. cruzi. Among them, compound 179 showed remarkable activity, with $\mathrm{IC}_{50}$ values of $3.4,3.1$ and $12.8 \mu \mathrm{M}$, respectively. Moreover, this molecule presented low cytotoxicity against COS-7 cell line $\left(\mathrm{CC}_{50}=770.9 \mu \mathrm{M}\right)$. Given the promising results obtained in vitro with compound 179, in vivo studies were conducted. Compound 179-treated mice presented a threefold reduction in the number of parasites when compared to untreated ones (1.5 and $4.5 \times 10^{6}$, respectively). Therefore, these outcomes classify this derivative as an excellent candidate for additional studies (Figure 86) [180].

\section{INSERT FIGURE 86 HERE}

Figure 86. Structure of 2-alkylaminomethylquinoline derivative

Upadhayaya et al. (2013) reported the identification of new lead compounds based on quinoline and indenoquinolines. Fifty-seven compounds were evaluated against T. cruzi, T. brucei, T. brucei rhodesiense, and L. infantum. Particularly for T. cruzi, compound 180, which possesses an imidazole substitution, appeared to be the most active and promising, with an $\mathrm{IC}_{50}$ value of $0.25 \mu \mathrm{M}$ and a selectivity index of 125.76 (Figure 87). Thus, this compound constitutes a new 'lead' for further structure-activity studies as a potential active trypanocidal agent [181].

\section{INSERT FIGURE 87 HERE}

Figure 87. Chemical structure of compound 180

Based on the mechanism of action of quinoline antimalarial drugs, Lechuga et al. (2016) synthesized and evaluated the activity of a series of 4-arylaminoquinoline-3-carbonitrile derivatives against all forms of $T$. cruzi in vitro. Among tested compounds, 181 presented an $\mathrm{IC}_{50}<1 \mu \mathrm{M}$ towards epimastigote forms when combined with hemin (Figure 88). Additionally, it also inhibited the viability of trypomastigotes and intracellular amastigotes, especially with the addition of hemin to the culture medium. These results suggest that the mechanism of action displayed by these molecules towards $T$. cruzi is similar to what occurs in Plasmodium spp. Therefore, the elucidation of the mechanism involving interactions with heme is an open field of research that can improve and guide rational drug development and combination strategies [151].

\section{INSERT FIGURE 88 HERE}

Figure 88. Quinoline derivative 181

Likewise, Chanquia et al. (2019) reported the synthesis of a series of 2- and 3arylaminoquinoline derivatives, trypanocidal evaluation and the participation of heme in the mechanism of action of these compounds. 3-arylaminoquinoline derivatives proved to be more active against epi-, trypo- and amastigote forms of T. cruzi, especially fluorine and chlorine derivatives 182, 183 and 184. These compounds did not show cytotoxicity against Vero cells. Moreover, they were capable to inhibit the degradation of heme, inducing intracellular oxidative damage, which is not countered by the antioxidative defense system of the parasite (Figure 89) [152].

\section{INSERT FIGURE 89 HERE}


Figure 89. Aryl 3-aminoquinoline derivatives synthesized by Chanquia et al. (2019)

\subsection{Antitrypanosomal activity: Trypanosoma brucei}

Based on alkaloids isolated from Cryptolepis sanguinolenta, such as cryptolepine, neocryptolepine, isocryptolepine, and isoneocryptolepine, previously commented on the antimalarials topic, Baelen et al. (2009) designed and evaluated novel derivatives against T. brucei rhodesiense. Compound 184 (Figure 90) and its hydroiodide salt were found to be more active and displayed $\mathrm{IC}_{50}$ values of 0.72 and $0.55 \mu \mathrm{M}$, respectively. Even though these analogs demonstrated strong trypanocidal activities, they exhibited cytotoxicity towards L6 cells ( $\mathrm{IC}_{50}=1.48$ and $2.2 \mu \mathrm{M}$, respectively) [182].

\section{INSERT FIGURE 90 HERE}

Figure 90. Chemical structure of 6-methyl-6H-indolo[3,2-c]isoquinoline (184)

As a complementation of antiprotozoal activity evaluation of neocryptolepines analogs, Mei et al. (2013) tested selected compounds towards T. brucei rhodesiense strain. These compounds presented $\mathrm{IC}_{50}$ values ranging from 1373 to $868.4 \mathrm{nM}$. Molecule 185 displayed the best result of the equivalent to $1.373 \mu \mathrm{M}$ (Figure 91). However, all compounds were proved to be more effective against chloroquinesensitive and resistant $P$. falciparum strains [158].

\section{INSERT FIGURE 91 HERE}

Figure 91. Structure of neocryptolepine analog 185

Aiming the polipharmacotherapy against sleeping sickness, Krstin et al. (2015) explored the potential synergism of mutual combinations of bioactive alkaloids and alkaloids with a membrane-active steroidal saponin. Within the selected alkaloids, chelerythrine (186), a quinoline derivative (Figure 92), was evaluated against T. brucei brucei alone and in combinations. The trypanocidal activity of this alkaloid is high, presenting an $\mathrm{IC}_{50}$ of $0.33 \mu \mathrm{M}$. Furthermore, chelerythrine was able to synergistically enhance the activity of berberine lowering the $\mathrm{IC}_{50}$ value from 6.85 to $2.80 \mu \mathrm{M}$, with a combination index value below 1. Likewise, the combination of chelerythrine with piperine lowered the $\mathrm{IC}_{50}$ of chelerythrine from 0.33 to $0.20 \mu \mathrm{M}$. Therefore, this study gives an insight into which combinations could be interesting for in vivo combination studies, to better understand the pharmacokinetics and pharmacodynamics of the corresponding drug combinations [183].

\section{INSERT FIGURE 92 HERE}

Figure 92. Structure of chelerythrine

Di Pietro et al. (2015) reported the synthesis of novel quinoline-based analogs of a benzonapthyridine compound, previously reported as a hit compound by Di Pietro et al. (2014). Compound 187 presented an $\mathrm{IC}_{50}$ of $1 \mu \mathrm{M}$ against $T$. brucei, being 3-fold more potent than benzonapthyridine $1\left(\mathrm{IC}_{50}=3.33 \mu \mathrm{M}\right)$, an $\mathrm{IC}_{90}$ of $1.19 \mu \mathrm{M}$, and a selectivity index of $6.8\left(\mathrm{IC}_{50} T\right.$. brucei/IC 50 L6 cells). This particular molecule had its structure modified by $N_{1}$-debenzylation, A-ring contraction and expansion, bioisosteric NH/O replacement at position 1, and substitution of the 5-(4aminomethyl)phenyl group by 5-(2-furyl) and 5-(2-thienyl), originating novel analogs. Within new 
molecules, the pyrrolo[3,2-c] quinoline 188 presented $\mathrm{IC}_{50}$ and $\mathrm{IC}_{90}$ values of $0.92 \mu \mathrm{M}$ and $1.19 \mu \mathrm{M}$, respectively. Therefore, based on this data, these tricyclic heterofused quinolines exhibited an interesting trypanosomatid profile (Figure 93) [184].

\section{INSERT 93 HERE}

Figure 93. Benzonaphthyridine 187 and heterofused quinoline analog 187

A series of 32 new synthetic Cinchona alkaloids and bile acids hybrids, added to a series of the 16 derivatives previously prepared from lithocholic and chenodeoxycholic acids, was tested in vitro for antiparasitic activities by Leverrier et al. (2015). All the examined hybrids displayed good activities against $T$. brucei, with $\mathrm{IC}_{50}$ values ranging from 0.48 to $5.39 \mu \mathrm{M}$ and selectivity indices from 1.3 to 12.3. From the quinine hybrid compounds, molecule 189 presented the best trypanocidal activity $\left(\mathrm{IC}_{50}=0.45\right.$ $\mu \mathrm{M} / \mathrm{SI}=8.3$ ). Among quinidine hybrids, 192 presented itself as the most efficient compound $\left(\mathrm{IC}_{50}=0.55\right.$ $\mu \mathrm{M} / \mathrm{SI}=5.3$ ). Molecule 190 , a cinchonine hybrid, showed an $\mathrm{IC}_{50}$ of $0.51 \mu \mathrm{M}$ and a SI of 8.3. Lastly, of the cinchonidine hybrid compounds, 191 exhibited an $\mathrm{IC}_{50}$ of $0.52 \mu \mathrm{M}$ and a SI of 7.2. In summary, the hybridization of bile acids with Cinchona alkaloids had a favorable effect on the trypanocidal activity for some of the compounds (Figure 94) [185].

\section{INSERT FIGURE 94 HERE}

Figure 94. Structures of the synthesized and most promising hybrids of Cinchona alkaloids

Noscapine is a phthalideisoquinoline alkaloid isolated from Papaver somniferum that has attracted the attention of research groups due to its anticancer capabilities. Based on the structure of this alkaloid, Harikandei et al. (2019) synthesized two series of novel $N$-substituted cyclic ether derivatives of $N$-nornoscapine. Most derivatives displayed promising activity against $T$. $b$. rhodesiense, with $\mathrm{IC}_{50}$ values between 2.5-10.0 $\mu \mathrm{M}$ and selectivity index (SI) ranged from 0.8 to 13.2. Compound 193 was responsible for showing the highest potency (Figure 93). Moreover, molecular docking studies concluded that 194 showed the most significant docking score $\left(-8.59 \mathrm{kcal} \mathrm{mol}^{-1}\right)$ for the ligand-TbTR protein complex, mainly by the formation of two hydrogen bonding interactions between MET333 and THR335 and the ligand amide side chain. Furthermore, compound 195 (Figure 95) showed the highest docking score ($8.86 \mathrm{kcal} \mathrm{mol}^{-1}$ ) with the TbUDPGE enzyme, the primary interaction was among the 3-phenoxyphenyl group of the ligand $6 \mathrm{~b} 2$ and hydrophobic residues containing TYR173, ALA100, LEU102, MET98, ILE12, and ALA9. Thus, according to these results, these novel semi-synthetic analogs represent potential drug candidates, being viable further researches for its optimization as an antitrypanosomal agent [186].

\section{INSERT FIGURE 95 HERE}

Figure 95. $N$-substituted $N$-nornoscapine derivatives 193 and 195

\subsection{Antischistosomal activity}

Two plant-derived compounds, plumbagin and sanguinarine (196), were evaluated for their antischistosomal activity by Zhang et al. (2013). Sanguinarine (Figure 96), a quinoline derivative, is obtained from the root of Sanguinaria spp. and possesses a broad spectrum of biological assets, as well as 
antimicrobial, antioxidant and anti-inflammatory properties. The compound 196, at a concentration of 10 $\mu \mathrm{M}$ (equivalent to $3.68 \mu \mathrm{g} \mathrm{mL}^{-1}$ ), caused a $100 \%$ of mortality at $48 \mathrm{~h}$. Moreover, it was found that sanguinarine does not cause morphological changes in worms from both sexes, but can cause tegumental alterations through severe erosion and disintegration of the tegumental surface between tubercles. Hence, obtained results meet the World Health Organization's (WHO) criterion of "hit" compound for the treatment of schistosomiasis [187].

\section{INSERT FIGURE 96 HERE}

Figure 96. Structure of evaluated alkaloid sanguinarine

Aiming the knowledge expansion about biological properties of the alkaloids of Cryptolepsis sanguinolenta, known for their antimalarial activity, semi-synthetic aminoalkylamino substituted neoand norneocryptolepine analogs were evaluated for their schistosomicidal and molluscicidal activities by El Bardicy et al. (2012). The schistosomicidal bioassay showed that 8 compounds (6 neocryptolepines, and 2 norneocryptolepines) exhibited $100 \%$ worm mortality at the concentration of $5 \mu \mathrm{g} \mathrm{mL}^{-1}$ after 5 days. Compounds 197 and 198 presented the lowest $\mathrm{IC}_{50}$ and $\mathrm{IC}_{90}$ values against S. mansoni Egyptian strain (1.26 and $4.05 \mu \mathrm{M}, 1.77$ and $4.55 \mu \mathrm{M}$, respectively) and the Puerto Rico strain (3.54 and 6.83 $\mu \mathrm{M}$, 3.29 and $5.57 \mu \mathrm{M}$, respectively) (Figure 97) [188].

\section{INSERT FIGURE 97 HERE}

Figure 97. Neocryptolepine derivatives 197 and 198

Soares et al. (2009) investigated the activity of three antimalarial compounds (quinine, quinidine and quinacrine), along with new synthetic quinolines, in a murine schistosomiasis model through the utilization of a combination of biochemical, cell biology and molecular biology approaches. All commercial quinolines and synthetic $\mathrm{C} 7$ and $\mathrm{C} 10$ inhibited heme crystallization, exhibiting $\mathrm{IC}_{50}$ values of $4.63,2.41,13.38,9.00$ and $17.50 \mu \mathrm{M}$, respectively. In vivo assays were carried out with commercial compounds, and results were promising, especially for the compounds quinine and quinidine. These were injected in daily doses of $75 \mathrm{mg} / \mathrm{kg} / \mathrm{day}$, through intraperitoneal route in $\mathrm{S}$. mansoni-infected female Swiss mice from the 11 th to 17 th day after infection, they caused significant decreases in worm burden (39\%-61\%) and egg production (42\%-98\%). Therefore, these results suggest that interference with hemozoin formation in S. mansoni represents an important mechanism of schistosomicidal action of these compounds and points out the heme crystallization process as a valid chemotherapeutic target to treat schistosomiasis [153].

Eweas et al. (2013) reported the synthesis and biological evaluation of two 8-hydroxyquinoline derivatives (199 and 200) In vitro anti-schistosomal assay against Schistosoma (S.) mansoni adult worms revealed that, at $200 \mu \mathrm{g} \mathrm{mL}^{-1}$ concentration, both compounds displayed potent activity by reducing the motor activity and caused their death within $24 \mathrm{~h}$. However, at lower concentrations (50 and $100 \mu \mathrm{g} \mathrm{mL}-$ ${ }^{1}$ ), both compounds presented unsatisfactory potency when compared to standard drug praziquantel [189] (Table 1). Therefore, Eweas et al. (2013b) aimed at the synthesis of more potent anti-schistosomal 8hydroxyquinoline-5-sufonyl 1,4-diazepine derivatives. Among all evaluated derivatives, 201 presented the most potent anti-schistosomal activity (Figure 96). This compound at 50 and $100 \mu \mathrm{g} \mathrm{mL} \mathrm{m}^{-1}$ concentrations caused $100 \%$ death of all worms after $72 \mathrm{~h}$ and $48 \mathrm{~h}$, respectively. At $200 \mu \mathrm{g} \mathrm{mL} \mathrm{m}^{-1}$ and 
after $24 \mathrm{~h}$ of incubation, this compound caused $75 \%$ and $100 \%$ death of male and female worms, respectively. Moreover, docking studies suggest that the schistosomicidal action developed by this molecule is possibly through the inhibition of thioredoxin-glutatione reductase, in view that 201 has performed high binding energy $\left(\Delta \mathrm{G}=-101.33 \mathrm{kcal} \mathrm{mol}^{-1}\right)$. Furthermore, 201 completely diminished egg deposition [190].

Subsequently, the same group published in vivo evaluation of 201 in S. mansoni-infected mice, along with two other promising compounds reported in the previous paper (Figure 98). Allam et al. (2013) affirmed that 201 reduced adult male and female count by $83.2 \%$ and $79.25 \%$, respectively; reduced the count of immature female by $56.84 \%$; decreased eggs per gram liver and intestine by $54.22 \%$ and $67.26 \%$, respectively; reduced granuloma volume by $72.09 \%$, etc. Once more, this compound was the most effective, in a way that it can be useful for the development of a new schistosomicidal drug [191].

\section{INSERT FIGURE 98 HERE}

Figure 98. Lead 8-hydroxyquinoline derivative against S. mansoni

\section{ACRIDINE DERIVATIVES}

\subsection{Antiparasitic mechanism of action}

The mechanism of action performed by acridine compounds with antiparasitic activity has been mostly related to their ability to intercalate between the bases of DNA [192-194]. This mechanism of action is well-known to acridine compounds with chemotherapeutic action, considering the structure of the nucleus, which characterized as polyaromatic and planar, with a positively charged heteroatom inserted into the ring system, which assists in relocating the molecule to the center of the DNA [195, 196].

In addition to this mode of interaction with the parasites, distinct mechanisms responsible for the activity developed by acridine derivatives has been reported, especially concerning the antimalarial action, such as the interference in the formation of hematin, inhibition of DNA decatenation performed by the enzyme topoisomerase II, interference with the food vacuole of the parasite, inhibition of falcipain-2, among others [197, 198].

\subsection{Antiplasmodial activity}

Acridine derivatives have shown remarkable activity as antimalarial agents. It all starts in the 1930s, during the II World War, with the clinical introduction of mepacrine (also known as quinacrine or atebrine) as the first synthetic antimalarial blood schizontocide. This 9-aminoacridine replaced quinine in the treatment of non severe malaria and was mainly used in malaria prophylaxis [199, 200]. Similarly, a Mannich base derivative of mepacrine was developed in the late 1970s. Pyronaridine, also referred to as '7351' and Malaridine ${ }^{\circledR}$, showed high efficacy against drug-resistant Plasmodium falciparum and has been used in China for the treatment of malaria as a single agent for the past 30 years, also being used as a fixed-dose combination with artesunate [197, 201, 202].

Following the rational strategy of molecular design based on a privileged structure, Fonte et al. (2019) proposed the development of a multi-step synthetic route towards $\mathrm{N}^{4}, \mathrm{~N}^{9}$-disubstituted 4,9- 
diaminoacridines. Considering mepacrine's historical relevance associated with its extensive biological spectrum, interest in mepacrine derivatives has aroused due to growth in the percentage of chloroquineresistant strains. These derivatives maintain the 9-amino-2-methoxy-6-chloroacridine core while altering moieties linked to the 9-amino groups. Hence, the research group aimed the synthesis of unpublished mepacrine derivatives, by embedding both the chloroquine and the primaquine moieties. Compound 202 was obtained as the final molecule, with an excellent yield in its final step (100\%) (Figure 99). Although it has not yet been biologically tested, this multi-step synthetic route is unprecedented and may pave the way towards novel bioactive compounds, which are likely to possess a multi-stage antimalarial activity, considering its distinct features of chloroquine, which acts on blood-stage parasites, and primaquine, that targets parasite liver-stage forms and gametocytes [203].

\section{INSERT FIGURE 99 HERE}

Figure 99. Final product of multi-step synthetic route (202)

Based on pyronaridine, an antimalarial drug, Sereekhajornjaru et al. (2014) synthesized pynacrine (203) and compared its hematin-targeting properties with pyronaridine (204), to understand the relevance of the benzonaphthyridine in the structure of the latter in its antiplasmodial property (Figure 100). The results of pynacrine were comparable to pyronaridine. It showed an $\mathrm{IC}_{50}$ value of $5.5 \pm 0.1 \mathrm{nM}$ against intra-erythrocytic growth of $P$. falciparum K1 strains, a minimum concentration of $2.0 \pm 0.1 \mathrm{nM}$ to enhance hematin-induced human RBC lysis, MIC of GSH-induced degradation of hematin of $2.5 \pm 0.5$ $\mu \mathrm{M}$, and the 1:2 stoichiometry of its interaction with hematin. Even though pynacrine was as potent as pyronaridine, it was 50 -fold less effective in inhibiting $\beta$-hematin formation, which suggests that it has other off-target(s) effects [204].

\section{INSERT FIGURE 100 HERE}

Figure 100. Structure of pyronaridine and its analogue, pynacrine

Silva et al. (2018) realized the synthesis of four acridine derivatives through an addition reaction between cyanoacetohydrazide and 6,9-dichloro-3-methoxyacridine (205), followed by treatment of the product with aromatic aldehydes (206-208). All synthesized compounds were active against $P$. falciparum W2 with $\mathrm{IC}_{50}$ values ranging from $0.90 \pm 0.08$ to $3.20 \pm 0.20 \mu \mathrm{M}$ (derivative 206 and 207, respectively), and were less toxic than reference drugs against HepG2 cells. Even though they were all less potent than mefloquine $\left(\mathrm{IC}_{50}=0.04 \pm 0.01 \mu \mathrm{M}\right.$, SI $\left.=295\right)$, derivative 206 demonstrated $\mathrm{IC}_{50}$ comparable to amsacrine $\left(\mathrm{IC}_{50}=0.80 \pm 0.10 \mu \mathrm{M}, \mathrm{SI}=6.5\right)$ and selectivity index 14 times higher, and also proved to be more efficient than primaquine in both aspects $\left(\mathrm{IC}_{50}=1.70 \pm 0.10 \mu \mathrm{M}, \mathrm{SI}=49\right)$ (Figure 101) [205].

\section{INSERT FIGURE 101 HERE}

\section{Figure 101. Chemical structure of acridine derivative 206}

In the article "Synthesis, characterization and antimalarial evaluation of new $\beta$-benzoylstyrene derivatives of acridine", Prajapati et al. (2017) synthesized a series of eighteen acridine derivatives and evaluated their antimalarial activity against chloroquine-sensitive strain (3D7) and chloroquine-resistant strain (Dd2) of P. falciparum through in vitro red blood cell based culture using the SYBR Green I fluorescence assay. Three compounds $(209,210,211)$ were the most potent against both strains, showing 
values of $\mathrm{IC}_{50}$ ranging from 0.30 to $0.52 \mu \mathrm{M}$ against 3D7 strain and values on the range of $0.15-0.32 \mu \mathrm{M}$ against Dd2 strain (Figure 102). Unexpectedly, some derivatives exhibited more potency against CQresistant strain in comparison to CQ-sensitive strain, with values of resistance index in the range of 0.15 0.7. All compounds were found to be selective to $P$. falciparum, in which the three most potent presented selectivity index in the range of 80-520. Therefore, this research exhibited very good antimalarial activity, high selectivity and promising resistance indices, where further exploration and optimization of these derivatives could provide novel antimalarial molecules [206].

\section{INSERT FIGURE 102 HERE}

Figure 102. Structure of $\beta$-benzoylstyrene derivatives of acridine 209, 210, and 211

Exploring Zanthoxylum simullans Hance, a popular natural spice from the Rutaceae family, Wang et al. (2014) isolated, from the root bark $\mathrm{MeOH}$ extract, five acridone alkaloids: normelicopidine (212), normelicopine (213), melicopine (214), melicopidine (215), and melicopicine (216) (Figure 103). All acridone alkaloids were isolated from this plant for the first time and were evaluated for their antimalarial activity against $P$. falciparum chloroquine-sensitive strain 3D7 and chloroquine-resistant strain Dd2. These compounds displayed $\mathrm{IC}_{50}$ values in a range of $18-42 \mu \mathrm{g} \mathrm{mL}^{-1}$ against 3D7 and Dd2, in which normelicopidine showed the strongest activity against $\mathrm{Dd} 2\left(\mathrm{IC}_{50}=18.9 \mu \mathrm{g} \mathrm{mL} \mathrm{L}^{-1}\right)$, while melicopine was the more active compound against $3 \mathrm{D} 7\left(\mathrm{IC}_{50}=25.5 \mu \mathrm{g} \mathrm{mL}^{-1}\right)$. All compounds tested showed no cytotoxicity against HEK293 up to $100 \mu \mathrm{g} \mathrm{mL}^{-1}$ [207].

\section{INSERT FIGURE 103 HERE}

Figure 103. Chemical structure of acridone alkaloids 212-216.

Since the 1940s, the antimalarial activity of 1,2,3,4-tetrahydroacridin-9(10H)-ones (THAs) has been known. Cross et al. (2011) synthesized several series of THA derivatives and examined each compound for its antimalarial activity against $P$. falciparum multidrug-resistant malarial strains $\mathrm{W} 2$ and TM90-C2B. Of all compounds synthesized, several potent compounds $\left(\mathrm{EC}_{50}<100 \mathrm{nM}\right)$ were identified, in which biaryl ether compound (217) demonstrated to be the most active by presenting $\mathrm{EC}_{50}$ of $12.2 \mathrm{nM}$ for W2, $9.1 \mathrm{nM}$ for TM90-C2B and resistance index of 0.75 (Figure 104). Furthermore, the entire THA series did not show any cytotoxicity to $\mathrm{J} 774$ mammalian cells at $20 \mu \mathrm{M}$. Structure activity and structure property relationship studies concluded that the discovery that the 6- or 7-position of the THA scaffold tolerates aryl substituents provides opportunities for next generation designs [198].

\section{INSERT FIGURE 104 HERE}

Figure 104. THA analogue 217

Based on the tacrine (1,2,3,4-tetrahydroacridine), a clinically used drug in the treatment of Alzheimer's disease that exhibited antimalarial activity in an antiprotozoal screening $\left(\mathrm{IC}_{50}=12.5 \mu \mathrm{M}\right.$ against chloroquine-sensitive strain 3D7), Schmidt et al. (2016) synthesized new dimeric tacrine derivatives. All compounds were found to have a good antiplasmodial activity, especially dimers, which showed $\mathrm{IC}_{50}$ in the nanomolar range, however, most of them presented low selectivity index. Nevertheless, derivative 218 demonstrated promising antimalarial activity due to its $\mathrm{IC}_{50}(3 \mathrm{D} 7)=0.02 \pm$ $0.014 \mu \mathrm{M}$ associated with its high selectivity index (1250) (Figure 105). Besides, the compound was tested against falcipain-2, showing an inhibition rate of $56.7 \%$ in a concentration of $20 \mu \mathrm{M}$, giving an $\mathrm{IC}_{50}$ 
$(\mathrm{FP}-2)=5.2 \mu \mathrm{M}$. Given that this enzyme is essential for parasite growth, these results indicate that falcipain-2 represents at least one target of the compound studied [208].

\section{INSERT FIGURE 105 HERE}

Figure 105. Structure of dimeric tacrine 218

Novel 9-aminoacridine derivatives linked to different cinnamic acids, previously noted to improve antimalarial activity, through an aminobutyl chain were designed and synthesized by Pérez et al. (2013). All seven compounds demonstrated mid-nanomolar against $P$. falciparum W2 strain, with values of $\mathrm{IC}_{50}$ ranging from $126 \pm 3$ to $892 \pm 152 \mathrm{nM}$. Compound $219\left(\operatorname{Pf} \mathrm{W} 2 \mathrm{IC}_{50}=138 \pm 2 \mathrm{nM}\right)$ showed greater active against liver-stage parasites of the rodent parasite $P$. berghei than the reference drug primaquine $\left(\mathrm{IC}_{50}=8 \mu \mathrm{M}\right.$ ), with an $\mathrm{IC}_{50}=3.2 \mu \mathrm{M}$ (Figure 106). All compounds were found to be non-toxic to human hepatoma cells at up to $5 \mu \mathrm{M}$. Therefore, this study establishes 9 -( $N$-cinnamoylbutyl)aminoacridines as a novel class of dual-stage antimalarial leads [209].

\section{INSERT FIGURE 106 HERE}

Figure 106. Hybrid aminoacridine-cinnamic acid 219

Synthesis and evaluation of antimalarial activity of new acridinone derivatives were performed by Fernández-Calienes et al. (2011). Most compounds were inactive or marginally activity against $P$. falciparum GHA-strain, exhibited $\mathrm{IC}_{50} \geq 64 \mu \mathrm{M}$. However, three compounds $(220,221,222)$ showed $\mathrm{IC}_{50}$ below $0.5 \mu \mathrm{g} \mathrm{mL}^{-1}$ and selectivity index greater than 39. Moreover, inhibition of $\beta$-hematin formation was investigated using spectrophotometric assay, nevertheless, all compounds showed $\mathrm{IC}_{50}$ values over 20 Meq, while the reference drug, chloroquine, presented $\mathrm{IC}_{50}=1.2 \pm 0.5 \mathrm{Meq}$. Besides, mitochondrial $b c_{1}$ complexes were isolated from $S$. cerevisiae and bovine heart cells to test derivatives' inhibitory activity, which displayed moderate inhibition of the $c y t b c_{l}$ complex from bovine and yeast. The study has gotten to a "hit" for an antimalarial drug (222) and work is underway to elucidate the mechanism of action and to evaluate in vivo efficacy in murine models of malaria (Figure 107) [210].

\section{INSERT FIGURE 107 HERE}

Figure 107. Hit acridinone derivative synthesized by Fernández-Calienes et al. (2011).

\subsection{Antileishmanial activity}

Based on the structure of mepacrine, two series of novel thiophene-acridine derivatives were synthesized and evaluated for antileishmania activity by Serafim et al. (2018) against promastigote Leishmania amazonensis strains. The eight new compounds demonstrated good antipromastigote activity, associated with hemolysis index $>1000 \mu \mathrm{M}$, particularly compounds 223 and 224, which exhibited better results than positive control drugs (tri and pentavalent antimonial), with $\mathrm{IC}_{50}$ of $9.60 \pm 3.19$ and $10.95 \pm$ $3.96 \mu \mathrm{M}$, respectively (Figure 108). These were selected for further evaluation against antimony-resistant L. amazonensis strains and presented the respective $\mathrm{IC}_{50}$ values of $14.83 \pm 0.44$ and $16.36 \pm 1.72 \mu \mathrm{M}$. Additionally, spectroscopic techniques revealed DNA intercalation as a mechanism of action executed by these molecules due to its binding constant of $10^{4} \mathrm{M}^{-1}$. The results suggested these compounds are promising as potential drug candidates [193]. 


\section{INSERT FIGURE 108 HERE}

Figure 108. Potential antileishmanial acridine derivatives 223 and 224

Baquedano et al. (2016) achieved the synthesis of a new series of selenocyanates and diselenides bearing bioactive scaffolds, in which the acridine nucleus was included. Two acridine analogs were synthesized, 225 and 226, and examined for their antiprotozoal activity against amastigotes of the pathogenic L. infantum and had their cytotoxicity determined using human THP-1 cells (Figure 109). These presented $\mathrm{ED}_{50}$ of $7.40 \pm 0.60$ and $5.46 \pm 0.01 \mu \mathrm{M}$, respectively, combined with low selectivity. Consequently, no additional studies were performed with these derivatives. However, joining all the results from each bioactive scaffold, it's supposed that analogs with the diselenide unit were more active than those with the selenocyanate moiety, and was observed that, in this scenario, tricyclic nitrogenated rings, such as acridine, are detrimental to the biological activity and selectivity compared with bicyclic nitrogenated rings [211].

\section{INSERT FIGURE 109 HERE}

Figure 109. Acridine analogs 225 and 226

Considering leishmaniasis as an important public health issue, Astelbauer et al. (2011) investigated the antileishmanial activity of 13 plant-derived compounds. Two acridones, 5hydroxynoracronycine (227) and yukocitrine (228), isolated from Glycosmis trichanthera stembark, first reported by Vajrodaya et al. (1998) [212, 213], revealed antipromastigote activity when tested against $L$. infantum (Figure 110). Results after $24 \mathrm{~h}$ of exposure were $\mathrm{EC}_{50}=34.84$ and $29.76 \mu \mathrm{M}, \mathrm{EC}_{90}=447.58$ and $327.58 \mu \mathrm{M}$, respectively. Likewise, results after $48 \mathrm{~h}$ of exposure were $\mathrm{EC}_{50}=4.42$ and $0.88 \mu \mathrm{M}, \mathrm{EC}_{90}=$ 20.77 and 9.94, respectively. Hence, yukocitrine (228) showed lower $\mathrm{EC}_{50}$ after $48 \mathrm{~h}$ of exposure than the reference compound, miltefosine $\left(\mathrm{EC}_{50}=1.1 \mu \mathrm{M}\right)$. These compounds also showed low hepatotoxic activity $\left(\mathrm{EC}_{50}=201.87\right.$ and $147.06 \mu \mathrm{M}$, respectively) and no hemolytic activity in concentrations ranging from 150 to $1.56 \mu \mathrm{M}$. According to the authors, both acridones can be chemically synthesized with high yield, which is an advantage for the performance of further investigations [213].

\section{INSERT FIGURE 110 HERE}

Figure 110. Isolated alkaloids 5-hydroxynoracronycine (227) and yukocitrine (228)

In the article "Development of an Ex Vivo Lymph Node Explant Model for Identification of Novel Molecules Active against Leishmania major", Peniche et al. (2014) describe the development and application of a medium-throughput screening approach to identify new drug candidates for cutaneous leishmaniasis using an ex vivo lymph node explant culture (ELEC) derived from the draining lymph nodes of Leishmania major-infected mice. For that purpose, a collection of 334 compounds, which included several molecules shown previously to have antileishmanial activity, especially against $L$. donovani, were screened in a concentration of $2.5 \mu \mathrm{M}$. Throughout this process, it has been identified eight 9-aminoacridines derivatives as hits (>50\% inhibition). In parallel, cytotoxicity quantification of the hits using human hepatocyte cell line and calculation of in vitro therapeutic index (IVTI) were investigated, in the presence and absence of S9 liver enzyme fraction. Four 9-aminoacridine derivatives (CID: 14169, 3131604, 3122093, and 2790597), considered most promising, showed values of $\mathrm{EC}_{50}$ ranging from 0.05 to $0.49 \mu \mathrm{M}$, in the absence of $\mathrm{S}$, and $\mathrm{EC}_{50}$ varying between $0.11-0.51 \mu \mathrm{M}$, in the 
presence of S9. IVTI values were in the range of 188.8-770.2, in the absence of S9, and between 227.8583 , in the presence of S9. The incorporation of the S9 liver enzyme fraction showed a decrease of IVTI in some cases (CID: 14169, and 3131604), attesting the need for medicinal chemistry approaches in lead optimization to protect against hepatic metabolism. Besides, according to PubChem searches, most of these compounds had not previously been reported to be active against Leishmania sp., except for 2790597 [214].

Using a known acridine derivative, acriflavine, Makwali et al. (2012) examined the influence of combination and monotherapy on L. major infection in BALB/c mice using plant extracts and herbicides. Firstly, used as a monotherapy in a single $0.2 \mathrm{mg} \mathrm{kg}^{-1}$ dose, acriflavine showed $85.4 \%$ of reduction in liver amastigote burden on day 7 and $80.44 \%$ on day 56 post-treatment. Moreover, within 7 days of treatment, control of liver infection was obtained with acriflavine $\left(1.25 \mathrm{mg} \mathrm{kg}^{-1}\right)$ with a reduction of 90.8\%. However, body weight loss was noted in all the animals and the spleen remained positive for amastigotes. When tested in combination with plumbaginacea extract, triterpenoid saponin extract, and trinfluralin, resulted in complete clearance of parasitemia from the lesion site and internal organs of $L$. major-infected BALB/c mice. Therefore, the authors suggest combination therapy as a promising approach for the treatment of L. major infection [215].

\subsection{Antitrypanosomal activity: Trypanosoma cruzi}

Chromatographic separation of the leaves of Teclea trichocarpa (Engl.) Engl. (Rutaceae) led Mwangi et al. (2010) to the isolation of acridone, furoquinoline alkaloids, and triterpenoids, in addition to other compounds. From the dichloromethane extract, three acridone alkaloids (melicopicine (229), normelicopicine (230), and arborinine (231)) were isolated and used in the antiprotozoal (against Plasmodium falciparum, Trypanosoma brucei rhodesiense, Trypanosoma cruzi, and Leishmania donovani) and cytotoxicity assay (Figure 111). Results of these compounds against T. cruzi (Tulahuen C4 strain) were not satisfying, showing low or no activity with an $\mathrm{IC}_{50}$ value equal to or greater than $30 \mu \mathrm{g}$ $\mathrm{mL}^{-1}$. However, they have demonstrated to be more promising against other parasites, with values ranging from 1.61 to $12.45 \mu \mathrm{g} \mathrm{mL}^{-1}$ for $P$. falciparum (K1 strain, chloroquine resistance), from 5.24 to $23.52 \mu \mathrm{g}$ $\mathrm{mL}^{-1}$ for T. b. rhodesiense (STIB 900 strain), and from 1.08 to $>30 \mu \mathrm{g} \mathrm{mL}^{-1}$ for L. donovani (MHOM-ET67/L82 strain). However, most data corroborate to the fact that compound 230 is a potential lead compound, since it has shown low $\mathrm{IC}_{50}$ against the parasites in this study and a high $\mathrm{MIC}\left(>90 \mu \mathrm{g} \mathrm{mL}^{-1}\right)$ against myoblasts in the cytotoxicity assay [216].

\section{INSERT FIGURE 111 HERE}

Figure 111. Isolated alkaloids 229-231.

\subsection{Antitrypanosomal activity: Trypanosoma brucei}

Two known acridone alkaloids, compound 227 (Figure 110) and 231 (Figure 112), were isolated from the methanolic extract of Citropsis articulata Root Bark, by Lacroix et al. (2011). Both were tested against $T$. b. brucei, but have not shown significant activity $\left(125 \mu \mathrm{g} \mathrm{mL} \mathrm{m}^{-1}\right)$. Nonetheless, the two compounds showed promising antimalarial activity against $P$. falciparum, with $\mathrm{IC}_{50}$ values of 0.9 and 3.0 
$\mu \mathrm{g} \mathrm{mL} \mathrm{mL}^{-1}$, respectively, both having a selectivity index of around 10 . They have also displayed antileishmanial activity against $L$. donovani, with $\mathrm{EC}_{50}$ values of 11.2 and $20.4 \mu \mathrm{g} \mathrm{mL}^{-1}$, respectively [217].

\section{INSERT FIGURE 112 HERE}

Figure 112. Structure acridone alkaloid 231

In the article "Antiprotozoal Activity and DNA Binding of Dicationic Acridones", published by Montalvo-Quirós et al. (2015), several series of acridone derivatives were synthesized and had their antiparasitic activity evaluated. These exhibited $\mathrm{IC}_{50}$ in the nanomolar range against $T$. $b$. rhodesiense STIB900 trypomastigotes, associated with high selectivity (>1000). Compound 232 in particular was as active as melarsoprol in vitro and also curative in the STIB900 mouse model of stage 1 HAT (Figure 113). Furthermore, some of these compounds have presented antimalarial activity in the submicromolar range against wild type (NF54) and resistant (K1) strains of P. falciparum. Additionally, antiparasitic assays against $T$. cruzi and L. donovani were performed, however, no significant activity was detected. Subsequently, UV spectrophotometric titrations and circular dichroism (CD) experiments were conducted, revealing binding constants with DNA in the $10^{4} \mathrm{M}^{-1}$ range, and binding mode mainly by intercalation. No apparent correlation was observed between antitrypanosomal activity and DNA binding affinity, which suggests that there may be additional mechanisms of action involved in the activity of these acridone derivatives against $T$. brucei $[194]$.

\section{INSERT FIGURE 113 HERE}

Figure 113. Acridone derivative 232

\subsection{Antischistosomal activity}

According to our findings and to the best of our knowledge, no researches involving acridine derivatives with antischistosomal activity were published within the timeframe established. This fact might be explained by the lack of satisfying results evolving this scenario. Khalil et al. (1934) have concluded, during an extensive clinic trial, that acriflavine doesn't present a curative effect on schistosomiasis due to Schistosoma haematobium or S. mansoni [218]. Similar results were found by Newsome (1953), through an experiment with four aminoacridines on S. mansoni infections in baboons, which revealed that these compounds were not effective at the dosages used [219]. However, a 9acridanone-hydrazone, compound 233 (10-2-(Diethylamino) ethyl-9-acridanone(2-thiazoline-2yl)hydrazine), has had its effects against schistosomiasis widely studied since 1984 and it's recognized as an interesting drug candidate, obtaining attention over the years from the academia, the World Health Organization and, recently, a company (http://selvarx.com/selva/) (Figure 114) [220-224].

\section{INSERT FIGURE 114 HERE}

Figure 114. Drug candidate 233 


\section{CONCLUSION}

The recent studies here addressed confirmed the biological potentiality attributed to heterocyclic nitrogenous nuclei, focusing on their application in the search for new antiparasitic agents capable of combating the main neglected diseases. The results obtained by the articles presented in this review showed that natural origin compounds have an important role in this pursuit, whether in the analyzes of the isolated natural product; obtained from total synthesis strategies; or obtained through the utilization of semi-synthetic routes to produce derivations of natural products, which, oftentimes, has been used as an strategy to insert nitrogenous rings in non-alkaloid natural compounds, aiming to increase their biological potentiality. Therefore, these strategies have shown as important alternatives, not only in the development of new antiparasitic agents but also in the observation of essential structural properties of these molecules, allowing the rational design of new pharmacophores.

According to our findings, several studies evolving heterocyclic nitrogenous compounds, such as pyrrole, pyridine, indole, quinoline, and acridine derivatives, focus their research mainly on the exploration of possible antimalarial drugs, among the neglected diseases group. This conclusion might be justifiable due to the preexistence of drugs containing some of these scaffolds directed to Plasmodium spp. parasites, and the high morbidity and mortality rate associated with the disease, which promotes efforts to fill the void of the need for novel antiplasmodials.

Nevertheless, in contrast, a limited quantity of recent studies directed to schistosomiasis was found. Concomitantly, few studies seek to elucidate the mechanism of action developed by the compounds evaluated. It is also observed the lack of investment, mainly by the pharmaceutical industry, for the development and obtainment of new candidates for drugs aimed at neglected parasitic diseases, which, in turn, increases the obstacles associated with these parasites and their consequences for public health.

\section{CONFLICT OF INTEREST}

The authors declare no conflict of interest, financial or otherwise.

\section{ACKNOWLEDGMENTS}

This study was financed in part by the Coordenação de Aperfeiçoamento Pessoal de Nível Superior Brasil (CAPES) - Finance Code 001.

\section{REFERENCES}

[1] Pushpangadan P, Ijinu TP, Dan VM, George V. Trends in bioprospecting of biodiversity in new drug design. Pleione 2015; 9(2): 267- 282.

[2] Harvey AL, Edrada-Ebel R, Quinn RJ. The re-emergence of natural products for drug. Discovery in the genomics era. Nat Rev Drug Discov 2015; 14(2): 111-29. http://dx.doi.org/10.1038/nrd4510 PMID: 
[3] Li JW, Vederas JC. Drug discovery and natural products: end of an era our an endless frontier?. Science 2009; 325 (5937): 161-65. http://dx.doi.org/10.1126/science.1168243 PMID: 19589993 [4] Sukuru SCK, Jenkins JL, Beckwith RE, et al. Plate-based diversity selection based on empirical HTS date to enhance the number of hits and their chemical diversity. J Biomol Screen 2009; 14(6): 690-99. http://dx.doi.org/ 10.1177/1087057109335678 PMID: 19531667

[5] Habtemariam S, Lentini G. Plant-derived anticancer agents: lessons from the pharmacology of geniposide and its aglycone, Genipin. Biomedicines 2018; 6(39): 1-28. http://dx.doi.org/ 10.3390/biomedicines6020039 PMID: 29587429

[6] Mukhatar E, Adhami VM, Mukhtar H. Targeting microtubules by natural agents for cancer therapy. Mol Cancer Ther. 2014;13(2):275-84. http://dx.doi.org/10.1158/1535-7163.MCT-13-0791 PMID: 24435445

[7] Amin A, Gali-Muhtasib H, Ocker M, Schneider-Stock R. Overview of major classes of plant-derived anticancer drugs. Int J Biomed Sci 2009; 5(1): 1-11. PMID: 23675107

[8] Guimarães DO, Momesso LS, Pupo MT. Antibióticos: importância terapêutica e perspectivas para a descoberta e desenvolvimento de novos agentes. Quim. Nova 2010; 33(3): 667-679.

http://dx.doi.org/10.1590/S0100-40422010000300035

[9] Wallace RJ. Antimicrobial properties of plant secondary metabolites. Proc Nutr Soc. 2004;63(4):6219. http://dx.doi.org/10.1079/PNS20044393

[10] Wink M. Medicinal plants: a source of anti-parasitic secondary metabolites. Molecules 2012, 17: 12771-12791. http://dx.doi.org/10.3390/molecules171112771 PMID: 23114614

[11] Buenz EJ, Verpoorte R, Bauer BA. The Ethnopharmacologic Contribution to Bioprospecting Natural Products. Annu Rev Pharmacol Toxicol 2018; 58:509-30. http://dx.doi.org/10.1146/annurev-pharmtox010617-052703 PMID: 29077533

[12] Soeiro MNC, Castro SL. Trypanosoma cruzi targets for new chemotherapeutic approaches. Expert Opin Ther Targets 2009; 13(1):105-21. http://dx.doi.org/ 10.1517/14728220802623881 PMID: 19063710 [13] Simoben CV, Ntie-Kang F, Akone SH, Sippl W. Compounds from African Medicinal Plants with Activities Against Selected Parasitic Diseases: Schistosomiasis, Trypanosomiasis and Leishmaniasis. Nat Prod Bioprospect 2018; 8:151-169. http://dx.doi.org/10.1007/s13659-018-0165-y PMID: 29744736 [14] Kalaria PN, Karad SC, Raval DK. A review on diverse heterocyclic compounds as the privileged scaffolds in antimalarial drug discovery. Eur J Med Chem 2018; 158: 917-936.

http://dx.doi.org/10.1016/j.ejmech.2018.08.040 PMID: 30261467

[15] Large JM, Birchall K, Bouloc NS, et al. Potent inhibitors of malaria P. falciparum protein kinase G: Improving the cell activity of a series of imidazopyridine. Bioorg Med Chem Lett 2019; 29 (3): 509-514. http://dx.doi.org/10.1016/j.bmcl.2018.11.039 PMID: 30553738

[16] Tripathi M, Taylor D, Khan SI, et al. Hybridization of fluoro-amodiaquine (FAQ) with pyrimidines: Synthesis and antimalarial efficacy of FAQ-pyrimidines. ACS Med Chem Lett 2019; 10 (5): 714-719. http://dx.doi.org/10.1021/acsmedchemlett.8b00496 PMID: 31097988

[17] Maurya SS, Khan SI, Bahuguna A, Kumar D, Rawat D. Synthesis, antimalarial activity, heme binding and docking studies of N-substituted 4-aminoquinoline-pyrimidine molecular hybrids. Eur J Med Chem 2017; 129: 175-185. http://dx.doi.org/10.1016/j.ejmech.2017.02.024 PMID: 28222317 
[18] Noonan TJ, Chibale K, Cheuka PM, Bourne SA, Caira MR. Cocrystal and salt forms of an imidazopyridazine antimalarial drug lead. J Pharm Sci 2019; 1-9.

http://dx.doi.org/10.1016/j.xphs.2019.02.006 PMID: 30817923

[19] Cheuka PM, Lawrence N, Taylor D, Wittlin S, Chibale, K. Antiplasmodial imidazopyridazines: structure-activity relationship studies lead to the identification of analogs with improved solubility and hERG profiles. Medchemcom 2018; 9(10):1733-1745. http://dx.doi.org/10.1039/c8md00382c PMID: 30429978

[20] Kumar V, Mahajan A, Chibale K. Synthetic medicinal chemistry of selected antimalarial natural products. Bioorg Med Chem 2009; 17: 2236-2275. http://dx.doi.org/10.1016/j.bmc.2008.10.072 PMID: 19157883

[21] Park BS, Kim DY, Rosenthal PJ, et al. Synthesis and Evaluation of New Antimalarial Analogs of Quinoline Alkaloids Derived from Cinchona ledgeriana Moens ex Trimen. Bioorg Med Chem Lett 2002; 12:1351-1355. http://dx.doi.org/10.1016/s0960-894x(02)00173-7 PMID: 11992775

[22] Kumar A, Katiyar SB, Agarwal A, Chauhan PMS. Perspective in Antimalarial Chemotherapy. Curr Med Chem 2003; 10: 1137-1150. http://dx.doi.org/10.2174/0929867033457494 PMID: 12678807

[23] Dewick P M. Medicinal Natural Products: A Biosynthetic Approach. 3rd ed. John Wiley \& Sons: Chichester, 2009.

[24] Adam R, Bilbao-Ramos P, Abarca B, et al. Triazolopyridopyrimidines: an emerging Family of effective DNA photocleavers. DNA binding. Antileishmanial activity. Org Biomol Chem 2015; 13: 49034917. http://dx.doi.org/10.1039/c5ob00280j PMID: 25812028

[25] Marhadour S, Marchand P, Pagniez F, et al. Synthesis and biological evaluation of 2,3diarylimidazo[1,2-a]pyridines as antileishmanial agents. Eur J Med Chem 2012; 58: 543-556. http://dx.doi.org/10.1016/j.ejmech.2012.10.048

[26] Marchand P, Bazin MA, Pagniez F, et al. Synthesis antileishmanial activity and cytotoxicity of 2,3diaryl- and 2,3,8-trisubstituted imidazo[1,2-a]pyrazines. Eur J Med Chem 2015; 103: 381-395.

http://dx.doi.org/10.1016/j.ejmech.2015.09.002 PMID: 26383125

[27] Lapier M, Ballesteros-Garrido R, Guzman-Rivera D, et al. Novel [1,2,3]triazolo[1,5-a]pyridine derivatives are trypanocidal by sterol biosynthesis pathway alteration. Future Med Chem 2019; 11(10): 1137-1155. http://dx.doi.org/ 10.4155/fmc-2018-0242 PMID: 31280672

[28] Salvador RRS, Bello ML, Barreto IRL, et al. New carbohydrazide derivatives of 1H-pyrazolo[3,4b]pyridine and trypanocidal activity. An Acad Bras Cienc 2016; 88(4): 2341-2348. http://dx.doi.org/10.1590/0001-3765201620160087 PMID: 27925033

[29] Thomas MG, Rycker M, Torrejon IC, et al. 2,4-Diamino-6-methylpyrimidines for the potential treatment of Chagas' disease. Bioorg Med Chem Lett 2018; 28: 3025-3030.

http://dx.doi.org/10.1016/j.bmcl.2018.08.005 PMID: 30104093

[30] Fersing C, Boudot C, Pedron J, et al. 8-Aryl-6-chloro-3-nitro-2-(phenylsulfonylmethyl)imidazo[1,2a]pyridines as potent antitrypanosomatid molecules bioactivated by type 1 nitroreductases. Eur J Med Chem 2018; 157:115-126. http://dx.doi.org/10.1016/j.ejmech.2018.07.064

[31] Venkatraj M, Salado IG, Heeres J, et al. Novel triazine dimers with potent antitrypanosomal activity. Eur J Med Chem 2017; 143:306-319. http://dx.doi.org/10.1016/j.ejmech.2017.11.075 PMID: 29197735 
[32] Silva VBR, Campos BRKL, Oliveira JF, Decout JL, Lima MCA. Medicinal chemistry of antischistosomal drugs: Praziquantel and oxamniquine. Bioorg Med Chem 2017; 25: 3259-3277. http://dx.doi.org/10.1016/j.bmc.2017.04.031 PMID: 28495384

[33] Brooker S, Clements AC, Bundy DA. Global epidemiology, ecology and control of soil-transmitted helminth infections. Adv Parasitol 2006; 62: 221-261. http://dx.doi.org/10.1016/S0065-308X(05)62007-6 PMID: 16647972

[34] Gryseels B, Polman K, Clerinx J, Kestens L. Human schistosomiasis. Lancet Lond Engl 2006; 368 : 1106-1118. http://dx.doi.org/10.1016/S0140-6736(06)69440-3 PMID: 16997665

[35] Oullette M. Biochemical and molecular mechanisms of drug resistance in parasites. Trop Med Int Health. 2001; 6(11):874-82. http://dx.doi.org/10.1046/j.1365-3156.2001.00777.x PMID: 11703841 [36] Pramanik PK, Alam MN, Chowdhury DR, Chakraborti T. Drug resistance in protozoan parasites: an incessant wrestle for survival. J Glob Antimicrob Re 2019; 18: 1-11.

http://dx.doi.org/10.1016/j.jgar.2019.01.023 PMID: 30685461

[37] Bozorov K, Zhao J, Aisa HA. 1,2,3-Triazole-containing hybrids as leads in medicinal chemistry: A recent overview. Bioorg Med Chem 2019; 27: 3511-31. http://dx.doi.org/10.1016/j.bmc.2019.07.005 PMID: 31300317

[38] Dai Y, Zhang T, Yiang'ai P, et al. Computational study on fused five membered heterocyclic compounds containing tertiary oxygen. J Mol Struct 2017; 1129: 98-104.

http://dx.doi.org/10.1016/j.molstruc.2016.09.058

[39] Menegatti R, Fraga CAM, Barreiro EJA. Importância da síntese de fármacos. QNEsc 2001, 3: 16-22. [40] Vitaku E, Smith DT, Njardarson JT. Analysis of the structural diversity, substitution patterns, and frequency of nitrogen heterocycles among U.S. FDA approved pharmaceuticals. J Med Chem 2014; 57(24): 10257-10274. http://dx.doi.org/10.1021/jm501100b PMID: 25255204

[41] Barbosa-Filho JM, Piuvezam MR, Moura MD, et al. Anti-inflammatory activity of alkaloids: a twenty-century review. Rev Bras Farmacogn 2006; 16: 109-39. http://dx.doi.org/10.1590/S0102$695 \times 2006000100020$

[42] Perviz S, Khan H, Pervaiz A. Plant alkaloids as an emerging therapeutic alternative for the treatment of depression. Front Pharmacol 2016; 7(28): 1-7. http://dx.doi.org/10.3389/fphar.2016.00028 PMID: 26913004

[43] Rodrigues JA, Araújo AR, Pitombeira NA, et al. Acetylated cashew gum-based nanoparticles for the incorporation of alkaloid epiisopiloturine. Int J Biol Macromol 2019; 128: 965-72.

http://dx.doi.org/10.1016/j.ijbiomac.2019.01.206 PMID: 30711562

[44] Santos JO, Pereira GR, Brandão GC, et al. Synthesis, in vitro antimalarial activity and in silico studies of hybrid kauranoid 1,2,3-triazoles derived from naturally occurring diterpenes. J Braz Chem Soc 2016; 27(3): 551-65. http://dx.doi.org/10.5935/0103-5053.20150287

[45] Li H, Aneja R, Chaiken I. Click chemistry in peptide-based drug design. Molecules 2013; 18: $9797-$ 817. http://dx.doi.org/10.3390/molecules18089797 PMID: 23959192

[46] Chu C, Liu R. Application of click chemistry on preparation of separation materials for liquid chromatography. Chem Soc Rev 2011; 40:2177-88. http://dx.doi.org/10.1039/c0cs00066c PMID: 21212875 
[47] Agalave SG, Maujan SR, Pore VS. Click chamistry: 1,2,3-triazoles as pharmacophores. Chem Asian J 2011; 6: 2696-718. http://dx.doi.org/10.1002/asia.201100432 PMID: 21954075

[48] Pagliai F, Pirali T, Del Grosso E, Di Brisco R, Tron GC, Sorba G, Genazzani AA. Rapid synthesis of triazole-modified resveratrol analogs via click chemistry. J Med Chem 2006; 49(2): 467-70.

http://dx.doi.org/10.1021/jm051118z

[49] Guantai EM, Ncokazi K, Egan TJ, et al. Design, synthesis and in vitro antimalarial evaluation of triazole-linked chalcone and dienone hybrid compounds. Bioorg Med Chem 2010; 18(23): 8243-56. http://dx.doi.org/10.1016/j.bmc.2010.10.009 PMID: 21044845

[50] Raether W, Hänel H. Nitroheterocyclic drugs with broad spectrum activity. Parasitol Res 2003; 90 (1): S19-39. http://dx.doi.org/10.1007/s00436-002-0754-9 PMID: 12811546

[51] Wilkinson SR, Bot C, Kelly JM, Hall BS. Trypanocidal activity of nitroaromatic prodrugs: current treatments and future perspectives. Curr Top Med Chem 2011; 11(16): 2072-84. http://dx.doi.org/ 10.2174/156802611796575894 PMID: 21619510

[52] Penna-Coutinho J, Cortopassi WA, Oliveira AA, França TC, Kreti AU. Antimalarial activity of potential inhibitors of Plasmodium falciparum lactate dehydrogenase enzyme selected by docking studies. PLoS One 2011; 6(7): e21237. http://dx.doi.org/10.1371/journal.pone.0021237 PMID: 21779323

[53] Hitchcock CA. Cytochrome P-450-dependent 14 alpha-sterol demethylase of Candida albicans and its interaction with azole antifungals. Biochem Soc Trans 1991; 19(3): 782-787.

http://dx.doi.org/10.1042/bst0190782 PMID: 1783216

[54] Fromtling RA. Overview of medically important antifungal azole derivatives. Clin Microbiol Rev 1988; 1(2): 187-217. http://dx.doi.org/10.1128/cmr.1.2.187 PMID: 3069196

[55] Fairlamb AH, Cerami A. Metabolism and functions of trypanothione in the kinetoplastida. Ann Rev Microbiol 1992; 46: 695-729. http://dx.doi.org/10.1146/annurev.mi.46.100192.003403 PMID: 1444271

[56] Botros SS, William S, Sabra ANA, et al. Screening of a PDE-focused library identifies imidazoles with in vitro and in vivo antischistosomal activity. Int J Parasitol Drug Resist 2019; 9: 35-43.

http://dx.doi.org/10.1016/j.ijpddr.2019.01.001 PMID: 30669086

[57] Riffel A, Medina LF, Stefani V, Santos RC, Bizani D, Brandelli A. In vitro antimicrobial activity of a new series of 1,4-naphtoquinones. Braz J Med Biol Res 2002; 35: 811-818.

http://dx.doi.org/10.1590/s0100-879x2002000700008 PMID: 12131921

[58] De Andrade-Neto VF, Goulart MOF, Da Silva JF, et al. Antimalarial activity of phenazines from lapachol, beta-lapachone and its derivatives against Plasmodium falciparum in vitro and Plasmodium berghei in vivo. Bioorg Med Chem Lett 2004; 14: 1145-1149. http://dx.doi.org/10.1016/j.bmcl.2003.12.069 PMID: 14980653

[59] Brandão GC, Rocha Missias FC, Arantes LM, et al. Antimalarial naphthoquinones. Synthesis via click chemistry, in vitro activity, docking to PfDHODH and SAR of lapachol-based compounds. Eur J Med Chem 2018; 145: 191-205. http://dx.doi.org/10.1016/j.ejmech.2017.12.051 PMID: 29324340

[60] Bonandi E, Christodoulou MS, Fumagalli G, Perdicchia D, Rastelli G, Passarella D. The 1,2,3triazole ring as a bioisostere in medicinal chesmistry. Drug Discov Today 2017; 22 (10): 1572-1581. http://dx.doi.org/10.1016/j.drudis.2017.05.014 PMID: 28676407 
[61] Amaratunga C, Lim P, Suon S, et al. Dihydroartemisinin-piperaquine resistance in Plasmodium falciparum malaria in Cambodia: a multisite prospective cohort study. Lancet Infect Dis 2016; 16(3): 357-65. http://dx.doi.org/10.1016/S1473-3099(15)00487-9 PMID: 26774243

[62] Spring MD, Lin JT, Manning JE, et al. Dihydroartemisinin-piperaquine failure associated with a triple mutant including kelch13 C580Y in Cambodia: an observational cohort study. Lancet Infect Dis 2015; 15(6): 683-91. http://dx.doi.org/10.1016/S1473-3099(15)70049-6 PMID: 25877962

[63] Lobo L, Cabral LIL, Sena MI, et al. New endoperoxides highly active in vivo and in vitro against artemisinin-resistant Plasmodium falciparum. Malar J 2018; 17:145-55. http://dx.doi.org/10.1186/s12936018-2281-x PMID: 29615130

[64] Gerber NN. A new prodiginine (prodigiosin-like) pigment from streptomyces. Antimalarial activity of several prodiginines. J Antibiot 1975; 28: 194-199. http://dx.doi.org/10.7164/antibiotics.28.194 PMID: 1092639

[65] Rahul S, Chandrashekhar P, Hermant B, et al. In vitro antiparasitic activity of microbial pigmanets and their combination with phytosynthesized metal nanoparticles. Parasitol Int 2015; 64(5): 353-56. http://dx.doi.org/10.1016/j.parint.2015.05.004 PMID: 25986963

[66] Kancharla P, Kelly JX, Reynolds KA. Synthesis and structure-activity relationships of tambjamines and B-Ring functionalized prodiginines as potent antimalarials. J Med Chem 2015; 58(18): 7286-309. http://dx.doi.org/10.1021/acs.jmedchem.5b00560 PMID: 26305125

[67] Salem SM, Kancharla P, Florova G, Gupta S, Lu W, Reynolds KA. Elucidation of final steps of the merineasins biosynthetic pathway through identification and characterization of the corresponding gene cluster. J Am Chem Soc 2014; 136: 4565-4574. http://dx.doi.org/10.1021/ja411544w PMID: 24575817 [68] Teixeira RR, Gazolla PAR, Silva AM, et al. Synthesis and leishmanicidal activity of eugenol derivatives bearing 1,2,3-triazole functionalities. Eur J Med Chem 2018; 146: 274-86. http://dx.doi.org/10.1016/j.ejmech.2018.01.046 PMID: 29407957

[69] Ueda-Nakamura E, Mendonça-Filho RR, Morgado-Díaz JA, et al. Antileishmanial activity of eugenol-rich essential oil from Ocimum gratissimum. Parasitol Int 2006; 55: 99-105.

http://dx.doi.org/10.1016/j.parint.2005.10.006 PMID: 16343984

[70] Dwivedi P, Mishra KB, Mishra BB, Singh N, Singh RK, Tiwari VK. Click inspired synthesis of antileishmanial triazolyl $O$-benzylquercetin glycoconjugates. Glycoconj J 2015; 32: 127-140. http://dx.doi.org/10.1007/s10719-015-9582-x PMID: 25869315

[71] Cassamale TB, Costa EC, Carvalho DB, et al. Synthesis and antitrypanosomastid activity of 1,4diaryl-1,2,3-triazole analogs of neolignans veraguensin, grandisin and machilin G. J Braz Chem Soc 2016; 27(7): 1217-28. http://dx.doi.org/10.5935/0103-5053.20160017

[72] Costa EC, Cassamale TB, Carvalho DB, et al. Antileishmanial activity and structure-activity relationship of triazolic compounds derived from the neolignans grandisin, veraguensin, and machilin $\mathrm{G}$. Molecules 2016; 21: 802-12. http://dx.doi.org/10.3390/molecules21060802 PMID: 27331807 [73] Rodríguez-Hernández D, Barbosa LCA, Demuner AJ, Almeida RM, Fujiwara RT, Ferreira SR. Highly potent anti-leishmanial derivatives of hederagenin, a triperpenoid from Sapindus saponaria L. Eur J Med Chem 2016; 124: 153-9. http://dx.doi.org/10.1016/j.ejmech.2016.08.030 PMID: 27569196 
[74] Rodríguez-Hernández D, Barbosa LCA, Demuner AJ, et al. Leishmanicidal and cytotoxic activity of hederagenin-bistriazolyl derivatives. Eur J Med Chem 2017; 140: 624-35.

http://dx.doi.org/10.1016/j.ejmech.2017.09.045 PMID: 29024910

[75] Sousa MC, Varandas R, Santos RC, Santos-Rosa M, Alves V, Salvador JAR. Antileishmanial activity of semisynthetic lupane triterpenoids betulin and betulin acid derivatives: synergistic effects with miltefosine. PLoS ONE 2014; 9(3): e89939. http://dx.doi.org/10.1371/journal.pone.0089939 PMID: 24643019

[76] Zimmermann LA, Moraes MH, Rosa R, et al. Synthesis and SAR of new isoxazole-triazole bisheterocyclic compounds as analogs of natural lignans with antiparasitic activity. Bioorg Med Chem 2018; 26(17): 4850-62. http://dx.doi.org/10.1016/j.bmc.2018.08.025

[77] Gould ER, King EFB, Menzies SK, et al. Simplifying nature: Towards the design of broad spectrum kinetoplastid inhibitors, inspired by acetogenins. Bioorg Med Chem 2017; 25: 6126-36.

http://dx.doi.org/10.1016/j.bmc.2017.01.021 PMID: 28185724

[78] Bermejo A, Figadere B, Zafra-Polo MC, Barrachina I, Estornell E, Cortes D. Acetogenins from Annonaceae: recent progress in isolation, synthesis and mechanisms of action. Nat Prod Rep 2005; 22 (2): 269-303 http://dx.doi.org/10.1039/B500186M PMID: 15806200

[79] Tulloch LB, Menzies SK, Fraser AL, et al. Photo-affinity labeling and biochemical analyses identify the target of trypanocidal simplified natural product analogs. PLoS Negl Trop Dis 2017; 11(9): e0005886. http://dx.doi.org/10.1371/journal.pntd.0005886 PMID: 28873407

[80] Scott FJ, Khalaf AI, Giordani F, et al. An evaluation of minor groove binders as anti-Trypanosoma brucei brucei therapeutics. Eur J Med Chem 2016; 116: 116-25.

http://dx.doi.org/10.1016/j.ejmech.2016.03.064

[81] Boger DL, Johnson DS. CC-1065 and the Duocarmycins: Understanding their biological function through mechanistic studies. Angew Chem 1996; 35: 1438-74. http://dx.doi.org/10.1002/anie.199614381 [82] Guimarães MA, Campelo YD, Véras LM, et al. Nanopharmaceutical approach of epiisopiloturine alkaloid carried in liposome system: preparation and in vitro schistosomicidal activity. J Nanosci Nanotechnol 2014; 14: 4519-4528. http://dx.doi.org/10.1166/jnn.2014.8248 PMID: 24738423

[83] Guimarães MA, De Oliveira RN, Véras, LMC, et al. Antihelmintic activity in vivo of epiisopiloturine against juvenile and adult worms of Schistosoma mansoni. PLoS Negl Trop Dis 2015; 9(3): e0003656. http://dx.doi.org/10.1371/journal.pntd.0003656 PMID: 25816129

[84] Rocha JA, Andrade IM, Véras LM, et al. Anthelmintic, antibacterial and cytotoxicity activity of imidazole alkaloids from Pilocarpus microphyllus leaves. Phytother Res 2017; 31(4): 624-30. http://dx.doi.org/10.1002/ptr.5771 PMID: 28111828

[85] Lima LI, Py-Daniel KR, Guimarães MA, et al. Self-nanoemulsifying drug-delivery systems improve oral absorption and antischistosomal activit of epiisopiloturine. Nanomedicine (Lond) 2018; 13(7): 689702. http://dx.doi.org/10.2217/nnm-2017-0308 PMID: 29564947

[86] Rocha JA, Rego NCS, Carvalho BTS, et al. Computational quantum chemistry, molecular docking, and ADMET predictions of imidazole alkaloids of Pilocarpus microphyllus with schistosomicidal properties. PLoS ONE 2018; 13(6): e0198476. http://dx.doi.org/10.1371/journal.pone.0198476 PMID: 
[87] Portes MC, De Moraes J, Véras LMC, et al. Structural and spectroscopic characterization of epiisopiloturine-metal complexes, and anthelmintic activity vs, S. mansoni. J Coord Chem 2016; 69(10):1663-83. http://dx.doi.org/10.1080/00958972.2016.1182162

[88] Véras LMC, Guimarães M, Campelo Y, et al. Activity of epiisopiloturine against Schistosoma mansoni. Curr Med Chem 2012; 19: 2051-8. http://dx.doi.org/10.2174/092986712800167347 PMID: 22420337

[89] Guimarães MA, De Oliveira RN, Almeida RL, et al. Epiisopilosine alkaloid has activity against Schistosoma mansoni in mice without acute toxocity. PLoS ONE 2018; 13(5): e0196667. http://dx.doi.org/10.1371/journal.pone.0196667 PMID: 29750792

[90] Xue L, Shi DH, Harjani JR, et al. 3,3'-Disubstituted 5,5'-Bi(1,2,4-triazine) derivatives with Potent in vitro and in vivo Antimalarial Activity. J Med Chem 2019; 62(5):2485-2498.

http://dx.doi.org/10.1021/acs.jmedchem.8b01799 PMID: 30715882

[91] Pathak M, Ojha H, Tiwari AK, Sharma D, Saini M, Kakkar R. Design, synthesis and biological evaluation of antimalarial activity of new derivatives of 2,4,6-s-triazine. Chem Cent J 2017; 11:132-11. http://dx.doi.org/10.1186/s13065-017-0362-5 PMID: 29256159

[92] Liñares GG, Parrraud G, Labriola C, Baldessari A. Chemoenzymatic synthesis and biological evaluation of 2- and 3-hydroxypyridine derivatives against Leishmania Mexicana. Bioorg Med Chem 2012; 20: 4614-4624. http://dx.doi.org/10.1016/j.bmc.2012.06.028 PMID: 22781310

[93] Suryawanshi SN, Kumar S, Shivahare R, Pandey S, Tiwari A, Gupta S. Design, Synthesis and biological evaluation of aryl pyrimidine derivatives as potential leishmanicidal agents. Bioorg Med Chem Lett 2013; 23: 5235-5238. http://dx.doi.org/10.1016/j.bmcl.2013.06.060 PMID: 23910597

[94] Khattab SN, Khalil HH, Bekhit AA, El-Rahman MMA, Torre BG, El-Faham A et al. 1,3,5-triazinopeptide derivatives: synthesis, characterization and preliminary antileishmanial activity. ChemMedChem 2018; 13: 725-735 http://dx.doi.org/10.1002/cmdc.201700770

[95] Chauhan K, Sharma M, Shivahare R, Debnath U, Gupta S, Prabhakar YS et al. Discovery of triazines mimetics as potent antileishmanial agents. ACS Med Chem Lett 2013; 4: 1108-1113. http://dx.doi.org/10.1021/ml400317e PMID: 24900613

[96] Davison EK, Sperry J. Natural Products with Heteroatom-Rich Ring Systems. J Nat Prod 2017; 80(11): 3060-3079. http://dx.doi.org/10.1021/acs.jnatprod.7b00575 PMID: 29135244

[97] Morita H, Oshimi, S, Hirasawa, Y, et al. Cassiarins A and B, Novel Antiplasmodial Alkaloids from Cassia siamea. Org Lett 2007; 9: 3691-3693. http://dx.doi.org/10.1021/ol701623n

[98] Zheng L, Bin Y, Wang Y, Hua R. Synthesis of Natural Product-like Polyheterocycles via One-Pot Cascade Oximation, C-H Activation, and Alkyne Annulation. J Org Chem 2016; 81(19): 8911-8919. http://dx.doi.org/10.1021/acs.joc.6b01460 PMID: 27626812

[99] Noonan TJ, Chibale K, Cheuka PM, Bourne SA, Caira MR. Co-crystal and salt forms of an imidazopyridazine antimalarial drug lead. J Pharm Sci 2019; 1-9.

http://dx.doi.org/10.1016/j.xphs.2019.02.006 PMID: 30817923

[100] Le Manach C, Cabrera DG, Douelle F, et al. Medicinal Chemistry Optimization of Antiplasmodial Imidazopyridazine Hits from High Throughput Screening of a SoftFocus Kinase Library: Part 1. J Med Chem 2014; 57(6): 2789-2798. http://dx.doi.org/10.1021/jm500098s PMID: 24568587 
[101] Le Manach C, Nchinda AT, Paquet, T, et al. Identification of a Potential Antimalarial Drug

Candidate from a Series of 2-Aminopyrazines by Optimization of Aqueous Solubility and Potency across the Parasite Life Cycle. J Med Chem 2016; 59(21): 9890-9905.

http://dx.doi.org/10.1021/acs.jmedchem.6b01265 PMID: 27748596

[102] Acevedo CH, Scotti L, Alves MF, Diniz MFFM, Scotti MT. Hybrid compounds in the search for alternative chemotherapeutic agents against neglected tropical diseases. Lett Org Chem 2019; 16:81-92. http://dx.doi.org/10.2174/1570178615666180402123057

[103] Castera-ducros C, Paloque L, Verhaeghe P, Casanova M, Cantelli C, Hutter S et al. Targeting the human parasite Leishmania donovani: Discovery of a new promising anti-infectious pharmacophore in 3 nitroimidazo[1,2-a]pyridine series. Bioorg Med Chem 2013; 21: 7155-7164.

http://dx.doi.org/10.1016/j.bmc.2013.09.002 PMID: 24080103

[104] Ajum K, Kleem S, Yi W, Zheng G, Lian X, Zhang Z. Novel antimicrobial indolepyrazines A and B from the marine-associated Acinetobacter sp. ZZ1275. Mar Drugs 2019; 17:89-94.

http://dx.doi.org/10.3390/md17020089 PMID: 30717135

[105] Medeiros ACRF, Borges JC, Becker KM, et al. Synthesis of new conjugates 1H-pyrazolo[3,4b]pyridine-phosphoramidate and evaluation against Leishmania amazonensis. J Braz Chem Soc 2018; 29: 159-167. http://dx.doi.org/10.21577/0103-5053.20170126

[106] Kumar R, Kumar N, Roy RK, Singh A. Triazines - A comprehensive review of their synthesis and diverse biological importance. Curr Med Drug Res 2017; 1:1.

[107] Scotti MT, Scotti L, Ishiki H, et al. Natural Products as a Source for Antileishmanial and Antitrypanosomal Agents. Comb Chem High Throughput Screen 2016; 19: 1-17. http://dx.doi.org/10.2174/1386207319666160506123921

[108] Braga SFP, Martins LC, Silva EB, et al. Synthesis and biological evaluation of potential inhibitors of the cysteine proteases cruzain and rhodesain designed by molecular simplification. Bioorg Med Chem 2017; 25(6): 1889-1900. http://dx.doi.org/10.1016/j.bmc.2017.02.009 PMID: 28215783

[109] Neves BJ, Andrade CH, Cravo PVL. Natural Products as Leads in Schistosome Drug Discovery. Molecules 2015; 20:1872-1903. http://dx.doi.org/10.3390/molecules20021872 PMID: 25625682

[110] Bracca ABJ, Heredia DA, Larghi EL, Kaufman TS. Neocryptolepine (cryprotackieine), a unique bioactive natural product: isolation, synthesis, and profile of Its biological activity. Eur J Org Chem 2014; 7979-8003. http://dx.doi.org/10.1002/ejoc.201402910

[111] Félix MB, Souza ER, Lima MCA; et al. Antileishmanial Activity of new Thiophene-indole Hybrids: Design, Synthesis, Biological and Cytotoxic Evaluation, and Chemometric Studies. Bioorg Med Chem 2016; 24: 3972-3977. http://dx.doi.org/10.1016/j.bmc.2016.04.057 PMID: 27515718

[112] Júnior ASAA, Oliveira JF, Silva A L, et al. In vitro activity, ultrastructural studies and in silico pharmacokinetic properties of indol-3-yl-thiosemicarbazones derivatives and analogs against juvenile and adult worms of S. mansoni. Eur J Pharm Sci 2019; 138. http://dx.doi.org/10.1016/j.ejps.2019.104985 PMID: 31283945

[113] Ngantchou I, Nyasse B , Denier C , Blonski C , Hannaert V , Schneider B . Antitrypanosomal alkaloids from Polyalthia suaveolens (Annonaceae): Their effects on three selected glycolytic enzymes of 
Trypanosoma brucei. Bioorg Med Chem Lett 2010; 20: 3495-3498.

http://dx.doi.org/10.1016/j.bmcl.2010.04.145 PMID: 20529682

[114] Sangshetti JN, Khan FAK, Kulkarni AA, et al. Antileishmanial activity of novel indolyl-coumarin hybrids: Design, synthesis, biological evaluation, molecular docking study and in silico ADME prediction. Bioorg Med Chem Lett. 2016; 26: 829-835. http://dx.doi.org/10.1016/j.bmcl.2015.12.085 PMID: 26778149

[115] Svogie AL, Isaacs M, Hoppe, HC, Khanye SD, Veale CGL. Indolyl-3-ethanone-a-thioethers: A promising new class of non-toxic antimalarial agents. Eur J Med Chem 2016; 114:79-88.

http://dx.doi.org/10.1016/j.ejmech.2016.02.056 PMID: 26974377

[116] Cimanga K, Bruyne T, Pieters L, Vlietinck A. In Vitro and in Vivo Antiplasmodial Activity of Cryptolepine and Related Alkaloids from Cryptolepis sanguinolenta. J Nat Prod 1997; 60: 688-691. http://dx.doi.org/10.1021/np9605246 PMID: 9249972

[117] Lisgarten JN, Coll M, Portugal J, Wright CW, Aymami J. The antimalarial and cytotoxic drug cryptolepine intercalates into DNA at cytosine -cytosine sites. Nat Struct Biol 2002; 9:57-60. http://dx.doi.org/10.1038/nsb729 PMID: 11731803

[118] Yadav RR, Khan SI, Singh S, Khan IA, Vishwakarma RA, Bharate SB. Synthesis, antimalarial and antitubercular activities of meridianin derivatives. Eur J Org Chem 2015; 98: p.160-169. http://dx.doi.org/10.1016/j.ejmech.2015.05.020 PMID: 26005918

[119] Onambele L, Riepl H, Fischer R, Pradel G, Prokop A, Aminake MN. Synthesis and evaluation of the antiplasmodial activity of tryptanthrin derivatives. Int J Parasitol Drugs Drug Resist 2015; 5:48-57. http://dx.doi.org/10.1016/j.ijpddr.2015.03.002 PMID: 25949928

[120] Fusetani, N., Asano, M., Matsunaga, S., \& Hashimoto, K. Bioactive marine metabolites-XV. Isolation of aplysinopsin from the scleractinian coral Tubastrea aurea as an inhibitor of development of fertilized sea urchin eggs. Comparative Biochemistry and Physiology Part B: Comparative Biochemistry 1986: 85: 845-846. http://dx.doi.org/10.1016/0305-0491(86)90184-7

[121] Yadav BPI, Ahmad I, Thakur M. Synthesis of some novel indole derivatives as potential antibacterial, antifungal and antimalarial agents. IOSR J Pharm 2016; 6:27-33.

[122] Luthra T, Nayak A., Kumar B S, Chakrabarti S, Gupta A, Sen S. Indole based antimalarial compounds targeting the melatonin pathway: Their design, synthesis and biological evaluation. Eur J Med Chem 2019; 168: p. 11-27. http://dx.doi.org/10.1016/j.ejmech.2019.02.019 PMID: 30798050

[123] Landa, S., Macháček, V. Sur l'adamantane, nouvel hydrocarbure extrait du naphte. Collection of Czechoslovak Chemical Communications. 1933, 5: 1-5. http://dx.doi.org/10.1135/cccc19330001

[124] Maugh, T. Panel urges wide use of antiviral drug. Science, 1979, 206: 1058-1060.

http://dx.doi.org/10.1126/science.386515 PMID: 386515

[125] Blanpied, T. A. Amantadine Inhibits NMDA Receptors by Accelerating Channel Closure during Channel Block. Journal of Neuroscience, 2005, 25: 3312-3322.

http://dx.doi.org/10.1523/JNEUROSCI.4262-04.2005 PMID: 15800186

[126] Devender N, Gunjan S, Tripathi R, Tripathi RP. Synthesis and antiplasmodial activity of novel indoleamide derivatives bearing sulfonamide and triazole pharmacophores. Eur J Med Chem 2017; 131: 171-184. http://dx.doi.org/10.1016/j.ejmech.2017.03.010 PMID: 28319782 
[127] Yeung, BKS. KAE609 (Cipargamin): Discovery of Spiroindolone Antimalarials. In:

Chackalamannil S, Rotella D, Ward SE, Eds. Comprehensive Medicinal Chemistry III. Amsterdam:

Elsevier 2017: 529-543.

[128] Gellért, E., Raymond-Hamet e Schlittler, E. Die Konstitution des Alkaloids Cryptolepin. Helvetica Chimica Acta 1951; 34 : 642-651. http://dx.doi.org/10.1002/hlca.19510340228

[129] Aroonkit P, Thongsornkleeb C, Tummatorn JG, Krajangsri S, Mungthin M, Ruchirawat S.

Synthesis of isocryptolepine analogs and their structureeactivity relationship studies as antiplasmodial and antiproliferative agents. Eur J Med Chem 2015; 94:56-62. http://dx.doi.org/10.1016/j.ejmech.2015.02.047 PMID: 25747499

[130] Chakka SK, KalamuddiN M, Sundararaman S, et al. Identification of novel class of falcipain-2 inhibitors as potential antimalarial agents. Bioorg Med Chem 2015; 23: 2221-2240.

http://dx.doi.org/10.1016/j.bmc.2015.02.062 PMID: 25840796

[131] Ugwu DI, Okoro UC, Ukoha PO, Okafor S, Ibezim A, Kumar NM. Synthesis, characterization, molecular docking and in vitro antimalarial properties of new carboxamides bearing sulphonamide. Eur $\mathbf{J}$ Med Chem 2017; 135:349-369. http://dx.doi.org/10.1016/j.ejmech.2017.04.029 PMID: 28460310 [132] Tempone AG, Oliveira C Martins, Berlinck RGS. Current approaches to discover marine antileishmanial natural products. Planta Med 2011; 77: 572-585. http://dx.doi.org/10.1055/s-00301250663 PMID: 21243582

[133] Ashok P, Chander S, Chow LMC, Wong ILK, Singh RP, Jha PN; Sankaranarayanan, M. Synthesis and in-vitro anti-leishmanial activity of (4-arylpiperazin-1-yl) (1-(thiophen-2-yl)-9H-pyrido[3,4-b]indol3-yl) methanone derivatives. Bioorg Chem 2016a; 70:100-106. http://dx.doi.org/10.1016/j.bioorg.2016.11.013 PMID: 27939960

[134] Ashok P, Chander S, Tejería A, García-calvo L, Balaña-fouce R, Sankaranarayanan M. Synthesis and anti-leishmanial evaluation of 1-phenyl-2,3,4,9- tetrahydro-1H-b-carboline derivatives against Leishmania infantum. Eur J Med Chem 2016b; 123: 814-821.

http://dx.doi.org/10.1016/j.ejmech.2016.08.014 PMID: 27541264

[135] Ashok P, Chander S, Smith TK, Sankaranarayanan M. Design, synthesis and biological evaluation of piperazinyl- $\beta$-carbolinederivatives as anti-leishmanial agents. Eur J Med Chem 2018; 150: 559-566. http://dx.doi.org/10.1016/j.ejmech.2018.03.022 PMID: 29549840

[136] Ashok P, Chander S, Smith TK, Singh RP, Jha PN, Sankaranarayanan M. Biological Evaluation and Structure activity relationship of 9-methyl-1-phenyl- $9 H$-pyrido[3,4-b]indole derivatives as antileishmanial agents. Bioorg Chem 2019; 84: 98-105. http://dx.doi.org/10.1016/j.bioorg.2018.11.037 PMID: 30500524

[137] Murray, R. D. H. Naturally Occurring Plant Coumarins. SpringerVerlag, 1978; 1: 200-209. http://dx.doi.org/10.1007/978-3-7091-9141-5_2

[138] V. Meyer, Ueber den begleiter des benzols im steinkohlentheer, Ber. Dtschn. Chem. Ges.1883; 1: 1465-1478. http://dx.doi.org/10.1002/cber.188301601324

[139] Rodrigues KAF, Silva DKF, Serafim VL, et al. SB-83, a 2-Amino-thiophene derivative orally bioavailable candidate for the leishmaniasis treatment. Biomed Pharmacother 2018; 108: 1670-1678. http://dx.doi.org/10.1016/j.biopha.2018.10.012 PMID: 30372869 
[140] Santiago EF, Oliveira AS, Oliveira-Filho GB, et al. Evaluation of the Anti- Schistosoma mansoni Activity of Thiosemicarbazones and Thiazoles. Antimicrob Agents Chemother 2014; 58: 352-363. http://dx.doi.org/10.1128/AAC.01900-13

[141] Fonseca NC, Cruz LF, Villela FS, et al. Synthesis of a sugar-based thiosemicarbazone series and structure-activity relationship versus the parasite cysteine proteases rhodesain, cruzain, and Schistosoma mansoni cathepsin B1. Antimicrob Agents Chemother 2015; 59: 2666-2677.

http://dx.doi.org/10.1128/AAC.04601-14 PMID: 25712353

[142] Miana GE, Ribone SR, Vera DMA, Sanchez-Moreno M, Mazzieri MR, Quevedo MA. Design, synthesis and molecular docking studies of novel N-arylsulfonyl-benzimidazoles with anti Trypanosoma cruzi activity. Eur J Med Chem 2019; 165: 1-10. http://dx.doi.org/10.1016/j.ejmech.2019.01.013 PMID: 30641409

[143] Karaman B, Alhalabi Z, Swyter S, et al. Identification of Bichalcones as Sirtuin Inhibitors by Virtual Screening and In Vitro Testing. Molecules 2018; 23: 416.

http://dx.doi.org/10.3390/molecules23020416 PMID: 29443909

[144] Farahat AA, Ismail MA, Kumar A. Indole and benzimidazole bichalcophenes: Synthesis, DNA binding and antiparasitic activity. Eur J Med Chem 2018; 143: 1590-1596.

http://dx.doi.org/10.1016/j.ejmech.2017.10.056 PMID: 29126729

[145] Ferrigno F, Biancofiore I, Malancona S, et al. Discovery of 2-(1H-imidazo-2-yl)piperazines as a new class of potent and non-cytotoxic inhibitors of Trypanosoma brucei growth in vitro. Bioorg Med Chem Lett 2018; 28: p. 3689-3692. http://dx.doi.org/10.1016/j.bmcl.2018.10.028 PMID: 30482621 [146] Lacerda RB. Alcaloides Marinhos Bromopirrólicos. Rev Virtual Quim 2015; 7: 713-729. http://dx.doi.org/10.5935/1984-6835.20150032

[147] Orban OCF, Korn RS, Benítez D, et al. 5-Substituted 3 chlorokenpaullone derivatives are potent inhibitors of Trypanosoma brucei bloodstream forms. Bioorg Med Chem 2016; 24(16): 3790-800. http://dx.doi.org/10.1016/j.bmc.2016.06.023 PMID: 27349574

[148] Liu, J.-F., Jiang, Z.-Y., Wang, R.-R., Zheng, Y.-T., Chen, J.-J., Zhang, X.-M., e Ma , Y.B . Isatisine A, um alcalóide novo com um esqueleto sem precedentes das folhas de Isatis indigotica. Organic Letters, 2007, 9: 4127-4129.

[149] Jiang L, Peng X, Huang P, Chen Z, Liu L. Tempo-catalyzed oxidative dimerization and cyanation of indoles for the synthesis of 2-(1H-indol-3-yl)-3-oxoindoline-2-carbonitriles. Tetrahedron 2017; 73: 1389-1396. http://dx.doi.org/10.1016/j.tet.2017.01.032

[150] Foley M,Tilley L. Quinoline antimalarials: Mechanisms of action and resistance. Int J Parasitol 1997; 27(2):231-240. http://dx.doi.org/101016/s0020-7519 (96) 00152-x. PMID: 9088993

[151] Lechuga GC, Borges JC, Calvet CM, et al. Interactions between 4-aminoquinoline and heme: Promising mechanism against Trypanosoma cruzi. Int J Parasitol Drugs Drug Resist 2016; 6(3): 154-64. http://dx.doi.org/10.1016/j.ijpddr.2016.07.001 PMID: 27490082

[152] Chanquia SN, Larregui F, Puente V, Labriola C, Lombardo E, Liñares GG. Synthesis and biological evaluation of new quinoline derivatives as antileishmanial and antitrypanosomal agents. Bioorg Chem 2019; 83:526-34. http://dx.doi.org/10.1016/ j.bioorg.2018.10.053_PMID:30469145 
[153] Soares JBC, Menezes D, Vannier-Santos MA, et al. Interference with hemozoin formation represents an important mechanism of schistosomicidal action of antimalarial quinoline methanols. PLoS Negl Trop Dis 2009; 3(7):e477. http://dx.doi.org/10.1371/journal.pntd.0000477 PMID:19597543

[154] Tejería A, Pérez-Pertejo Y, Reguera RM, et al. Antileishmanial activity of new hybrid tetrahydroquinoline and quinoline derivatives with phosphorus substituents. Eur J Med Chem 2019; 162 : 18-31. http://dx.doi.org/10.1016/ j.ejmech.2018.10.065 PMID:30408746

[155] Upadhyay A, Chandrakar P, Gupta S, et al. Synthesis, Biological Evaluation, Structure-Activity Relationship, and Mechanism of Action Studies of Quinoline-Metronidazole Derivatives Against Experimental Visceral Leishmaniasis. J Med Chem 2019; 62(11):5655-71. http://dx.doi.org/10.1021/acs.jmedchem.9b00628 PMID:31124675 [156] Roberts BF, Zheng Y, Cleaveleand J, et al. 4-Nitro styrylquinoline is an antimalarial inhibiting multiple stages of Plasmodium falciparum asexual life cycle. Int J Parasitol Drugs Drug Resist 2017; 7: 120-9. http://dx.doi.org/10.1016/ j.ijpddr.2017.02.002 PMID:28285258

[157] El Sayed I, Veken PV, Steert K, et al. Synthesis and Antiplasmodial Activity of AminoalkylaminoSubstituted Neocryptolepine Derivatives. J Med Chem 2009; 52: 2979-88. http://dx.doi.org/10.1021/jm801490z PMID:19364118

[158] Mei Z, Wang L, Lu W, et al. Synthesis and in Vitro Antimalarial Testing of Neocryptolepines: SAR Study for Improved Activity by Introduction and Modifications of Side Chains at C2 and C11 on Indolo[2,3-b]quinolines. J Med Chem 2013; 56: 1431-42. http://dx.doi.org/10.1021/jm300887b PMID: 23360309

[159] Wang N, Wicht KJ, Wang L, et al. Synthesis and in vitro testing of antimalarial activity of nonnatural-type neocryptolepines: structure-activity relationship study of 2,11- and 9,11-disubstituted 6methylindolo[2,3-b]quinolines. Chem Pharm Bull 2013; 61(12): 1282-90. http://dx.doi.org/10.1248/cpb.c13-00639 PMID: 24436959

[160] Silva LFR, Montoia A, Amorim RC, et al. Comparative in vitro and in vivo antimalarial activity of the indole alkaloids ellipticine, olivacine, cryptolepine and a synthetic cryptolepine analog. Phytomedicine 2012; 20(1):71-6. http://dx.doi.org/10.1016/j.phymed.2012.09.008 PMID: 23092722 [161] Çapcı A, Lorion MM, Wang H, et al. Artemisinin-(Iso)quinoline Hybrids by C-H Activation and Click Chemistry: Combating Multidrug-Resistant Malaria. Angew Chem Int Ed Engl 2019; 58(37):13066-79. http://dx.doi.org/10.1002/anie.201907224 PMID: 31290221

[162] Okanya PW, Mohr KI, Gerth K, Jansen R, Müller R. Marinoquinolines A-F, pyrroloquinolines from Ohtaekwangia kribbensis (Bacteroidetes). J Nat Prod 2011; 74(4): 603-8. http://dx.doi.org/10.1021/np100625a PMID: 21456549

[163] Davis RA, Buchanan MS, Duffy S, et al. Antimalarial activity of pyrroloiminoquinones from the Australian marine sponge Zyzzya sp. J Med Chem 2012; 55(12): 5851-8. http://dx.doi.org/10.1021/jm3002795 PMID: 22686608 [164] Stringer T, Wiesner L, Smith GS. Ferroquine-derived polyamines that target resistant Plasmodium falciparum. Eur J Med Chem 2019; 179:78-83. http://dx.doi.org/10.1016/j.ejmech.2019.06.023 PMID: 31238252 
[165] Mombo-Ngoma G, Supan C, Dal-Bianco MP, et al. Phase I randomized dose-ascending placebocontrolled trials of ferroquine--a candidate anti-malarial drug--in adults with asymptomatic Plasmodium falciparum infection. Malar J 2011; 10:53. http://dx.doi.org/10.1186/1475-2875-10-53 PMID: 21362162 [166] Wani WA, Jameel E, Baig U, Mumtazuddin S, Hun LT. Ferroquine and its derivatives: new generation of antimalarial agents. Eur J Med Chem 2015; 101:534-51. http://dx.doi.org/10.1016/j.ejmech.2015.07.009 PMID: 26188909

[167] Raj R, Saini A, Gut J, Rosenthal PJ, Kumar V. Synthesis and in vitro antiplasmodial evaluation of 7-chloroquinoline-chalcone and 7-chloroquinoline-ferrocenylchalcone conjugates. Eur J Med Chem 2015; 95:230-9. http://dx.doi.org/10.1016/j.ejmech.2015.03.045 PMID: 25817773

[168] Coa JC, García E, Carda M, et al. Synthesis, leishmanicidal, trypanocidal and cytotoxic activities of quinoline-chalcone and quinoline-chromone hybrids. Med Chem Res 2017; 26: 1405-14.

http://dx.doi.org/10.1016/j.ejmech.2015.07.018 PMID: 26218652

[169] Antinarelli LM, Carmo AM, Pavan FR, et al. Increase of leishmanicidal and tubercular activities using steroids linked to aminoquinoline. Org Med Chem Lett 2012; 2(1): 16.

http://dx.doi.org/10.1186/2191-2858-2-16 PMID: 22551300

[170] Sobarzo-Sánchez E, Bilbao-Ramos P, Dea-Ayuela M, et al. Synthetic oxoisoaporphine alkaloids: in vitro, in vivo and in silico assessment of antileishmanial activities. PLoS One 2013;8(10): e77560. http://dx.doi.org/10.1371/journal.pone.0077560 PMID: 24204870

[171] Sharma M, Chauhan K, Shivahare R, et al. Discovery of a new class of natural product-inspired quinazolinone hybrid as potent antileishmanial agents. J Med Chem 2013; 56(11): 4374-92.

http://dx.doi.org/10.1021/jm400053v PMID: 23611626

[172] Sharma R, Pandey AK, Shivahare R, Srivastava K, Gupta S, Chauhan PM. Triazino indolequinoline hybrid: a novel approach to antileishmanial agents. Bioorg Med Chem Lett 2014; 24(1): 298 301. http://dx.doi.org/10.1016/j.bmcl.2013.11.018 PMID: 24314395

[173] Upadhyay A, Kushwaha P, Gupta S, et al. Synthesis and evaluation of novel triazolyl quinoline derivatives as potential antileishmanial agents. Eur J Med Chem 2018; 154: 172-81.

http://dx.doi.org/10.1016/j.ejmech.2018.05.014 PMID: 29793211

[174] Almandil NB, Taha M, Rahim F, et al. Synthesis of novel quinoline-based thiadiazole, evaluation of their antileishmanial potential and molecular docking studies. Bioorg Chem 2019; 85: 109-16. http://dx.doi.org/10.1016/j.bioorg.2018.12.025 PMID: 30605884

[175] Valdivieso E, Mejías F, Torrealba C, et al. In vitro 4-Aryloxy-7-chloroquinoline derivatives are effective in mono- and combined therapy against Leishmania donovani and induce mitocondrial membrane potential disruption. Acta Trop 2018; 183: 36-42. http://dx.doi.org/10.1016/j.actatropica.2018.03.023 PMID: 29604246

[176] Cretton S, Breant L, Pourrez L, et al. Antitrypanosomal quinoline alkaloids from the roots of Waltheria indica. J Nat Prod 2014; 77(10): 2304-11. http://dx.doi.org/10.1021/np5006554 PMID: 25314007

[177] Cretton S, Bréant L, Pourrez L, et al. Chemical constituents from Waltheria indica exert in vitro activity against Trypanosoma brucei and T. cruzi. Fitoterapia 2015; 105: 55-60.

http://dx.doi.org/10.1016/j.fitote.2015.06.007 PMID: 26072041 
[178] Ramírez-Prada J, Robledo SM, Vélez ID, et al. Synthesis of novel quinoline-based 4,5-dihydro-1Hpyrazoles as potential anticancer, antifungal, antibacterial and antiprotozoal agents. Eur J Med Chem 2017; 131: 237-54. http://dx.doi.org/10.1016/j.ejmech.2017.03.016 PMID: 28329730

[179] Coa JC, Castrillón W, Cardona W, et al. Synthesis, leishmanicidal, trypanocidal and cytotoxic activity of quinoline-hydrazone hybrids. Eur J Med Chem 2015; 101: 746-53.

http://dx.doi.org/10.1016/j.ejmech.2015.07.018 PMID: 26218652

[180] Muscia GC, Cazorla SI, Frank FM, et al. Synthesis, trypanocidal activity and molecular modeling studies of 2-alkylaminomethylquinoline derivatives. Eur J Med Chem 2011; 46(9):3696-703.

http://dx.doi.org/10.1016/j.ejmech.2011.05.035 PMID: 21664012

[181] Upadhayaya RS, Dixit SS, Földesi A, Chattopadhyaya J. New antiprotozoal agents: their synthesis and biological evaluations. Bioorg Med Chem Lett 2013; 23(9): 2750-8.

http://dx.doi.org/10.1016/j.bmcl.2013.02.054 PMID: 23518280

[182] Baelen GV, Hostyn S, Dhooghe L, et al. Structure-activity relationship of antiparasitic and cytotoxic indoloquinoline alkaloids, and their tricyclic and bicyclic analogs. Bioorg Med Chem 2009; 17(20):7209-17. http://dx.doi.org/10.1016/j.bmc.2009.08.057 PMID: 19781948

[183] Krstin S, Peixoto HS, Wink M. Combinations of alkaloids affecting different molecular targets with the saponin digitonin can synergistically enhance trypanocidal activity against Trypanosoma brucei brucei. Antimicrob Agents Chemother 2015; 59(11): 7011-7. http://dx.doi.org/10.1128/AAC.01315-15 PMID: 26349826

[184] Di Pietro O, Vicente-García E, Taylor MC, et al. Multicomponent reaction-based synthesis and biological evaluation of tricyclic heterofused quinolines with multi-trypanosomatid activity. Eur J Med Chem 2015;105: 120-37. http://dx.doi.org/10.1016/ j.ejmech.2015.10.007 PMID: 26479031

[185] Leverrier A, Bero J, Cabrera J, Frédérich M, Quetin-Leclercq J, Palermo JA. Structure-activity relationship of hybrids of Cinchona alkaloids and bile acids with in vitro antiplasmodial and antitrypanosomal activities. Eur J Med Chem 2015; 100: 10-7. http://dx.doi.org/10.1016/j.ejmech.2015.05.044 PMID: 26063305

[186] Harikandei KB, Salehi P, Ebrahimi SN, et al. N-substituted noscapine derivatives as new antiprotozoal agents: Synthesis, antiparasitic activity and molecular docking study. Bioorg Chem 2019; 91: 103116. http://dx.doi.org/10.1016/j.bioorg.2019.103116 PMID: 31377384

[187] Zhang SM, Coultas KA. Identification of plumbagin and sanguinarine as effective chemotherapeutic agents for treatment of schistosomiasis. Int J Parasitol Drugs Drug Resist 2013; 3:2834. http://dx.doi.org/10.1016/j.ijpddr.2012.12.001 PMID: 23641325

[188] El Bardicy S, El Sayed I, Yousif F, et al. Schistosomicidal and molluscicidal activities of aminoalkylamino substituted neo- and norneocryptolepine derivatives. Pharm Biol 2012; 50(2):134-40. http://dx.doi.org/10.3109/13880209.2011.578278 PMID: 22338119

[189] Eweas AF, Allam G, Abu-Elsaad ASA, Maghrabi IA, AlGhamdi AH. Synthesis, Anti-Schistosomal Activity and Molecular Modeling of Two Novel 8-Hydroxyquinoline Derivatives. Anti-Infective Agents 2013; 11: 31-40. http://dx.doi.org/10.2174/22113626130104

[190] Eweas AF, Allam G, Abuelsaad AS, ALGhamdi AH, Maghrabi IA. Design, synthesis, antischistosomal activity and molecular docking of novel 8-hydroxyquinoline-5-sufonyl 1,4-diazepine 
derivatives. Bioorg Chem 2013;46: 17-25. http://dx.doi.org/10.1016/ j.bioorg.2012.10.003 PMID: 23247256

[191] Allam G, Eweas AF, Abuelsaad AS. In vivo schistosomicidal activity of three novels 8hydroxyquinoline derivatives against adult and immature worms of Schistosoma mansoni. Parasitol Res 2013;112(9): 3137-49. http://dx.doi.org/10.1007/s00436-013-3490-4 PMID: 23793335

[192] Ehsanian R, Van Waes C, Feller SM. Beyond DNA binding - a review of the potential mechanisms mediating quinacrine's therapeutic activities in parasitic infections, inflammation, and cancers. Cell Commun Signal 2011; 9:13. http://dx.doi.org/10.1186/1478-811X-9-13 PMID: 21569639

[193] Serafim VL, Félix MB, Frade Silva DK, et al. New thiophene-acridine compounds: synthesis, antileishmanial activity, DNA binding, chemometric, and molecular docking studies. Chem Biol Drug Des 2018; 91(6): 1141-55. http://dx.doi.org/10.1111/cbdd.13176 PMID: 29415325

[194] Montalvo-Quirós S, Taladriz-Sender A, Kaiser M, Dardonville C. Antiprotozoal activity and DNA binding of dicationic acridones. J Med Chem 2015; 58(4):1940-9. http://dx.doi.org/10.1021/jm5018303 PMID: 25642604

[195] Ihmels H, Faulhaber K, Vedaldi D, Dall'Acqua F, Viola G. Intercalation of organic dye molecules into double-stranded DNA. Part 2: the annelated quinolizinium ion as a structural motif in DNA intercalators. Photochem Photobiol 2005;81(5):1107-15. http://dx.doi.org/10.1562/2005-01-25-IR-427 PMID:15934789

[196] Lafayette EA, Vitalino de Almeida SM, Pitta MG, et al. Synthesis, DNA binding and topoisomerase I inhibition activity of thiazacridine and imidazacridine derivatives. Molecules. 2013;18(12):15035-50. http://dx.doi.org/10.3390/molecules181215035 PMID: 24322489

[197] Croft SL, Duparc S, Arbe-Barnes SJ, et al. Review of pyronaridine anti-malarial properties and product characteristics. Malar J 2012; 11:270-98. http://dx.doi.org/10.1186/1475-2875-11-270 [198] Cross RM, Maignan JR, Mutka TS, et al. Optimization of 1,2,3,4-Tetrahydroacridin-9(10H)-ones as antimalarials utilizing structure-activity and structure-property relationships. J Med Chem 2011; 54(13): 4399-426. http://dx.doi.org/10.1021/jm200015a PMID: 21630666

[199] Kumar R, Sharma S, Prasad D. Chapter 3 - Acridones: A Relatively Lesser Explored Heterocycle for Multifactorial Diseases. In: Silakari O. Key Heterocycle Cores for Designing Multitargeting Molecules. Amsterdam: Elsevier 2018; pp. 53-132. http://dx.doi.org/10.1016/B978-0-08-1020838.00003-0

[200] Wernsdorfer WH, Payne D. The dynamics of drug resistance in Plasmodium falciparum. Pharmacol Therapeut 1991; 50(1): 95-121. http://dx.doi.org/10.1016/0163-7258 (91) 90074-v PMID:1891480 [201] Kurth F, Pongratz P, Bélard S, Mordmuller B, Kremsner PG, Ramharter M. In vitro activity of pyronaridine against Plasmodium falciparum and comparative evaluation of antimalarial drug susceptibility assays. Malar J 2009; 8: 79-84. http://dx.doi.org/10.1186/1475-2875-8-79 PMID: 19389221 [202] Chang C, Lin-Hua T, Jantanavivat C. Studies on a new antimalarial compound: pyronaridine. Trans R Soc Trop Med Hyg 1992; 86:7-10. http://dx.doi.org/10.1016/0035-9203 (92) 90414-8 PMID: 1566313 [203] Fonte M, Fagundes N, Gomes A, et al. Development of a synthetic route towards N4,N9disubstituted 4,9-diaminoacridines: on the way to multi-stage antimalarials. Tetrahedron Lett 2019; 60: 1166-69. http://dx.doi.org/10.1016/j.tetlet.2019.03.052 
[204] Sereekhajornjaru N, Somboon C, Rattanajak R, Denny WA, Wilairat P, Auparakkitanon S. Comparison of hematin-targeting properties of pynacrine, an acridine analog of the benzonaphthyridine antimalarial pyronaridine. Acta Trop 2014, 140: 181-83. http://dx.doi.org/10.1128/AAC.00119-06 PMID: 16723583

[205] Silva MM, Macedo TS, Teixeira HMP, et al. Correlation between DNA/HSA-interactions and antimalarial activity of acridine derivatives: proposing a possible mechanism of action. J Photochem Photobiol B 2018; 189: 165-75. http://dx.doi.org/10.1016/j.jphotobiol.2018.10.016 PMID: 30366283 [206] Prajapati SP, Kaushik NK, Zaveri M, Mohanakrishanan D, Kawathekar N, Sahal D. Synthesis, characterization and antimalarial evaluation of new $\beta$-benzoylstyrene derivatives of acridine. Arab $\mathbf{J}$ Chem 2017; 10: S274-S80. http://dx.doi.org/10.1016/j.arabjc.2012.07.033

[207] Wang C, Wan J, Mei Z, Yang X. Acridone alkaloids with cytotoxic and antimalarial activities from Zanthoxylum simullans Hance. Phcog Mag 2014; 10(37): 73-6. http://dx.doi.org/10.4103/09731296.126669 PMID: 24696549

[208] Schmidt I, Pradel G, Sologub L, et al. Bistacrine derivatives as new potent antimalarials. Bioorg Med Chem 2016; 24: 3636-42. http://dx.doi.org/10.1016/j.bmc.2016.06.003 PMID: 27316542

[209] Pérez B, Teixeira C, Gomes AS, et al. In vitro efficiency of 9-(N-cinnamoylbutyl)aminoacridines against blood- and liver-stage malaria parasites. Bioorg Med Chem Lett 2013; 23: 610-3. http://dx.doi.org/10.1016/j.bmcl.2012.12.032 PMID: 23290049

[210] Fernández-Calienes A, Pellón R, Docampo M, et al. Antimalarial activity of new acridinone derivatives. Biomed Pharmacother 2011; 65: 210-4. http://dx.doi.org/10.1016/j.biopha.2011.04.001 PMID: 21641752

[211] Baquedano Y, Alcolea V, Toro MÁ, et al. Novel heteroaryl selenocyanates and diselenides as potent antileishmanial agents. Antimicrob Agents Chemother 2016; 60(6): 3802-12. http://dx.doi.org/10.1128/AAC.02529-15 PMID: 27067328

[212] Vajrodaya S, Bacher M, Greger H, Hofer O. Organ-specific chemical differences in Glycosmis trichanthera. Phytochemistry 1998; 48:897-902. DOI: https://doi.org/10.1016/S0031-9422(97)00986-2 [213] Astelbauer F, Obwaller A, Raninger A, et al. Anti-Leishmanial activity of plant-derived acridones, flavaglines, and sulfur-containing amides. Vector Borne Zoonotic Dis 2011; 11(7): 793-8. http://dx.doi.org/10.1089/ vbz.2010.0087 PMID: 21417924

[214] Peniche AG, Osorio Y, Renslo AR, Frantz DE, Melby PC, Travi BL. Development of an ex vivo lymph node explant model for identification of novel molecules active against Leishmania major. Antimicrob Agents Chemother 2014; 58: 78-87. http://dx.doi.org/10.1128/AAC.00887-13 PMID: 24126577

[215] Makwali JA, Wanjala FME, Kaburi JC, Ingonga J, Byrum WW, Anjili CO. Combination and monotherapy of Leishmania major infection in BALB/c mice using plant extracts and herbicides. J Vector Borne Dis 2012; 49: 123-30. PMID: 23135005

[216] Mwangi ESK, Keriko JM, Machocho AK, et al. Antiprotozoal activity and cytotoxicity of metabolites from leaves of Teclea trichocarpa. J Med Plant Res 2010; 4(9): 726-31.

http://dx.doi.org/10.5897/JMPR10.188 
[217] Lacroix D, Prado S, Kamoga D, Kasenene J, Bodo B. Structure and in vitro antiparasitic activity of constituents of Citropsis articulata root bark. J Nat Prod 2011; 74: 2286-9.

http://dx.doi.org/10.1021/np2004825 PMID: 21985060

[218] Khalil Bey M, Salah M. Treatment of schistosomiasis with acridine compounds. The Lancet 1934; 224(5799): 862-3. http://dx.doi.org/10.1016/S0140-6736(00)74658-7

[219] Newsome J. Experiments with some miracil, acridine, and diamidine compounds on Schistosoma mansoni infections in baboons. Trans R Soc Trop Med Hyg 1953; 47(5): 428-30.

http://dx.doi.org/10.1016/s0035-9203 (53) 80027-1 PMID: 13102587

[220] Panic G, Keiser J. Acting beyond 2020: better characterization of praziquantel and promising antischistosomal leads. Curr Opin Pharmacol 2018, 42: 27-33.

http://dx.doi.org/10.1016/j.coph.2018.06.004 PMID: 30077117

[221] Stohler HR, Montavon M. 9-Acridanone-hydrazones, a novel class of broad-spectrum schistosomal agents. In: International Congress for Tropical Medicine and Malaria 11, Calgary, Canada, 1984, pp. 1622.

[222] Metwally A, Abdel Hadi A, Mikhail EG, Abou’ Shadi O, Sabry H, el-Nahal H. Study of the efficacy of the new antischistosomal drug 10-[2-(diethylamino)ethyl]-9-acridanone-(thiazolidin-2ylidene) hydrazone against an Egyptian strain of Schistosoma mansoni in mice. Arzneimittelforschung 1997; 47: 975-9. PMID: 9296287

[223] Guirguis FR. Efficacy of praziquantel and Ro 15-5458, a 9-acridanone-hydrazone derivative, against Schistosoma haematobium. Arzneimittelforschung 2003; 53: 57-61. http://dx.doi.org/10.1055/s0031-1297071 PMID: 12608016

[224] Abdul-Ghani RA, Loutfy N, Hassan A. Experimentally promising antischistosomal drugs: a review of some drug candidates not reaching the clinical use. Parasitol Res 2009;105: 899-906.

http://dx.doi.org/10.1007/s00436-009-1546-2 PMID: 19588166 